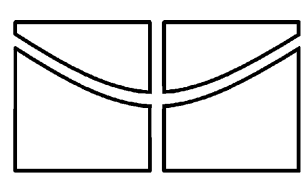

UNIVERSIDADE DE BRASÍLIA FACULDADE DE TECNOLOGIA

DEPARTAMENTO DE ENGENHARIA ELÉTRICA

\title{
DESENVOLVIMENTO DE PLATAFORMA PARA AQUISIÇÃO E PROCESSAMENTO DE SINAIS DE OXIMETRIA DE PULSO
}

THIAGO DE CARVALHO RESENDE
TIAGO ROQUES CORREA BORGES

ORIENTADOR: ADSON FERREIRA DA ROCHA

PROJETO FINAL DE GRADUAÇÃO

BRASÍLIA/DF: MARÇO/2006 


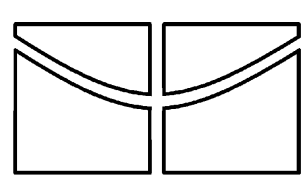

UNIVERSIDADE DE BRASÍLIA

FACULDADE DE TECNOLOGIA

DEPARTAMENTO DE ENGENHARIA ELÉTRICA

\section{DESENVOLVIMENTO DE PLATAFORMA PARA AQUISIÇÃO E PROCESSAMENTO DE SINAIS DE OXIMETRIA DE PULSO}

\section{THIAGO DE CARVALHO RESENDE TIAGO ROQUES CORREA BORGES}

PROJETO FINAL DE GRADUAÇÃO SUBMETIDA AO DEPARTAMENTO DE ENGENHARIA ELÉTRICA DA FACULDADE DE TECNOLOGIA DA UNIVERSIDADE DE BRASÍLIA, COMO PARTE DOS REQUISITOS NECESSÁRIOS PARA A OBTENÇÃO DO GRAU DE ENGENHEIRO.

APROVADA POR:

ADSON FERREIRA DA ROCHA, ENE/UnB (ORIENTADOR)

GEOVANY ARAÚJO BORGES, ENE/UnB (EXAMINADOR)

EDSON MINTSU HUNG, CEPESC/ABIN (EXAMINADOR)

DATA: BRASÍLIA/DF, 28 DE MARÇO DE 2006 
RESENDE, THIAGO DE CARVALHO

Desenvolvimento de Plataforma para Aquisição e Processamento de Sinais de Oximetria de Pulso [Distrito Federal] 2006

(ENE/FT/UnB, Engenheiro, Engenharia Elétrica, 2006).

Projeto Final de Graduação - Universidade de Brasília, Faculdade de Tecnologia. Departamento de Engenharia Elétrica.

BORGES, TIAGO ROQUES CORREA

Desenvolvimento de Plataforma para Aquisição e Processamento de Sinais de Oximetria de Pulso [Distrito Federal] 2006

(ENE/FT/UnB, Engenheiro, Engenharia Elétrica, 2006).

Projeto Final de Graduação - Universidade de Brasília, Faculdade de Tecnologia. Departamento de Engenharia Elétrica.

\section{REFERÊNCIA BIBLIOGRÁFICA}

RESENDE, THIAGO DE CARVALHO (2005). Desenvolvimento de Plataforma para Aquisição e Processamento de Sinais de Oximetria de Pulso. (Projeto Final de Graduação), Departamento de Engenharia Elétrica, Universidade de Brasília, Brasília, DF.

BORGES, TIAGO ROQUES CORREA (2005). Desenvolvimento de Plataforma para Aquisição e Processamento de Sinais de Oximetria de Pulso. (Projeto Final de Graduação), Departamento de Engenharia Elétrica, Universidade de Brasília, Brasília, DF. 


\section{CESSÃO DE DIREITOS}

NOME DO AUTOR: Thiago de Resende Carvalho, Tiago Roques Correa Borges

TÍTULO DA DISSERTAÇÃO: Desenvolvimento de Plataforma para Aquisição e Processamento de Sinais de Oximetria de Pulso.

GRAU/ANO: Engenheiro/2006.

É concedida à Universidade de Brasília permissão para reproduzir cópias deste Projeto Final de Graduação e para emprestar ou vender tais cópias somente para propósitos acadêmicos e científicos. Os autores reservam outros direitos de publicação e nenhuma parte desta dissertação de graduação pode ser reproduzida sem a autorização por escrito dos autores.

Thiago de Carvalho Resende

SQN 304 Bloco G Ap. 408

CEP 70.736-070 - Brasília - DF - Brasil

Tiago Roques Correa Borges

SHIS QI 09 Conjunto 18 Casa 18

CEP 71625-180 - Brasília - DF - Brasil 


\section{AGRADECIMENTOS}

Pelas graças e as bênçãos concebidas durante toda minha vida, pela sabedoria e discernimento recebidos durante momentos delicados e que pareciam sem solução, sou imensamente grato a nosso amado Deus.

Agradeço a minha linda e amada família: meu pai Geraldo, minha mãe Dagmar, minha irmã Vanessa, meu avô Jerônimo (in memorian), que souberam me apoiar, motivar e dar todo amor possível para que eu superasse mais esse desafio. É de uma felicidade imensa saber que existe uma FAMÍLIA a qual sempre poderei contar. A todos os meus familiares: avós, tios, primos, cumpadres, pelo incentivo e todos os momentos.

Como não poderia agradecer minha amada e eterna Rosana? Ela que praticamente participou de toda minha graduação como minha amada namorada, viveu juntamente comigo todas as dificuldades dessa jornada da engenharia e soube compreender e me ajudar com sua atenção e seu carinho constantes.

Grandes agradecimentos também aos meus amigos. Àqueles de infância: Paulo, Ângela, Thiago Menon; do Marista: Gustavo, Poliana, Carla, Aline, Mariana, Leandrinho, Tatiane, Thailisa; da Católica: Fernando, Lorena, George e Oséias; do Objetivo: Márcio Guerra, Flávia, Ilana, Eduardo, Catarina; amigos da UnB: Michelle, Sumaia, Patrícia, Du, Fernandinha, Dedé, Girão, Tiago Alves, Mintsu, Sarah, Chico, Guilherme Solino; ao pessoal da Veton: Elve, Wellington, Henderson, e aos amigos da GE: Marcus, Henrique, Luizinho, Fábio, Rafael, pessoal da GE Brasília. Obrigado pelos diversos momentos que passamos juntos, desde madrugadas infinitas de estudos a dias inesquecíveis de diversão.

Meus especiais agradecimentos por todo tipo de colaboração aos amigos de projeto Marcus Vinícius, Eumann, Roques, principalmente último camarada, que compartilhou comigo as intermináveis madrugadas de projeto no GPDS dos últimos seis meses.

Agradeço também aos professores que me ajudaram e foram responsáveis pelo cumprimento dessa jornada acadêmica.

A todos que direta ou indiretamente contribuíram para esse sonho se realizar. 


\section{AGRADECIMENTOS}

Inicialmente, não poderia deixar de agradecer a Deus, o qual sempre esteve presente nos momentos de superação, dando forças para alcançar novos horizontes.

Agradeço aos meus familiares, meus pais, Alberto e Luciana, às meus avós Elita, Maria (In Memorian) e João Batista (In Memorian), às minhas irmãs e a todos os meus primos, tios e tias, por sempre darem apoio nesta caminhada acadêmica, mostrando os valores essenciais para o alcance de tal conquista.

Não poderia deixar de agradecer a todos os meus professores, os quais foram os pilares da edificação de tal sonho, servindo como exemplo de dedicação e esforço.

Agradeço aos amigos incondicionais Eric, William, Yuri, Ricardo, Rogério, Fábio, Rafa, Marcelo, Junim, Tita, Fred, Tio Ricks, Leco, Thaiana, Sam e Luiza Diniz, por sempre estarem presentes em minha vida, compartilhando alegrias e bons momentos.

Agradeço aos meus grandes amigos da Universidade de Brasília, Sumaia, Patrícia, Thiago Resende e Rosana, Fernando, Michelle, Fernanda Brandi, Isa Helena, Chico, Bianchi, Tiago Alves, Chaffim, Dedé, Girão, Eumann, Izume, Sarah, Mintsu, Ortis, Karen e Diogo Caetano com os quais fortaleci laços de amizade nessa caminhada acadêmica, seja em noites de estudo, seja em momentos de descontração.

Agradeço aos amigos do Colégio Marista, Andréa, Gustavo Amaral, Vitor, Marina, Lisandra, Ana Carla, Gustavo Félix, Maria Helena, Victor, Tatiana e Tássia por compartilharem momentos inesquecíveis nesses últimos 8 anos de vida.

A todos, que diretamente e indiretamente, ajudaram na concretização de tal sonho, o meu mais sincero agradecimento.

Tiago Roques Correa Borges 


\section{DEDICATÓRIA}

O autor Thiago de Carvalho Resende dedica este trabalho a Deus, meus amados pais Geraldo e Dagmar, minha querida irmã Vanessa, meu adorado avô Jerônimo (in memorian) e meu sábio avô Manoel (in memorian), minha amada Rosana e meus grandes amigos.
O autor Tiago Roques Correa Borges dedica este trabalho a todos que ajudaram na concretização de tal sonho, principalmente aos seus familiares e amigos. 


\section{DESENVOLVIMENTO DE PLATAFORMA PARA AQUISIÇÃO E PROCESSAMENTO DE SINAIS DE OXIMETRIA DE PULSO}

\section{RESUMO}

O presente trabalho apresenta um estudo e elaboração de um sistema de captação e processamento em tempo real de sinais de oximetria de pulso. Tal plataforma produz informações que são utilizadas para o monitoramento da saturação de oxigênio no sangue, a qual pode indicar possíveis problemas nos sistemas respiratório e circulatório.

O projeto é formado por circuitos digitais e analógicos, os quais trabalham em conjunto com o microcontrolador MSP 430 no processo de captação e controle dos sinais de oximetria de pulso. Tais sinais são processados e enviados a aplicativos de monitoramento instalados em um microcomputador, onde é possível fazer uma análise gráfica do comportamento da oxigenação sanguínea. A interface foi desenvolvida por meio de estudos relacionados aos aspectos fisiológicos referentes ao sinal a ser captado, os quais serão abordados ao longo do trabalho. 


\begin{abstract}
The actual work presents a study and elaboration of a system for capturing and processing signals of pulse oximeters in real time. This platform builds information that are used for the monitoring of the arterial oxygen saturation, which can show possible problems in the circulatory and respiratory systems.

The project is composed by analog and digital circuits, which work together with the TI MSP 430 microcontroller in capturing and controling the signals of pulse oximeters. Such signals are processed and sent to the applications of monitoring, where is possible to make a graphical analysis of the behavior of the blood oxygenation. The interface was developed through studies related to the physiological aspects of the signal supposed to be captured, which will be approached in the present work.
\end{abstract}




\section{ÍNDICE}

AGRADECIMENTOS VI

DEDICATÓRIA VIII

RESUMO IX IX

ABSTRACT $\quad x$

LISTA DE ABREVIAÇÕES X XIV

ÍNDICE DE FIGURAS

ÍNDICE DE TABELAS XVII

1 - INTRODUÇÃ

\begin{tabular}{lr}
1.1 - OBJETIVOS DO TRABALHO & $\mathbf{1}$ \\
\hline 1.2 - MOTIVAÇÕES DO ESTUDO DE OXIMETRIA DE PULSO & $\mathbf{1}$ \\
\hline 1.3 - TRANSPORTE DE OXIGÊNIO & $\mathbf{3}$ \\
\hline 1.4 - SPO2 NO MONITORAMENTO DA OXIGENAÇÃO DAS HEMOGLOBINAS & $\mathbf{4}$ \\
\hline 1.4.1 - IDÉIA COMPREENSIVA DO PAPEL DO OXÍMETRO DE PULSO & 4 \\
\hline 1.5 - SATURAÇÃO ARTERIAL DE OXIGÊNIO & $\mathbf{5}$ \\
\hline 1.6 - ORGANIZAÇÃO GERAL DO TRABALHO & $\mathbf{6}$
\end{tabular}

$\underline{2 \text { - FUNDAMENTOS FISIOLÓGICOS DE OXIMETRIA DE PULSO_......................................8 }}$

2.1 - IMPORTÂNCIA DO SISTEMA RESPIRATÓRIO NA OXIGENAÇÃO SANGUÍNEA 8

\begin{tabular}{lr}
2.1 .1 - CONTROLE DA VENTILAČ̃̃O PULMONAR & 8 \\
\hline
\end{tabular}

2.1.2 - RESPOSTA DO CORPO HUMANO A POSSÍVEIS PROBLEMAS NA RESPIRACÃO

\begin{tabular}{lr}
2.1 .3 - MECANISMOS DE VENTILAÇ̃̃O PULMONAR & 9 \\
\hline
\end{tabular}

\begin{tabular}{lr}
\hline 2.1 .4 - Difusão Do SANGUE & 10 \\
\hline $21.5-$ TrOCAS GaSOSAS
\end{tabular}

2.1 .5 - TROCAS GASOSAS 11

2.2 - IMPORTÂNCIA DA HEMOGLOBINA NA OXIGENAÇÃO SANGUÍNEA

\begin{tabular}{ll}
2.2 .1 - UNIÃO DE OXIGÊNIO À HEMOGLOBINA & 12 \\
\hline
\end{tabular}

2.2.2 - CARACTERÍSTICAS DA HEMOGLOBINA E SUA IMPORTÂNCIA NA PIGMENTAC̄̃̃ DO SANGUE 12

2.3 - SISTEMA CIRCULATÓRIO E O TRANSPORTE DE SANGUE

2.3.1 - O CORAÇ̃̃O E OS SINAIS DE ELETROCARDIOGRAMA (ECG) 14

2.3.2 - CiRCULAÇ̃̃o PULMONAR 16

2.4 - PRINCÍPIOS DO OXÍMETRO DE PULSO

2.5 - USO DE OXÍMETROS DE PULSO NO MONITORAMENTO DE POSSÍVEIS PROBLEMAS NA OXIGENAÇÃO SANGUÍNEA $\quad 17$

\begin{tabular}{lr}
2.5 .1 - HIPOXIA E HIPOXEMIA & 17 \\
\hline $2.5 .2-$ PAPE DO SPO2 & 17
\end{tabular}

2.5.2 - PAPEL DO SPO2 NA PREVENÇ̃̃O DE HIPOXIA 18

2.5.3 - O PAPEL DA OXIMETRIA DE PULSO NA ANESTESIOLOGIA, EM UNIDADES DE TRATAMENTO INTENSIVO E \begin{tabular}{ll} 
UNIDADES DE SITUACÕES PÓS-OPERATÓRIA & 19 \\
\hline
\end{tabular}

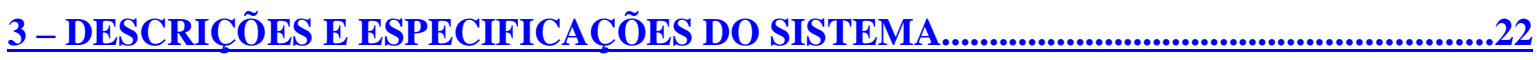

3.1 - CARACTERÍSTICAS GERAIS

3.2 - ESQUEMÁTICO DO OXÍMETRO DE PULSO 23

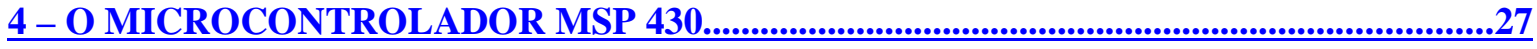

4.1 - A UTILIZAÇÃO DO MICROCONTROLADOR MSP $430 \quad 27$

4.1.1 - CARACTERÍSTICAS BÁSICAS DO MICROCONTROLADOR MSP 430 27

4.2 - ENTRADAS E SAÍDAS (DISPOSITIVOS I/O) 
4.3 - REGISTRADORES (OPERAÇÕES DIGITAIS DE I/O)

\begin{tabular}{lr} 
4.3.1 - Registrador de DiREÇ̃̃o DE DADOS PXDIR & 29 \\
\hline 4.2 .2
\end{tabular}

4.3.2 - Registrador DE ENTRADA PXIN 30

\begin{tabular}{ll}
4.3 .3 - REGISTRADOR DE SAÍDA PXOUT & 31 \\
\hline
\end{tabular}

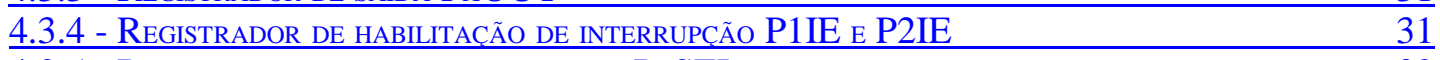

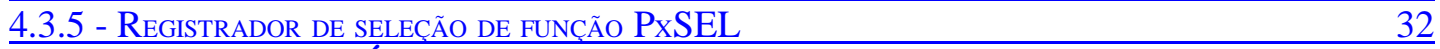

4.4 - CONVERSOR ANALÓGICO DIGITAL DE 12 BITS

4.4.1 - SeleÇ̃̃o do Relógio do CONVERSOR

4.4.2. Registradores de Controle do Conversor Analógico Digital 35

\begin{tabular}{ll}
4.4 .3 - GERADOR DE TENSÃo De REFERÊNCIA & 37 \\
\hline
\end{tabular}

\begin{tabular}{ll}
$4.5-$ O CONTADOR/TEMPORIZADOR TIMER A & 37 \\
\hline
\end{tabular}

\begin{tabular}{lr}
4.6 - INTERFACE SERIAL UNIVERSAL & 39 \\
\hline
\end{tabular}

\begin{tabular}{lr} 
4.6.1 - MOdO ASSÍNCRONO & 39 \\
\hline
\end{tabular}

\begin{tabular}{lr}
$4.6 .1-$ Modo Ś́nCRONO SPI & 40 \\
\hline
\end{tabular}

4.7 - PROGRAMAÇÃO DO MSP $430 \quad 41$

\begin{tabular}{ll} 
4.7.1 - GERAÇÃo DE ONDA QUADRADA NECESSÁRIa PARA OS SINAIS DE CONTROLE & 41 \\
\hline
\end{tabular}

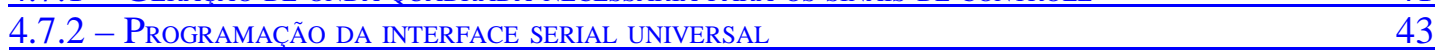

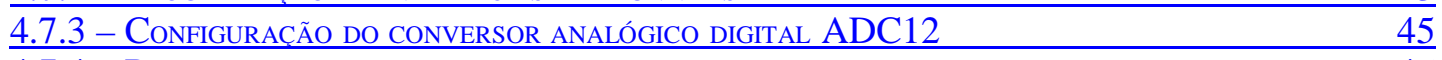

4.7 .4 - ROTINA DE DETECÇ̃̃o DE MÁXIMOS E MÍNIMOS DO SINAL RECEBIDO $\quad 46$

\begin{tabular}{ll}
4.7 .5 - ROTINA DE CÁLCULO DO GANHO FORNECIDO AO SINAL & 46 \\
\hline
\end{tabular}

\begin{tabular}{|rr}
\hline 4.7 .6 - ROTINA DE CÁLCULO DO RESISTOR DO POTENCIÔMETRO DIGITAL & 48 \\
\hline $4.7 .7-$ ROTINA DE CALCULO DA SATURACO DE OXIGENO
\end{tabular}

4.7 .7 - Rotina de CÁlCUlo da SATURAÇ̃̃o DE OXIGÊNIO 48

5 - SISTEMAS E CIRCUITOS DO OXÍMETRO DE PULSO.....................................................49

5.1 - SISTEMA DE GERAÇÃO DE ONDAS DE CONTROLE

5.2 - SISTEMA DE CONTROLE DOS LEDS

5.2.1 - HABILITAÇ̃̃O DO LED VERMELHO

\begin{tabular}{ll}
$5.2 .2-\mathrm{H}_{\text {ABILITACC̃̃O DO LED INFRAVERMELHO }}$ & 55 \\
\hline $5.3-L E D$
\end{tabular}

\begin{tabular}{lr}
5.2 .3 - LED VERMELHO E LED INFRAVERMELHO DESABILITADOS & 56 \\
\hline
\end{tabular}

5.3 - SENSOR DE OXIMETRIA DE PULSO

\begin{tabular}{lr}
$\mathbf{5 . 4}$ - SISTEMA DE RECEPÇ̃̃O & $\mathbf{5 7}$ \\
\hline
\end{tabular}

\begin{tabular}{lr} 
5.4.1 - MódULO DE PRÉ-AMPLIFICAÇÃO E DEMODULAÇ̃̃O. & 57 \\
\hline
\end{tabular}

\begin{tabular}{ll}
5.4 .2 - FILTRO PASSA-BAIXA COM FREQÜÊNCIA DE CORTE DE $24 \mathrm{~Hz}$ & 62 \\
\hline
\end{tabular}

\begin{tabular}{ll}
5.4 .3 - Módulo De ADEQUAÇ̃̃o do SINAL À FAIXA DINÂMICA DE CONVERSÃo & 68 \\
\hline
\end{tabular}

5.5 - APLICATIVOS DE MONITORAMENTO

5.5.1 - PRotocolo de COMUNICAÇ̃̃o SERIAL PARA A COMUNICAÇ̃̃o ENTRE MSP430 E MICROCONPUTADOR 72

\begin{tabular}{lr}
$5.5 .2-$ INTERFACE GRÁFICA DO APLICATIVO & 73 \\
\hline
\end{tabular}

\begin{tabular}{lr}
$5.5 .3-$ VERSÃO COMERCIAL DE APLICATIVO DE MONITORAMENTO & 75 \\
\hline
\end{tabular}

\begin{tabular}{ll}
$5.6-$ FONTE ANALÓGICA & $\mathbf{7 6}$ \\
\hline
\end{tabular}

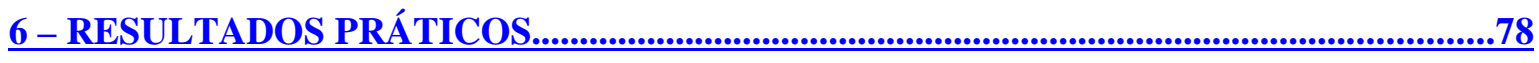

6.1 - AVALIAÇÃO DO SISTEMA DE GERAÇÃO DE ONDAS DE CONTROLE $\quad 78$

6.2 - AVALIAÇÃO DO SISTEMA DE CONTROLE DOS LEDs

\begin{tabular}{ll} 
6.3 - AVALIAÇÃO DO SISTEMA DE RECEPÇÃO & 81 \\
\hline
\end{tabular}

6.3.1 - ANÁLISE DO MÓDULO DE PRÉ-AMPLIFICAÇ̃̃o E DEMODULAC̃̃̃O

6.3.2 - ANÁlISE DO FILTRO PASSA-BAIXA COM FREQÜÊNCIA DE CORTE DE $24 \mathrm{~Hz} \quad 83$

\begin{tabular}{ll}
6.3 .3 - ANÁLISE DO MÓDULO DE ADEQUACC̃̃o DO SINAL À FAIXA DINÂMICA DE CONVERSÃo & 86 \\
\hline $6.3 .4-A N A$
\end{tabular}

\begin{tabular}{lr}
\hline $6.3 .4-$ ANÁLISE GERAL DO SISTEMA DE RECEPČ̃̃o & 87 \\
\hline
\end{tabular}

6.4 - AVALIAÇÃO DOS APLICATIVOS DE MONITORAMENTO

7-CONCLUSÃO_...............................................................................................................................91 
7.1 - CONCLUSÃO DOS OBJETIVOS PROPOSTOS

\begin{tabular}{ll}
7.2 - DIFICULDADES ENCONTRADAS NO TRABALHO & 91 \\
\hline
\end{tabular}

\begin{tabular}{ll}
7.3 - PROPOSTAS PARA TRABALHOS FUTUROS & 93 \\
\hline
\end{tabular}

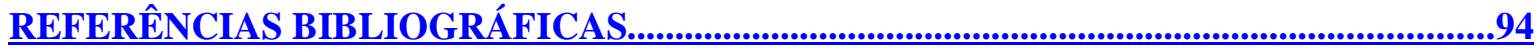

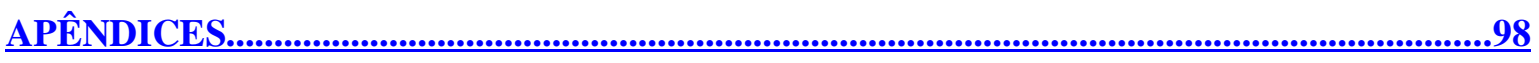




\section{LISTA DE ABREVIAÇÕES}

\begin{tabular}{|c|l|}
\hline Abreviação & \multicolumn{1}{c|}{ Significado } \\
\hline $\mathrm{SpO} 2$ & Saturação de oxigênio mensurada pelo oxímetro de pulso \\
\hline $\mathrm{SaO} 2$ & Saturação de oxigênio do sangue arterial \\
\hline $\mathrm{LED}$ & Diodo emissor de luz \\
\hline $\mathrm{ATP}$ & Adenosina tri-fosfato \\
\hline $\mathrm{A} / \mathrm{D}$ & Analógico para digital \\
\hline $\mathrm{D} / \mathrm{A}$ & Digital para analógico \\
\hline $\mathrm{DC}$ & Corrente contínua \\
\hline $\mathrm{CPU}$ & Unidade de processamento central \\
\hline $\mathrm{ADC} 12$ & Conversor analógico para digital de 12 bits \\
\hline USART & $\begin{array}{l}\text { Universal Synchronous and Asynchronous Receive/Transmit } \\
\text { Peripheral Interface }\end{array}$ \\
\hline JTAG & Joint Test Action Group \\
\hline SPI & Serial Peripheral Interface \\
\hline INA & Instrumentation Amplifier \\
\hline
\end{tabular}




\section{ÍNDICE DE FIGURAS}

Figura 2.1 - Processo de expiração e inspiração $\quad \mathbf{1 0}$

Figura 2.2 - Trocas gasosas no processo de respiração pulmonar $\quad \mathbf{1 1}$

Figura 2.3 - Demonstração do complexo de hemoglobina $\quad \mathbf{1 2}$

Figura 2.4 - Glóbulos vermelhos e hemoglobinas com e sem oxigênio $\mathbf{1 3}$

Figura 2.5 - O Sistema Circulatório $\quad \mathbf{1 4}$

Figura 2.6 - O coração

Figura 2.7 - Sinal típico de eletrocardiograma $\quad \mathbf{1 5}$

Figura 2.8 - O sensor de oximetria de pulso $\quad \mathbf{2 1}$

Figura 3.1 - Diagrama de blocos do Projeto $\quad \mathbf{2 3}$

Figura 3.2 - Esquemático do Sistema de Geração de Sinais de Controle $\mathbf{2 5}$

Figura 4.1 - Exemplo de operação do registrador PxDIR. 30

Figura 4.2 - Exemplo de operação do registrador PxIN 3

Figura 4.3 - Exemplo de operação do registrador PxOUT

Figura 4.4 - Exemplo de operação do registrador PxIE $\quad 32$

Figura 4.5 - Exemplo de operação do registrador PxSEL 32

Figura 4.6 - Seleção do relógio do conversor analógico digital $\mathbf{3 5}$

Figura 4.7 - O registrador ADC12CTL0

Figura 4.8 - O registrador ADC12CTL1 $\mathbf{3 6}$

Figura 4.9 - O registrador ADC12MEMx $\quad 37$

Figura 4.10 - Fluxograma do processo de geração de tensão de referência $\quad \mathbf{3 7}$

Figura 4.11 - Formato de envio de dados por modo serial assíncrono $\quad \mathbf{4 0}$

Figura 4.12 - Exemplo de comunicação por modo síncrono SPI, MSP430 como "mestre".

Figura 4.13 - Geração da onda quadrada de $4.8 \mathrm{kHz}$

Figura 4.14 - Esquemático do método de geração de onda quadrada de $4.8 \mathrm{kHz}$

Figura 4.15 - Janela de 32 inversões do pino P1.1 e ilustração dos momentos em que são realizadas as conversões analógico-digital de cada LED

Figura 4.16 - Esquemático de funcionamento da rotina de cálculo do ganho fornecido ao sinal

Figura 5.1 - Sistema de geração de sinais de controle.

Figura 5.2 - Contador digital síncrono de quatro bits e ondas de saída.

Figura 5.3 - Comportamento adotado para o sinal $\mathrm{Q}_{\mathrm{B}}$

Figura 5.4 - Comportamento adotado para o sinal $\mathrm{Q}_{\mathrm{A}}$

Figura 5.5 - Operações booleanas com ondas de saída do contador síncrono

Figura 5.6 - Circuito gerador de ondas de controle

Figura 5.7 - Esquemático do circuito e das comunicações do sistema de controle dos LEDS

Figura 5.8 - O circuito de controle dos LEDs

Figura 5.9 - a) Esquemático das conexões do sensor de oximetria; b) Ilustração do sensor DS-100A

Figura 5.10 - Esquemático das conexões do módulo de pré-amplificação e demodulação.

Figura 5.11 - Circuito típico de transimpedância com fotodiodo.

Figura 5.12 - Circuito de transimpedância com módulo diferencial.

Figura 5.13 - O amplificador de instrumentação INA 118 
Figura 5.14 - Eleito da escolha da capacitância $C_{\mathrm{f}}$ na recepção do sinal.

Figura 5.15 - Chaves digitais para transmissão e multiplexação de sinais analógicos e digitais

Figura 5.16 - Configuração de Filtro passa-baixa de segunda ordem, tipo SallenKey

Figura 5.17 - Diagrama de pólos e zeros de um filtro de Butterworth de quarta ordem e a resposta da sua respectiva função complexa.

Figura 5.18 - Localização dos pólos do filtro de Butterworth de quarta ordem, freqüência de corte de $24 \mathrm{~Hz}$.

Figura 5.19 - Diagrama de Bode do filtro passa-baixa de Butterworth implementado, com freqüência de corte de $24 \mathrm{~Hz}$.

Figura 5.20 - Diagrama de blocos do módulo de adequação do sinal à faixa dinâmica de conversão.

Figura 5.21 - a) Amplificador operacional TLV2464; b) Resposta do circuito seguidor de tensão; c) Circuito seguidor de tensão.

Figura 5.22 - Adequação do sinal de oximetria à faixa de conversão Figura 5.23 - Circuito de ajuste final do sinal de oximetria

Figura 5.24 - Ilustração do circuito montado com o MAX232 para a comunicação serial assíncrona entre o MSP430 e o microcomputador

Figura 5.25 - Ilustração do aplicativo de monitoramento desenvolvido Figura 5.26 - Janela do aplicativo para a configuração da porta serial

Figura 5.27 - Ilustração do modelo comercial do aplicativo de monitoramento desenvolvido

Figura 5.28 - Fonte analógica simétrica

Figura 6.1 - Avaliação do sistema de geração de ondas de controle

Figura 6.2 - Ilustração do sistema de geração de ondas de controle

Figura 6.3 - Avaliação do sistema de controle dos LEDs

Figura 6.4 - Ilustração do sistema de controle dos LEDs.

Figura 6.5 - Avaliação do circuito de transimpedância

Figura 6.6 - Ilustração do circuito de transimpedância.

Figura 6.7 - Avaliação do circuito de demodulação.

Figura 6.8 - Resposta em freqüência do filtro passa-baixa implementado

Figura 6.9 - Comportamento do filtro passa-baixa na freqüência de $24 \mathrm{~Hz}$

Figura 6.10 - Ilustração do filtro passa-baixa de $24 \mathrm{~Hz}$.

Figura 6.11 - Atuação do módulo de adequação do sinal à faixa dinâmica de conversão

Figura 6.12 - Placa desenvolvida para o módulo de adequação do sinal à faixa dinâmica de conversão

Figura 6.13 - Funcionamento do aplicativo de monitoramento

Figura 6.14 - a) Sinal Captado b) Ilustração da aplicação do filtro de média móvel com janela de 26 amostras em sinal de oximetria captado.

Figura 6.15 - Funcionamento do aplicativo de monitoramento comercial. 


\section{ÍNDICE DE TABELAS}

Tabela 1.1 - Tempo de sobrevivência de órgãos após anoxia

Tabela 1.2 - Problemas respiratórios

Tabela 2.1 - Diferentes tipos de hipoxia

Tabela 4.1 - Operação do registrador PxDIR

Tabela 4.2 - Operação do registrador PxIN

Tabela 4.3 - Operação do registrador PxOUT

Tabela 4.4 - Operação do registrador PxIE

Tabela 4.5 - Operação do registrador PxSEL

Tabela 4.6 - Modo de operação do TAR

Tabela 4.7 - Configuração da USART0 para modo assíncrono

Tabela 4.8 - Configuração da velocidade de transmissão da USART1

Tabela 4.9 - Configuração da USART 1 para o modo SPI

Tabela 4.10 - Configuração da velocidade de transmissão da USART1

Tabela 4.11 - Configuração do módulo ADC12

Tabela 5.1 - Tabela verdade da porta lógica NÂO-E

Tabela 5.2 - Reguladores para as tensões positivas

Tabela 5.3 - Reguladores para as tensões negativas

Tabela 6.1 - Resposta em freqüência do filtro passa-baixa, freqüência de corte de $24 \mathrm{~Hz}$. 



\section{1 - INTRODUÇÃO}

\section{1 - OBJETIVOS DO TRABALHO}

Este trabalho tem como objetivo apresentar um sistema de captação e processamento de sinais de oximetria de pulso, a qual foi introduzida em 1983 como um método não invasivo para o monitoramento da oxigenação do sangue arterial de pacientes. Reconhecida mundialmente como um marco do ramo de anestesiologia, tal técnica é bastante usada dentro de unidades de terapia intensiva, salas de operações e no ramo de medicina veterinária. Oxímetros de pulso fornecem informações rápidas sobre problemas que possam estar ocorrendo na condução de oxigênio para os tecidos do corpo humano.

O sistema completo é composto de diversos módulos, os quais têm a função de captar e controlar o sinal recebido. Vários desses módulos se comunicam entre si para poder obter uma estimação da oxigenação sanguínea mais próxima da realidade e um sinal com o maior valor de detalhes possíveis.

Praticamente todos os módulos são formados por dispositivos analógicos e digitais, os quais trabalham como filtros, amplificadores, chaves, sistemas lógicos, dentre diversas outras funções. O resultado de todo o processo pode ser visualizado em aplicativos que foram desenvolvidos com o intuito de permitir uma análise gráfica do processo de oxigenação, bem como criar a possibilidade de armazenamento dos dados captados para a realização de um futuro processamento do sinal.

\section{2 - MOTIVAÇÕES DO ESTUDO DE OXIMETRIA DE PULSO}

Atualmente, vem se tornando cada vez maior a preocupação por parte da população por técnicas que sejam capazes de monitorar a saúde e que ao mesmo tempo minimizem dores ou possíveis constrangimentos aos pacientes.

Com isso, estudos em aparelhos mais eficazes, com respostas rápidas e análises contínuas e não invasivas foram se tornando cada vez mais populares dentro do âmbito acadêmico e científico. 
O monitoramento da oxigenação sanguínea é uma das variáveis mais importantes em se tratando de salas de cirurgia e unidades de terapia intensiva. Bons índices de oxigenação no sangue podem ser vistos como o resultado do bom funcionamento dos sistemas respiratório e circulatório, os quais são de extrema importância e fornecem informações vitais sobre a existência de condições apropriadas para o funcionamento de todas as outras partes do corpo humano. [11]

Oximetria de pulso é somente uma dentre as diversas técnicas que foram desenvolvidas e aprimoradas ao longo dos últimos anos para o monitoramento da saturação de oxigênio no sangue. Oximetria é um termo genérico que se refere a tal medição por meio de instrumentos ópticos. [11]

Oxímetros de pulso ficaram comercialmente acessíveis em meados da década de 90 e tiveram um crescimento bastante intenso em sua popularidade, transformando-se em um dispositivo modelo para o monitoramento de condições vitais de oxigenação. Tais aparelhos fornecem medições empíricas da saturação do sangue. Entretanto, com o avanço tecnológico, acaba-se criando uma correlação bastante adequada entre as medições de oxímetros de pulso, $\mathrm{S}_{\mathrm{p}} \mathrm{O}_{2}$, e a atual saturação de oxigênio do sangue arterial no paciente, $\mathrm{S}_{\mathrm{a}} \mathrm{O}_{2}$. [11]

A rápida aceitação de oxímetros de pulso como equipamentos para o monitoramento em cirurgias, estabelecimentos de unidades de tratamento intensivo e de pesquisa mostrou que perdas pequenas na precisão, as quais são associadas à medição da saturação de oxigênio de forma não invasiva, são compensadas pelas vantagens de um dispositivo com disponibilidade de dados de forma contínua e imediata, sem a necessidade de causar dores aos pacientes.[11]

Porém, em algumas aplicações onde tal precisão é essencial, como na detecção de hiperoxia (alta oxigenação do sangue), o uso de oxímetros de pulso não é bastante recomendado e ainda continua a ser discutida pela comunidade científica médica. Entretanto, a importância no campo de detecção de hipoxemia (baixa oxigenação do sangue), onde oxímetros de pulso são bastante aceitos, é tão grande, que o instrumento exerce um papel crítico na medicina, mesmo com todas as suas limitações.[11]

Seguindo essa necessidade pela aprendizagem e o incentivo pelo aprimoramento da 
tecnologia, com o intuito de se construir aparelhos cada vez mais eficientes no tratamento de pacientes e com dados cada dia mais próximos da realidade, decidiu-se realizar um estudo que abordasse os aspectos inovadores do oxímetro de pulso, afim de se apontar as suas peculiaridades, dificuldades encontradas no seu desenvolvimento, modos de funcionamento, bem como toda a gama de circuitos eletrônicos, analógicos e digitais que, combinados, fazem este aparelho não invasivo funcionar de forma adequada no monitoramento da oxigenação do sangue arterial.

O presente projeto final de graduação apresenta a elaboração de uma plataforma de aquisição e processamento, em tempo real, de sinais de oximetria de pulso, sendo possível também salvar todos os dados para uma análise futura mais aprofundada. O sistema também conta com um hardware que foi desenvolvido com o intuito de se fazer as devidas modificações na aquisição, taxa de transmissão e análise dos sinais captados, de acordo com a necessidade em estudo.

\section{3 - TRANSPORTE DE OXIGÊNIO}

O uso de oxigênio é vital para o funcionamento de cada uma das células do corpo humano. A abstinência por um período prolongado de tempo de tal molécula, acaba ocasionando a morte das células. Por isto, o seu transporte para todas as partes do corpo humano é um importante indicador da saúde do paciente. [11]

Como explicado anteriormente, vários métodos têm sido desenvolvidos para analisar e acompanhar o transporte de oxigênio. Oximetria de pulso é um método comum, não invasivo e bastante usado em aplicações clínicas.

O processo de ventilação é o passo inicial do transporte de oxigênio, pois é através dele que ar é movido para dentro e para fora dos pulmões, onde a troca de gases do corpo com o meio externo ocorre.

Em tal processo, moléculas de oxigênio são difundidas pelo sangue, enquanto moléculas de dióxido de carbono, um dos produtos resultante da respiração celular, são expelidas. O sangue oxigenado (sangue arterial) circula pelo corpo alcançando as áreas mais remotas, onde o oxigênio é difundido pelas células. Como resultado do processo de respiração celular, dióxido de carbono também é transferido para o sangue, de onde segue 
para os pulmões para ser expelido. [11]

O processo de ventilação é controlado por neurônios do sistema nervoso central. O sistema circulatório também pode modular a frequiência cardíaca para que esta influencie na velocidade com que o transporte de oxigênio é realizado. [11]

\section{4 - $\mathrm{S}_{\mathrm{p}} \mathrm{O}_{2}$ NO MONITORAMENTO DA OXIGENAÇÃO DAS HEMOGLOBINAS}

As células de tecidos que possuem uma taxa alta de metabolismo, como as células do coração e as células do sistema nervoso central, podem ser conduzidas rapidamente a um perigo irreversível devido à falta de oxigênio.

Apesar de o corpo humano ser surpreendentemente robusto em vários sentidos, o processo fisiológico de fornecer condições apropriadas para o funcionamento das células através do transporte de oxigênio é um delicado e complexo sistema. Qualquer alteração significativa pode levar a uma situação instável na qual não seja possível alimentar as necessidades de oxigênio de tecidos e órgãos do corpo humano. [11]

Para enfatizar a importância da oxigenação apropriada, a Tabela 1.1 lista o tempo de sobrevivência para diferentes tipos de órgão depois de uma parada cardíaca ou do princípio de anoxia (falta total de oxigênio em um determinado tecido). Portanto, é possível perceber a importância de se evitar que situações patológicas levem a uma má oxigenação aos diversos tecidos do corpo, o que pode causar definitivamente a sua falência.

Tabela 1.1 - Tempo de Sobrevivência de órgãos após anoxia [11]

\begin{tabular}{|c|c|}
\hline Órgão & $\begin{array}{c}\text { Tempo de sobrevivência depois } \\
\text { de princípio de anoxia }\end{array}$ \\
\hline Cérebro & Menos de 1 minuto \\
\hline Coração & 5 minutos \\
\hline Fígado e Rim & 10 minutos \\
\hline Músculos do Esqueleto & 2 horas \\
\hline
\end{tabular}

\subsection{1 - Idéia compreensiva do papel do oxímetro de pulso}

A saturação arterial, variável a qual os oxímetros de pulso se propõem a medir, é somente uma dentre as diversas variáveis que um médico irá considerar quando for avaliar as condições e o funcionamento do sistema cardiorespiratório de um paciente. 
Sendo assim, o clínico deve direcionar o tratamento de acordo com o nível de oxigenação do sangue. Isso requer uma noção do papel que a saturação do sangue arterial exerce e uma idéia compreensiva de como ela pode estar afetando o funcionamento do corpo humano. É um fato extremamente importante, mas médicos tipicamente não utilizam $\mathrm{S}_{\mathrm{a}} \mathrm{O}_{2}$ como o único meio de se monitorar condições patológicas na oxigenação.

\section{5 - SATURAÇÃO ARTERIAL DE OXIGÊNIO}

O sangue oxigenado circula pelo corpo através das artérias e capilares. Este sangue possui a mesma saturação por todo o sistema arterial. É nos capilares que o nível de saturação muda. Em adultos saudáveis, a taxa normal para $\mathrm{S}_{\mathrm{a}} \mathrm{O}_{2}$ é maior do que $90 \%$.

Devido à complexidade do processo de oxigenação, fica difícil especificar as inúmeras vantagens do monitoramento da saturação arterial em casos críticos, como unidades de terapia intensiva, salas de operação ou laboratórios de pesquisa.

Médicos têm interesse em tal monitoramento por uma variedade de razões. Em alguns momentos ela é utilizada apenas como uma variável das condições gerais do sistema cardiorespiratório do paciente. Porém, em outras situações, tal monitoramento serve como um importante indicativo de prevenção contra baixas taxas de oxigenação, mesmo não sendo um indicador direto de qual seja a causa da condição perigosa que esteja causando tal problema.

A Tabela 1.2 ilustra alguns dentre os diversos problemas respiratórios que podem causar uma baixa taxa $\mathrm{S}_{\mathrm{a}} \mathrm{O}_{2}$.

Tabela 1.2 - Problemas Respiratórios [11]

\begin{tabular}{|l|l|}
\hline \multicolumn{1}{|c|}{ Problema Respiratório } & $\begin{array}{c}\text { Exemplos de Doenças ou possíveis causas } \\
\text { do problema }\end{array}$ \\
\hline Pouco ar fornecido pelos pulmões & Pneumonia, Enfisema, Fibrose \\
\hline Aumento da resistência respiratória & Asma, Bronquite crônica. Fibrose crítica \\
\hline Obstruções do ar no caminho dos pulmões & Apnéa, Choque, Secreções \\
\hline Problemas no complexo hemoglobina & Doença cardíaca congênita \\
\hline Baixa pressão parcial do oxigênio & Altas altitudes \\
\hline Hipoventilação & Desequilíbrio do $\mathrm{pH}$ sanguíneo \\
\hline
\end{tabular}




\section{6 - ORGANIZAÇÃO GERAL DO TRABALHO}

O presente trabalho está dividido em sete capítulos, os quais estão dispostos da seguinte forma: Introdução, Fundamentos Fisiológicos de Oximetria de Pulso, Descrições e Especificações do Sistema, O Microcontrolador MSP 430, Sistemas e Circuitos do Oxímetro de Pulso, Resultados Práticos e Conclusão.

No capítulo de Introdução, é feita uma abordagem geral do projeto desenvolvido, analisando as motivações e objetivos, bem como uma explicação sucinta do transporte de oxigênio e a importância da saturação arterial sanguínea.

No capítulo de Fundamentos Fisiológicos de Oximetria de Pulso, como o próprio nome sugere, é feito um embasamento teórico acerca dos princípios que regem o funcionamento do oxímetro. Sendo assim, é feita uma abordagem sobre a importância dos sistemas respiratório e circulatório no transporte de oxigênio, bem como do papel essencial exercido pelo complexo de hemoglobina. Também é dado um enfoque à variação da pigmentação de tal complexo de acordo com o nível de oxigenação e como este fato é utilizado no monitoramento realizado pelo oxímetro de pulso.

No capítulo de Descrições e Especificações do Sistema, é feito um detalhamento da estrutura geral do projeto, enfatizando a importância exercida por cada um dos diferentes módulos e como tais módulos se interagem no controle e captação do sinal de oximetria de pulso. O projeto foi dividido em cinco sistemas, os quais são: Sistema de Controle dos LEDs, Sistema de Recepção, Microcontrolador, Sistema de Geração de Ondas de Controle e Aplicativos de Monitoramento.

No capítulo O Microcontrolador MSP 430, é feita uma explicação acerca dos parâmetros que levaram à escolha do microcontrolador, bem como uma breve análise de alguns dos módulos incorporados ao MSP que utilizados na implementação do projeto, como o conversor analógico digital, o contador/temporizador Timer A e a interface universal serial. Outra abordagem foi feita em cima da programação do microcontrolador envolvida.

No capítulo Sistemas e Circuitos do Oxímetro de Pulso é feita uma descrição acerca da implementação e do funcionamento dos quatro principais sistemas existentes no 
oxímetro: Sistema de Geração de Sinais de Controle, Sistema de Controle dos LEDs, Sistema de Recepção e Aplicativos de Monitoramento. É apresentada uma explicação de como cada módulo age e a função que ele exerce dentro do sistema em que faz parte.

No capítulo Resultados Práticos é feita uma avaliação acerca do comportamento que foi observado na realização experimental dos diversos sistemas, bem como uma análise do funcionamento do sistema completo. Vários resultados são apresentados, ilustrando as peculiaridades desejadas e obtidas de cada sistema.

Por último, no capítulo de Conclusão, é feita uma descrição das principais dificuldades que foram enfrentadas ao logo do desenvolvimento do projeto, bem como a conclusão dos autores acerca dos objetivos propostos. No final, são feitas sugestões e recomendações relacionadas ao oxímetro em trabalhos e projetos futuros. 


\section{2 - FUNDAMENTOS FISIOLÓGICOS DE OXIMETRIA DE PULSO}

\section{1 - IMPORTÂNCIA DO SISTEMA RESPIRATÓRIO NA OXIGENAÇÃo SANGUÍNEA}

\subsection{1 - Controle da ventilação pulmonar}

A Ventilação é um processo involuntário e rítmico de mover ar para dentro e para fora dos pulmões. Este processo é controlado por neurônios do sistema nervoso central os quais são responsáveis pelas funções desempenhadas pelo sistema respiratório. Tais neurônios excitam os neurônios motores que, em consequiência, resultam na movimentação de diversos músculos que ocasionam a respiração.

A resposta dos neurônios respiratórios é modulada pelos receptores químicos e pelos receptores mecânicos, os quais indicam o comportamento da respiração e a existência de possíveis problemas de oxigenação em tecidos ou órgãos do corpo humano. [11]

\subsection{2 - Resposta do corpo humano a possíveis problemas na respiração}

Como explicado anteriormente, o sistema nervoso central recebe informações de diversos receptores químicos e mecânicos, que são responsáveis pelo monitoramento das condições de funcionamento dos vários tecidos e órgão do corpo humano. Em relação ao sistema respiratório, a entrada de informação de tais receptores é analisada pelos neurônios respiratórios, os quais determinam a taxa apropriada e a potência da ventilação nos pulmões.

Receptores mecânicos dão respostas correspondentes às movimentações que ocorrem durante o processo de respiração. Por exemplo, determinados receptores fornecem informações relacionadas à expansão dos pulmões e do dos músculos peitorais tanto durante a inspiração quanto durante a expiração.

Índices analisados pelos receptores mecânicos, referentes à inflação dos pulmões, podem causar a inibição da inspiração para prevenir uma possível inflação excessiva dos músculos pulmonares. Outro índice referente à contração dos pulmões também é analisado 
por tais receptores, e tem um propósito similar na expiração, evitando assim o colapso aos pulmões. [11]

Já receptores químicos fornecem informações acerca do nível de dióxido de carbono, de íons de oxigênio e de hidrogênio no sangue. Tais receptores estão localizados na artéria carótida, enquanto o oxigênio é enviado ao cérebro, e na aorta, logo depois que o sangue oxigenado é bombeado do coração para o resto do corpo. Sob condições normais, os níveis de oxigênio no sistema arterial são altos, e os de dióxido de carbono e de hidrogênio são baixos. [11]

O cérebro deve interpretar todas as informações recebidas das diversas partes do corpo humano relacionadas ao processo de oxigenação apropriada, e não somente o controle das variáveis relacionadas à ventilação. Sobre condições normais de respiração, o cérebro é mais sensível ao monitoramento dos níveis de dióxido de carbono e de hidrogênio. As concentrações de oxigênio só são importantes quando as taxas estão extremamente baixas. [11]

Considerando, por exemplo, uma taxa bastante alta de dióxido de carbono no sangue, como ocorreria durante o momento máximo de exaustão em um exercício. Mesmo os receptores responsáveis pela expansão dos pulmões indicarem que tal órgão e os músculos peitorais alcançaram a sua máxima expansão, o corpo humano pode reagir a tal situação aumentando a taxa de respiração para compensar a alta taxa de dióxido de carbono, sem que para isso ocorra um aumento proporcional da expansão dos pulmões e músculos peitorais. [11]

\subsection{3 - Mecanismos de ventilação pulmonar}

Os mecanismos que o corpo humano utiliza para realizar a ventilação pulmonar são baseados no princípio de escoamento do ar de áreas de alta pressão para áreas de baixa pressão. A contração dos músculos intercostais, dos músculos peitorais e do diafragma causa a expansão dos pulmões e a conseqüente diminuição da pressão dentro da cavidade torácica.

A pressão atmosférica acaba se tornando maior do que a pressão dentro dos pulmões, ocasionando um escoamento de ar para dentro do órgão, fato que é mais 
conhecido como inspiração.

O relaxamento dos músculos intercostais e do diafragma causa a diminuição do volume dentro dos pulmões, aumentando assim a pressão na cavidade torácica. Como a pressão nos pulmões aumenta, alcançando assim valores superiores aos da pressão atmosférica, o ar escoa para fora do órgão, processo o qual é conhecido como expiração. [11]

Ambos os processos podem ser visualizados na Figura 2.1, ilustrada abaixo, a qual demonstra também o comportamento do diafragma e o caminho do ar para dentro e para fora dos pulmões.

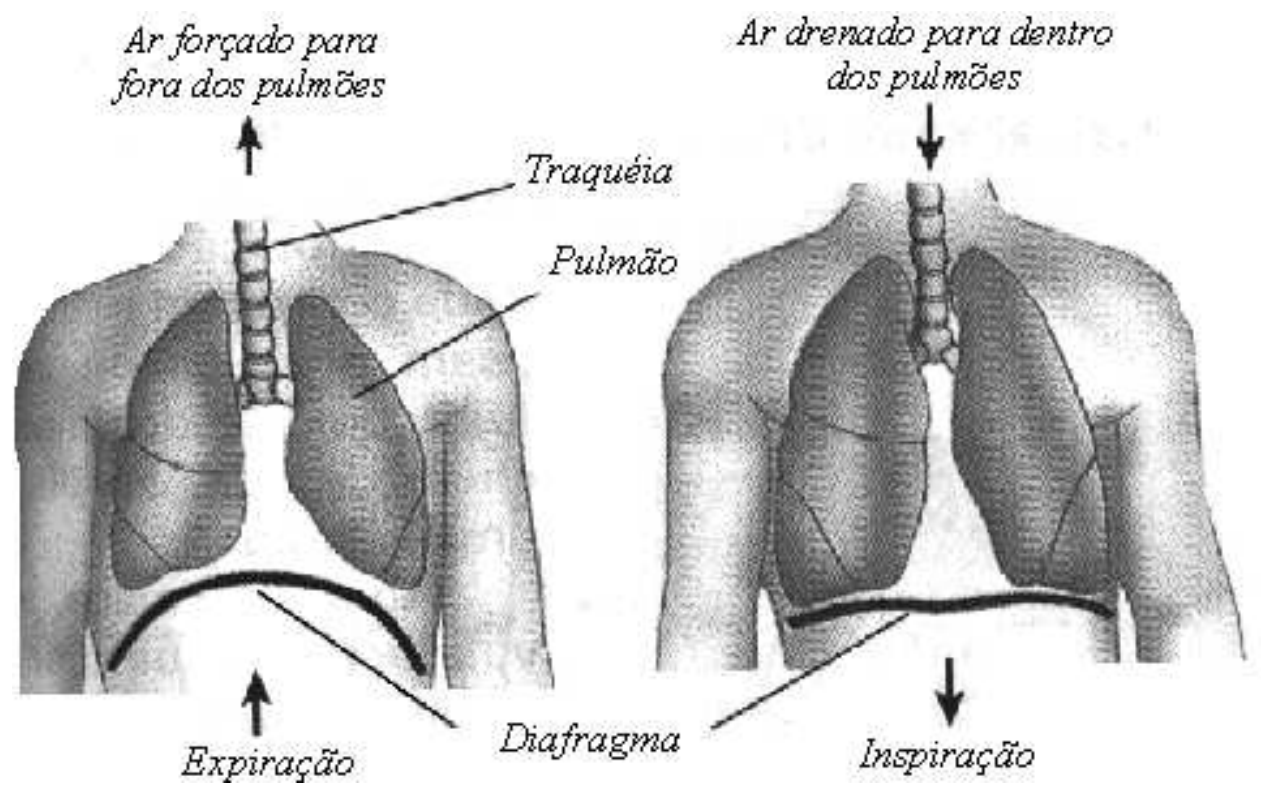

Figura 2.1 - Processo de expiração e inspiração. (modificado, [11])

\subsection{4 - Difusão do sangue}

O processo de ventilação proporciona suprimentos contínuos de ar fresco aos pulmões. Depois que o sangue provido de oxigênio circulou por todo o corpo humano, é trazido de volta aos pulmões por capilares arteriais para que seja realizada a troca de gases, momento o qual o corpo humano recebe oxigênio e se livra do dióxido de carbono resultante do processo de respiração. Após isso, o sangue é re-oxigenado e passa a circular novamente pelo corpo. 
A troca de oxigênio ocorre durante o processo de difusão. A difusão é o conjunto de movimentos randômico de partículas de uma área de pressão parcialmente maior para uma outra área de pressão parcialmente menor. A troca de gases com o sangue, referenciada acima, acontece dentro dos alvéolos.

\subsection{5 - Trocas gasosas}

$\mathrm{O}$ ar que se encontra nos alvéolos tem uma pressão parcialmente maior de oxigênio e uma pressão parcialmente menor de dióxido de carbono do que o sangue venoso. Assim, a difusão ocorre devido o gradiente de pressão. [11]

O conjunto de movimentos do dióxido de carbono será realizado na direção dos alvéolos e o conjunto de movimentos do oxigênio será realizado na direção do sangue. Tal processo pode ser visualizado na Figura 2.2, ilustrada abaixo. [11]

O sangue, então, retorna para o coração via veia pulmonar, de onde será bombeado para o resto do corpo. Outros gases podem se difundir, como um resultado do gradiente parcial de pressão entre o ar nos alvéolos e o sangue arterial pulmonar.

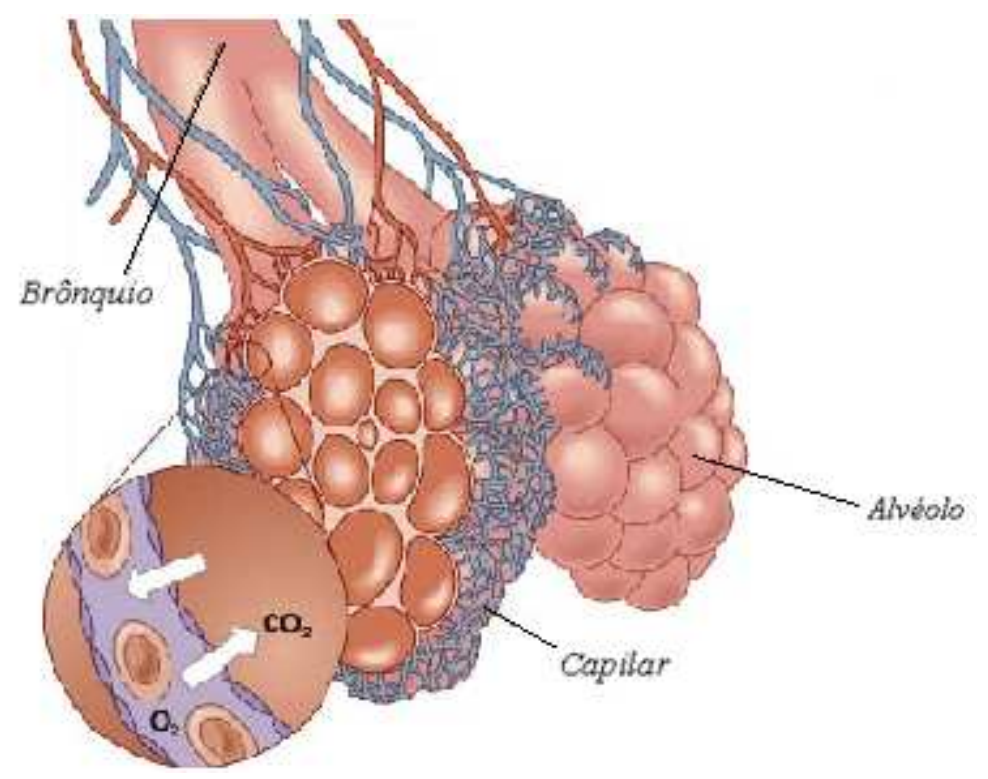

Figura 2.2 - Trocas gasosas no processo de respiração pulmonar. (modificado, [29]) 


\section{2 - IMPORTÂNCIA DA HEMOGLOBINA NA OXIGENAÇÃO SANGUÍNEA}

\subsection{1 - União de oxigênio à hemoglobina}

Gases, particularmente, não são solúveis em sangue, fluído que é composto basicamente de água. Por isso, para um transporte efetivo de oxigênio, um método secundário é necessário.O composto de hemoglobina fornece um mecanismo bastante eficiente que permite a união do oxigênio ao composto para que este seja transportado pelo sangue. Hemoglobina exerce um papel essencial no transporte das necessidades de oxigênio do corpo. Para uma mesma quantidade de plasma, é possível se transportar 65 vezes mais oxigênio com hemoglobina do que seria possível sem hemoglobina. [11]

\subsection{2 - Características da hemoglobina e sua importância na pigmentação do sangue}

Hemoglobina é um composto encontrado nos glóbulos vermelhos do sangue importantíssimo no processo de respiração. Um único glóbulo vermelho contém aproximadamente 265 milhões de moléculas do composto de hemoglobina. [11]

A Hemoglobina é composta de quatro cadeias polipeptídicas de globina e quatro grupos heme, os quais são formados por átomos de ferro ferroso $\left(F e^{++}\right)$, que exercem a função de ligação com o oxigênio. Sendo assim, uma molécula de hemoglobina pode carregar até quatro moléculas de oxigênio. Tal molécula de oxigênio se liga ao átomo de ferro ferroso $\left(\mathrm{Fe}^{++}\right)$, que é relativamente abundante nos pulmões e é liberado depois nos tecidos e órgãos do corpo humano viabilizando a respiração celular. [26]

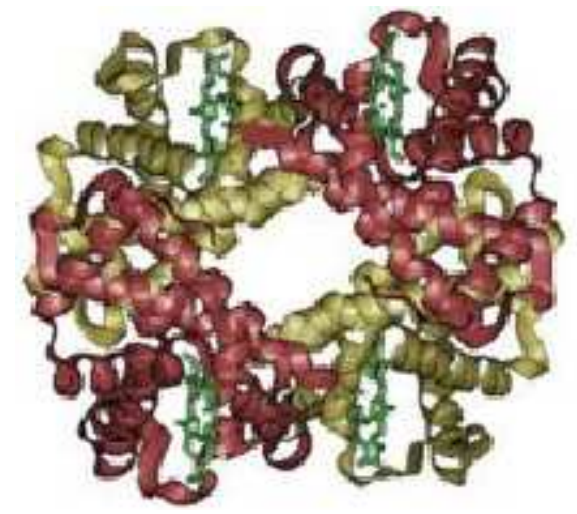

Figura 2.3 - Demonstração do complexo de hemoglobina. [26] 
Tal substância, a hemoglobina, possui diferentes tipos de pigmentação, que variam de acordo com o nível de oxigenação. Caso a molécula se encontre oxigenada, sua coloração se torna vermelha e brilhante. Caso contrário, se a hemoglobina estiver sem oxigênio, sua coloração se torna vermelha escura. Esta mudança de cor é usada em aplicações de oximetria de pulso para medir a saturação de oxigênio do sangue. [11]

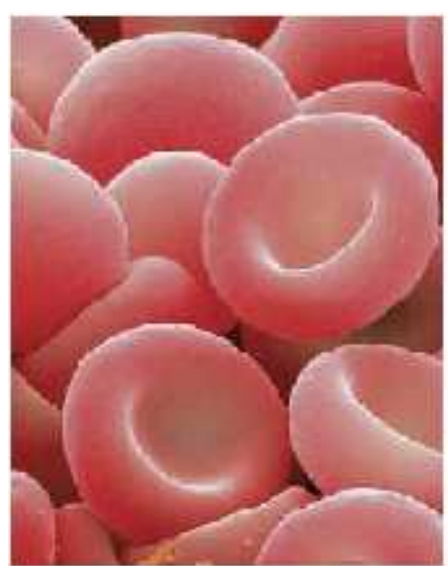

Glóbulos Vermelhos

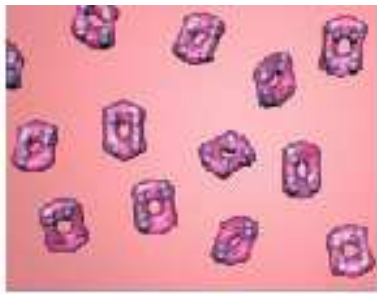

Hemoglobina com moléculas de oxigênio

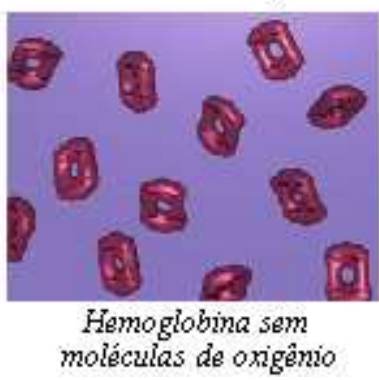

Figura 2.4 - Glóbulos vermelhos e hemoglobinas com e sem oxigênio. (modificado, [26])

Depois que uma molécula que esteja totalmente desoxigenada se combinar com uma molécula de oxigênio, ela passa a ter uma grande afinidade para uma segunda molécula. Isso é verdade para cada molécula adicional de oxigênio. [26]

O processo reverso também é verdadeiro. Depois que a primeira molécula se libera da hemoglobina, se torna mais fácil que outras moléculas de oxigênio também se liberem.

\section{3 - SISTEMA CIRCULATÓRIO E O TRANSPORTE DE SANGUE}

Uma vez que o sangue teve o oxigênio difundido nos alvéolos, com a ajuda expressiva do composto hemoglobina, o fluído retorna ao coração. O sistema circulatório é utilizado como meio de transporte do sangue oxigenado para as mais diversas células do corpo.

O coração é o mecanismo primário de bombeamento e transporte de sangue através do corpo humano. A Figura 2.5 faz uma demonstração da cadeia de veias e artérias que compõem o sistema junto com o coração. 


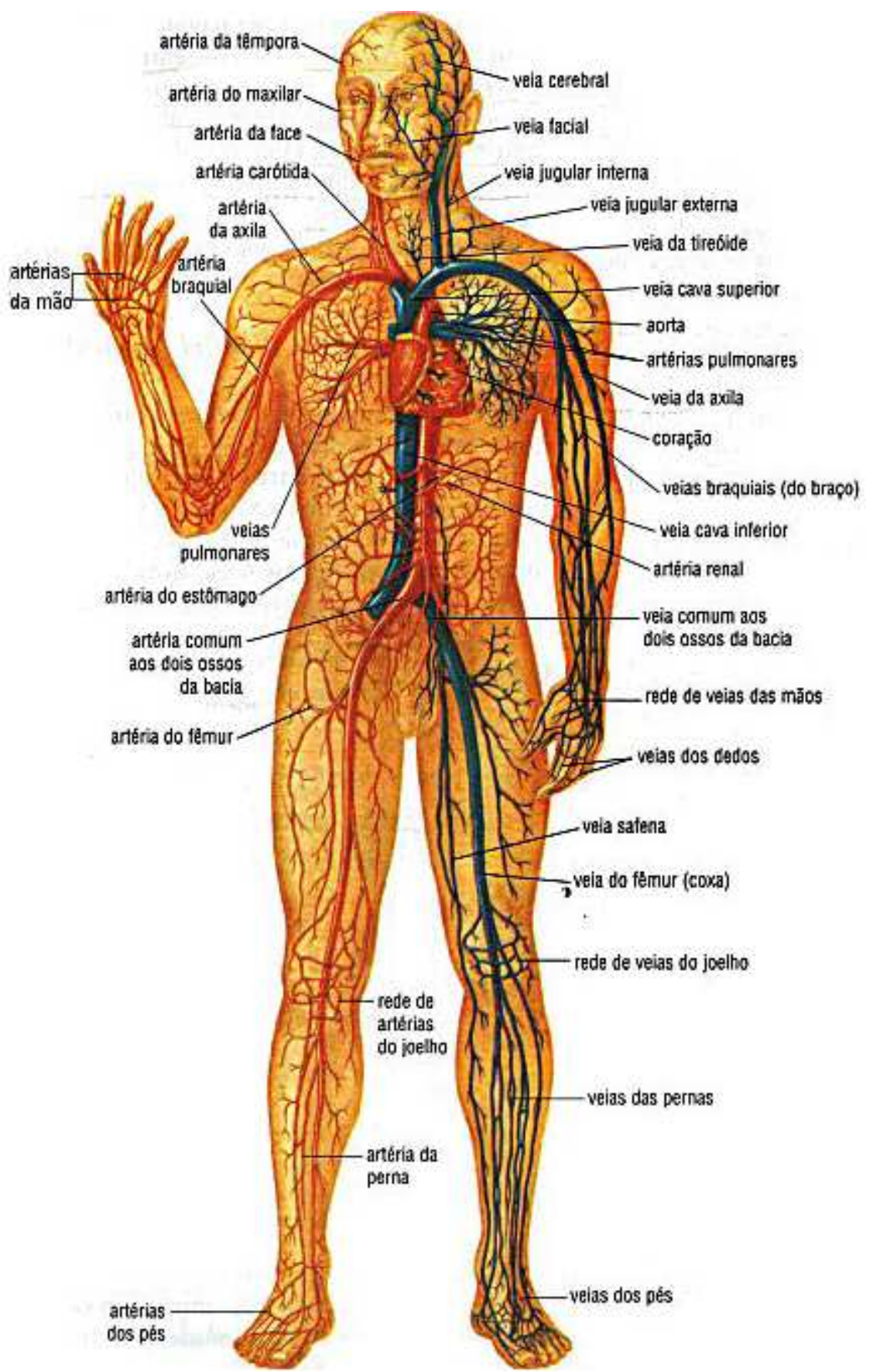

Figura 2.5 - O Sistema Circulatório. [31]

\subsection{1 - O coração e os sinais de eletrocardiograma (ECG)}

O sangue é bombeado para o resto do corpo através do coração. A contração deste órgão é controlada por uma série de impulsos elétricos, que são originários do nodo sinoatrial (AS nodo) e percorrem até o nodo atrioventricular (AV node), causando a polarização e despolarização das fibras musculares do coração, órgão o qual pode ser 
visualizado na Figura 2.6. [30]

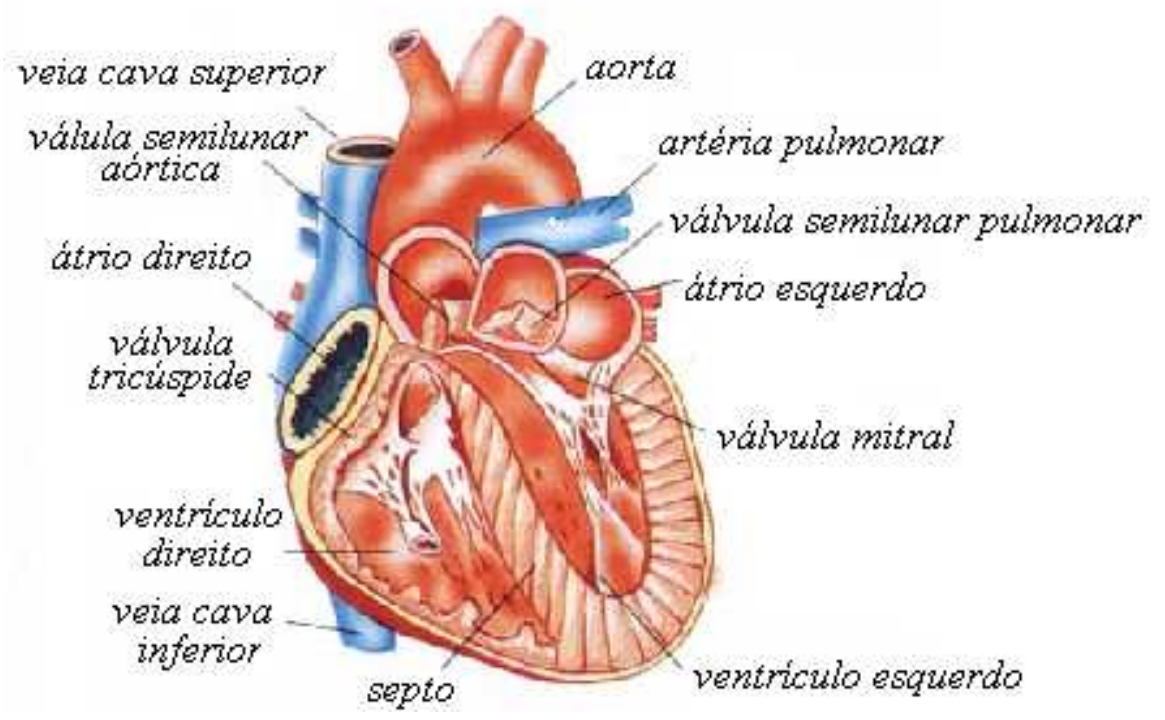

Figura 2.6 - O coração. (modificado, [15])

Uma importante ferramenta médica na análise das condições gerais do funcionamento deste órgão é o monitoramento dos sinais de eletrocardiograma, os quais podem indicar possíveis comportamentos anômalos ou problemas como cardiopatia. A Figura 2.7, traz uma ilustração de um sinal típico de eletrocardiograma, mostrando os principais intervalos do ciclo cardíaco, como o complexo QRS e as ondas P e T.

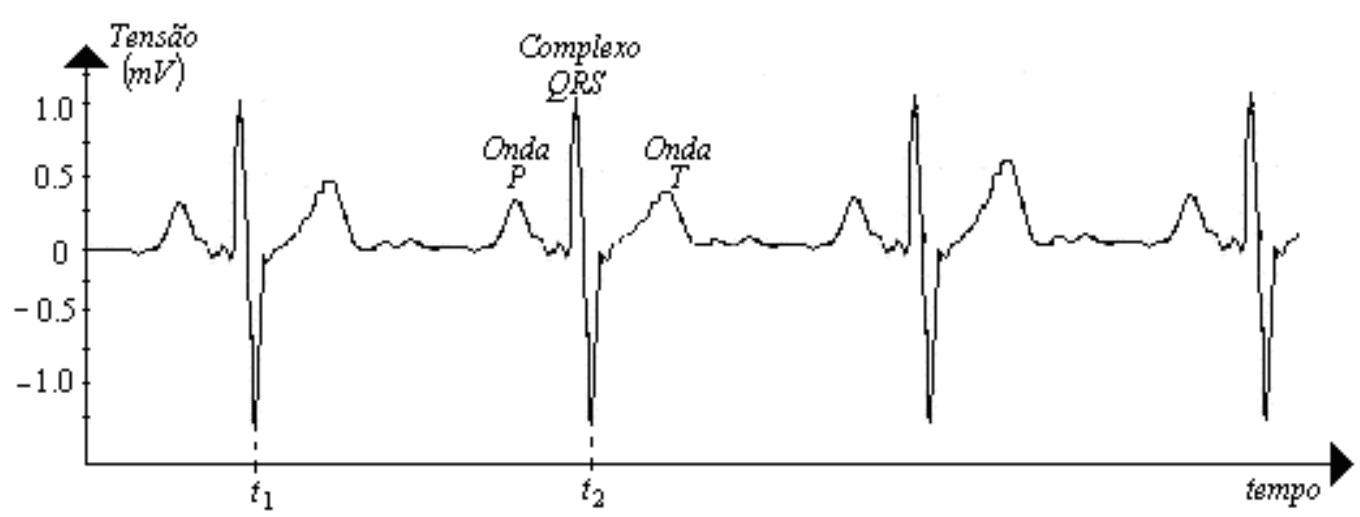

Figura 2.7 - Sinal típico de eletrocardiograma.

Cada uma dessas ondas advém de situações distintas no processo rítmico da circulação de sangue. Tais situações podem ser listadas a seguir:

$\checkmark$ A onda P é causada pela despolarização das fibras do átrio, que ocorre antes de sua contração; [35]

$\checkmark$ O complexo QRS é gerado pela despolarização dos ventrículos, o que causa a contração dos mesmos; [35] 
$\checkmark$ A onda T é causada pela polarização dos ventrículos, assim que o músculo relaxa e se recupera do estado de despolarização. [35]

\subsection{2 - Circulação pulmonar}

Como explicado anteriormente, o coração funciona como um mecanismo de bombeamento do sangue para as diversas partes do corpo humano. Terminado o processo de respiração celular, o sangue retorna ao coração com altas taxas de dióxido de carbono e, em seguida, é bombeado do ventrículo direito para os pulmões.

As artérias pulmonares se ramificam em artérias menores e, eventualmente em capilares arteriais, os quais têm calibres bastante pequenos, variando de 4 a 16 milésimos de milímetro (comparável a um cabelo). Como explicado anteriormente, é exatamente neste nível que ocorre a troca de gases entre os alvéolos e os capilares, resultando na oxigenação do sangue.

Terminado todo este processo, o sangue retorna através das veias pulmonares para o átrio esquerdo do coração, completando o ciclo circulatório. [30]

\section{4 - PRINCÍPIOS DO OXÍMETRO DE PULSO}

O Oxímetro de Pulso emite luz de dois comprimentos de onda através de uma extremidade do corpo, como um dedo ou orelha. Logo em seguida, o aparelho mede o sinal de luz que foi transmitido ou refletido na região analisada. O dispositivo opera basicamente da seguinte forma:

1) Como explicado anteriormente na seção 2.2.2, a pigmentação da hemoglobina oxigenada é diferente da que fluí sem o transporte de oxigênio. Isso faz com que a absorção para ambas seja diferente nos dois comprimentos de onda os quais o oxímetro emite luz. Para ser mais exato, o coeficiente de absorção da luz para tais comprimentos é linearmente independente, mas não tão distantes, o que faz com que o sangue pareça opaco para ambas as fontes de luz. Esse modelo assume que somente a hemoglobina oxigenada e aquela que não se encontra oxigenada estão presentes no sangue. 
2) A pulsação natural do sangue arterial resulta em uma forma de onda no sinal transmitido que permite identificar os efeitos da absorção do sangue arterial diante dos efeitos não pulsantes do sangue venoso e também dos tecidos do corpo. Ao se usar um quociente dos dois efeitos nos diferentes comprimentos de onda é possível se obter uma medida que não necessita de calibração absoluta com respeito à absorção geral dos tecidos. Esta é uma vantagem clara do uso de oxímetros de pulso sobre outros tipos de oxímetro.

3) Com a luz adequada dispersa no sangue e nos tecidos, será possível iluminar suficientemente o sangue arterial, permitindo assim, uma detecção confiável do sinal pulsante. Exatamente dessa propriedade que é possível se extrair as características usadas no monitoramento e verificação de uma oxigenação adequada.

Os princípios acima descritos, associados a todas as outras aplicações que foram desenvolvidas, resumem um pouco o conjunto completo do que foi implementado neste trabalho, o qual procura mostrar a importância da oximetria de pulso e suas limitações.

\section{5 - USO DE OXÍMETROS DE PULSO NO MONITORAMENTO DE POSSÍVEIS PROBLEMAS NA OXIGENAÇÃO SANGUÍNEA}

\subsection{1 - Hipoxia e Hipoxemia}

O termo hipoxia refere-se a uma taxa menor do que o normal de oxigenação dos tecidos. Já o termo hipoxemia refere-se a uma taxa menor do que o normal de oxigenação do sangue. Esses dois termos são conceitos ligeiramente diferentes. Hipoxia se refere a condição criticamente perigosa onde a função desempenhada pelas células de um determinado tecido está sob sério risco. [11]

A Tabela 2.1 ilustra diferentes categorias de situação de hipoxia e uma descrição de suas prováveis causas. A primeira categoria, hipoxia hipóxica, é uma das consequiências de uma baixa taxa de saturação arterial no sangue.

Apesar da hipoxemia (taxa menor do que o normal de oxigenação do sangue) ser bastante perigosa, não é necessário que a hipoxia exista sobre a condição de hipoxemia. Da mesma forma como a Tabela 2.1 sugere, hipoxia pode ocorrer quando não existe a menor evidência de hipoxemia. Entretanto, um médico deve interpretar cuidadosamente os 
resultados do monitoramento do oxigênio no sangue, pois $\mathrm{S}_{\mathrm{a}} \mathrm{O}_{2}$, e conseqüentemente $\mathrm{S}_{\mathrm{p}} \mathrm{O}_{2}$, fornece apenas uma medição de hipoxemia, e não uma medição de hipoxia.

Tabela 2.1 - Diferentes tipos de hipoxia [11]

\begin{tabular}{|c|l|}
\hline Tipos de Hipoxia & \multicolumn{1}{|c|}{ Descrição } \\
\hline Hipoxia Hipóxica & $\begin{array}{l}\text { O sangue arterial possui uma oxigenação escassa, que pode ser } \\
\text { causada por problemas respiratórios, por baixo fluxo de } \\
\text { oxigênio nos alvéolos ou pela perda da fosforilação oxidativa } \\
\text { e da produção de ATP pelas mitocôndrias. }\end{array}$ \\
\hline Hipoxia Anêmica & $\begin{array}{l}\text { O sangue não consegue transportar uma quantidade adequada } \\
\text { de oxigênio devido a anormalidades na hemoglobina. }\end{array}$ \\
\hline Hipoxia Circulatória & $\begin{array}{l}\text { O coração não consegue drenar muito oxigênio para o corpo } \\
\text { devido a uma baixa potência cardíaca ou uma perfusão } \\
\text { inadequada de sangue nos tecidos. }\end{array}$ \\
\hline Hipoxia Histotóxica & $\begin{array}{l}\text { Mesmo recebendo fontes de oxigênio, o tecido é incapaz de } \\
\text { usá-las. }\end{array}$ \\
\hline
\end{tabular}

\subsection{2 - Papel do $\mathrm{S}_{\mathrm{p}} \mathrm{O}_{2}$ na prevenção de hipoxia}

Apesar do monitoramento da saturação sanguínea arterial fornecer apenas pistas da oxigenação das células, existe uma variável bastante importante a qual proporciona melhores evidências da existência de hipoxia. Tal variável é a quantidade de lactato presente no sangue.

A utilização de energia pode ser necessária em uma situação anaeróbica (ausência de oxigênio), e o produto resultante de tal processo é o lactato, o qual é originado de uma molécula de glicose. Tal processo é ineficiente na geração de energia, pois, diferentemente do processo aeróbico (presença de oxigênio), o qual gera 38 moléculas de ATP (Adenosina tri-fosfato), o processo anaeróbico gera apenas duas moléculas de ATP. Isso implica que um determinado órgão ou tecido não deve operar por muito tempo nessa situação.

Inicialmente, a presença do lactato não é um problema, pois tal substância pode ser quebrada caso os estoques de oxigênio forem reabastecidos em um período curto de tempo.

Porém, se este não for o caso, ocorre a formação de ácido lático. Isto, em conseqüência, acaba afetando o pH do sangue, o qual influencia no controle do sistema respiratório e cardíaco. Entretanto, se a taxa cardíaca e respiratória não conseguirem aumentar o fluxo de oxigênio transmitido aos tecidos, acaba-se criando uma situação resultante bastante perigosa. 
Apesar da presença de ácido lático ser um indicador melhor da existência de hipoxia do que a saturação arterial sanguínea, existe um problema que esse encontra no fato de que tal processo ocorrer somente depois de um período longo de baixas taxas de oxigenação nos tecidos.

Com isso, não fica difícil perceber que o dano que está se passando às células está ocorrendo no momento em que se observa o aumento das taxas de lactato. E é exatamente neste ponto que se encontra o verdadeiro valor da medição da saturação do sangue. Se monitorado apropriadamente, ela pode ajudar na tomada de decisões quando o sinal aponta para uma condição patológica perigosa antes que o dano celular ocorra. Entretanto, como explicado anteriormente, a medição de $\mathrm{S}_{\mathrm{p}} \mathrm{O}_{2}$ sozinha não é tão útil quando se comparada com a medição realizada com diversas outras variáveis, como frequiência cardíaca, taxa de hemoglobina, pressão sanguínea, freqüência respiratória, o conforto do paciente e uma variedade de outras variáveis.

\subsection{3 - O papel da oximetria de pulso na anestesiologia, em unidades de tratamento intensivo e unidades de situações pós-operatória}

A oxigenação dos tecidos, e consequentemente a saturação do sangue são de extrema importância dentro do ramo de anestesiologia. Isso acontece pelo simples motivo de o sistema cardiorespiratório ser reconhecido pelo fato de que, sem ele, o paciente não conseguiria suprir as demandas de oxigênio por conta própria.

Por este fato, dentro do ramo de anestesiologia, o controle das condições respiratórias de um paciente e as informações fornecidas pelo monitoramento $\mathrm{S}_{\mathrm{p}} \mathrm{O}_{2}$ se transformaram em uma das melhores variáveis de resposta contra possíveis condições de risco.

Trabalhando como um dispositivo de controle de anestesistas, os oxímetros de pulso literalmente revolucionaram o campo de anestesiologia, principalmente pelo fato de ser um equipamento não invasivo, e que fornece uma resposta rápida e de uma forma bastante simples.

Porém, a transição para o uso de oxímetros de pulso não ocorreu sem controvérsias. 
Antigamente, a freqüência cardíaca e a pressão sanguínea eram as principais variáveis que estavam disponíveis aos anestesistas para a detecção de hipoxia, antes do advento de oxímetros de pulso. Porém, da mesma forma que o lactato, todas essas variáveis forneciam informações de situações de perigo depois da ocorrência de hipoxia.

Assim, mesmo pelo fato de o $\mathrm{S}_{\mathrm{p}} \mathrm{O}_{2}$ não fornecer uma indicação direta da causa da hipoxia, o que de fato é um ponto negativo, tal medição pode ser um aviso bastante antecipado da ocorrência de baixas taxas de oxigenação nos tecidos.

O uso mais freqüente de oxímetros de pulso é realizado por anestesistas durante cirurgias e por aproximadamente uma hora depois do procedimento, nos quartos de recuperação. Anestesistas administram diversos narcóticos para reprimir o sistema nervoso central. Tais narcóticos param com o desejo e habilidade do paciente de respirar o que faz com que o fluxo natural de ar entre em colapso. Desta forma, é necessário se restabelecer a respiração por meio de entubação e respiração artificial. [11]

Anestesistas podem monitorar diversas variáveis da condição do paciente. Porém, muitas delas possuem limitações ou fornecem dados que não são muito confiáveis sobre as reais condições de oxigenação e possíveis situações críticas.

A pressão sanguínea decresce bem depois da diminuição dos níveis de oxigênio. Já o monitoramento dos sinais de eletrocardiograma chega a indicar possíveis problemas após a indicação feita pela pressão sanguínea. Uma análise através de um estetoscópio esofageal indica o momento em que o coração de fato para, mas tal situação é extremamente crítica e ocorre bem depois do declínio dos níveis de oxigenação.

Com o oxímetro de pulso, resolveu-se o problema de atraso através de um monitoramento da saturação de oxigenação arterial de forma continua e não invasiva. Vale relembrar que uma saturação arterial adequada não implica em uma oxigenação adequada. Entretanto, existe um atraso entre a detecção da queda no $\mathrm{S}_{\mathrm{p}} \mathrm{O}_{2}$ e suas causas. Porém, dentre as diversas variáveis que podem ser monitoradas, $\mathrm{S}_{\mathrm{p}} \mathrm{O}_{2}$ é atualmente a melhor indicação da existência de problemas na oxigenação ou que tais problemas estão para acontecer. [11]

O sensor do oxímetro de pulso é geralmente posicionado no dedo do paciente, pelo 
fato de que o nível de oxigenação do sangue irá diminuir primeiramente nas extremidades do que em outros órgãos vitais. Em outros locais do corpo, como orelha, nariz ou testa, os resultados fornecidos pelos sensores não são tão seguros. [11]

Quando uma saturação arterial cair de $98 \%$ para $96 \%$ servirá de indício ao anestesista que algum problema possa estar acontecendo. Se tal saturação arterial cair para 90\%, será uma forte indicação de que algo bastante sério está ocorrendo ao paciente.

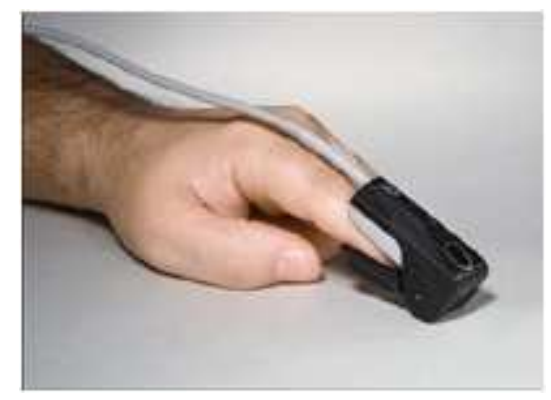

Figura 2.8 - O sensor de oximetria de pulso [25]

Os oxímetros de pulso também provaram ser bastante eficientes em quartos de recuperação de pacientes pós-operatório, pois o controle do sistema respiratório de tais pessoas ainda pode estar comprometido pelos efeitos do uso de anestesia.

O papel do oxímetro de pulso em unidades de tratamento intensivo é bastante similar ao dos anestesistas. Entretanto, neste caso o sistema respiratório pode não estar sob o efeito de narcóticos ou de relaxantes musculares. Porém, o instrumento continua agindo contra perigosas situações de baixa saturação do sangue arterial, que podem ser causadas por uma variedade grande de condições de saúde. [11] 


\section{3 - DESCRIÇÕES E ESPECIFICAÇÕES DO SISTEMA}

\section{1 - CARACTERÍSTICAS GERAIS}

O sistema de oximetria de pulso desenvolvido é composto por diversos módulos, os quais têm características bastante específicas, funções determinadas, porém trabalham em conjunto com o objetivo de captar um sinal que indique com clareza a oxigenação de um determinado indivíduo com a maior fidelidade possível.

O sistema é composto basicamente por cinco módulos principais, que foram implementados com dispositivos digitais e analógicos para o desenvolvimento das funções pré-determinadas. Tais módulos são:

$\checkmark$ Sistema de controle dos LEDs: Este sistema, como o próprio nome diz, é utilizado para controle dos LEDs, os quais serão responsáveis pela emissão de luz nos dois comprimentos de onda utilizados para a medição da taxa de oxigenação de sangue. Os aspectos relacionados a tal sistema são mais bem explicados na seção 5.2.

$\checkmark$ Sistema de recepção: Tal sistema é composto basicamente por amplificadores, filtros e um demodulador para separar os dois diferentes sinais (vermelho e infravermelho). Tal conjunto, como explicitado no nome, é responsável pela recepção do sinal obtido pelo sensor. Os aspectos relacionados a tal sistema são mais bem explicados na seção 5.4.

$\checkmark$ Microcontrolador: Tal parte do projeto é de fundamental importância no conjunto completo. Além de controlar e sincronizar outros sistemas, o microcontrolador também é responsável pela amostragem e digitalização do sinal, pelo controle dos ganhos que serão dados por filtros no sistema de recepção, controle da corrente enviada aos LEDs, além de ser o meio de comunicação com o meio externo ao sistema de oximetria. Os aspectos relacionados ao microcontrolador são mais bem explicados no Capítulo 4 (O Microcontrolador MSP 430).

$\checkmark$ Sistema de geração de ondas de controle: Tal sistema é composto basicamente por portas lógicas, as quais são responsáveis pela geração de ondas que irão sinalizar o tráfico de informações, bem como acionar ou desabilitar o funcionamento de 
diversos componentes. Os aspectos relacionados a tal sistema são mais bem explicados na seção 5.1 .

$\checkmark$ Aplicativos de monitoramento: Tal módulo foi desenvolvido com o intuito de facilitar a visualização do sinal de oximetria de pulso, bem como os resultados do processamento realizado pelo microcontrolador. Os aspectos relacionados a aos aplicativos de monitoramento são melhor explicados na seção 5.5 .

\section{2 - ESQUEMÁTICO DO OXÍMETRO DE PULSO}

Uma forma bastante simplificada de análise do conjunto de sistemas que formam o oxímetro de pulso pode ser feita pela compreensão de como cada módulo do projeto trabalha e como este módulo atua nas outras diferentes partes. Na Figura 3.1 (Diagrama de blocos do Projeto), podemos compreender um pouco como se realiza essa dinâmica e toda a atuação dos diferentes sistemas.

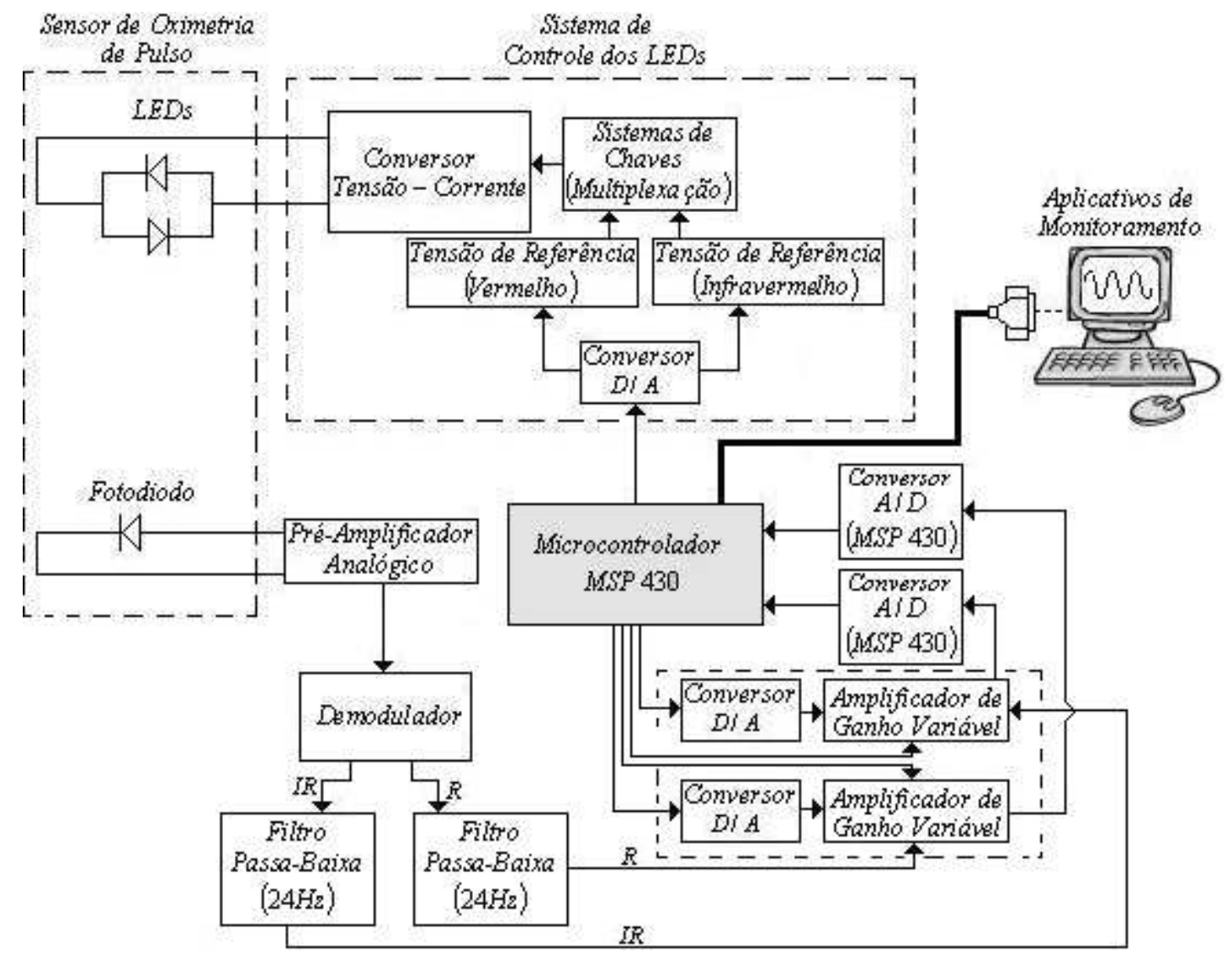

Figura 3. 1 - Diagrama de blocos do Sistema 
Primeiramente, não fica difícil perceber o papel centralizador exercido pelo microcontrolador MSP 430. Ele atua não somente no controle de diversos dispositivos, mas também como meio de comunicação com os aplicativos externos desenvolvidos para o monitoramento da oxigenação sanguínea.

Inicialmente, o MSP 430 atua sobre um conversor D/A que faz parte do sistema de controle dos LEDs. Tal conversor recebe sinais na forma digital do microcontrolador, e gera tensões de referência analógicas para os LEDs vermelho e infravermelho, como ilustrado no diagrama de blocos da Figura 3.1. Como os dois LEDs não devem estar ligados ao mesmo tempo, é necessário que tais tensões sejam enviadas a um sistema de chaves, as quais são responsáveis em fazer um chaveamento seletivo, ajustando de forma dinâmica e automática a tensão que será enviada a um conversor de tensão-corrente. Tal conversor, por final, envia uma corrente específica a cada um dos LEDs, que são ligados ou desativados de forma síncrona e com uma freqüência pré-estabelecida.

Os LEDs, como mostrado no diagrama da Figura 3.1, juntamente com o fotodiodo, fazem parte do sensor de oximetria de pulso, o qual é aplicado sobre o dedo indicador do paciente. Como explicado anteriormente na seção 2.4 (Princípios do oxímetro de pulso), com a emissão de luz nos dois comprimentos de onda distintos (vermelho e infravermelho), é possível captar um sinal pelo fotodiodo que demonstra os efeitos da absorção pelas diversas camadas do dedo. Neste sinal, podemos observar duas componentes: uma pulsante, que é causada pela absorção do sangue arterial, e outra não pulsante, causada pela absorção dos tecidos, sangue venoso e ossos.

Tal sinal é enviado a um módulo de pré-amplificação, que faz parte do sistema de recepção do oxímetro de pulso. A partir de tal etapa, seguem-se alguns módulos que são responsáveis pela filtragem e amplificação do sinal captado, pela separação dos sinais individuais gerados pelos LEDs vermelho e infravermelho e, por fim, um último módulo responsável pelo ajuste do sinal aos valores limites do conversor analógico-digital (A/D) do microcontrolador MSP 430, o qual realiza a amostragem e digitalização do resultado final entregue pelo sistema de recepção.

Terminado isso, cabe ao microcontrolador fazer uma análise dos dados recebidos, com o intuito de tomar decisões que irão ajustar os sistemas do oxímetro de pulso a condições que permitam uma captação melhor dos dados, sem perder resolução, ou saturar 
o sinal nos canais do conversor A/D.

Sendo assim, o microcontrolador irá atuar primeiramente no conversor D/A pertencente ao sistema de controle dos LEDs, alterando a tensão de referência, o que causará uma maior ou menor iluminação no dedo do paciente.

Uma segunda forma de atuação do microcontrolador no sistema é fazendo modificações no conjunto composto pelo conversor D/A e amplificador de ganho variável (ambos pertencentes ao sistema de recepção). Dessa forma, o MSP 430 pode dar um ganho diferenciado ao sinal, ou retirar um determinado valor de DC (através do conversor D/A), para que a onda, ao ser amostrada e digitalizada, tenha uma resolução melhor no canal do conversor A/D do microcontrolador.

Os sinais recebidos pelo microcontrolador são então enviados ao sistema de aplicativos de monitoramento, junto com as informações de quais modificações e respostas estavam sendo realizadas pelo microcontrolador no momento em que o determinado sinal foi captado.

Outro esquemático que deve ser abordado é o que especifica as funções desempenhadas pelo sistema de geração de sinais de controle. Como o próprio nome adianta, tal módulo será responsável pela geração de sinais que indicarão em que estágio de processamento o oxímetro de pulso se encontra. Tal esquemático simplificado pode ser visualizado na Figura 3.2 (Esquemático do Sistema de Geração de Sinais de Controle).

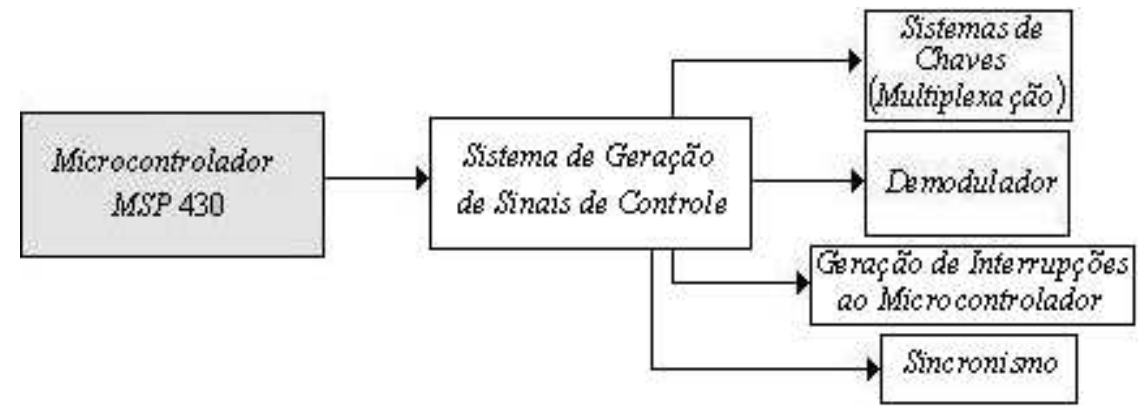

Figura 3.2 - Esquemático do Sistema de Geração de Sinais de Controle

É exatamente deste sistema que partirão as ondas que irão ou não ativar o funcionamento de diversos outros módulos do oxímetro de pulso, bem como sinalizar o fluxo de informações por meio de interrupções ao MSP 430 ou criar ondas de sincronismo que freqüentemente irão ajustar os tempos de recepção e transmissão de dados. 
Não é difícil perceber que ambos esquemáticos funcionam em conjunto. Um bom monitoramento da oxigenação sanguínea irá depender do bom andamento dos diversos módulos que foram desenvolvidos.

Por isso, o estudo de cada parte será feito em separado, para que seja possível demonstrar a importância que cada um dos subsistemas e como a função designada para cada módulo foi implementada e realizada. 


\section{4 - O MICROCONTROLADOR MSP 430}

\section{1 - A UTILIZAÇÃO DO MICROCONTROLADOR MSP 430}

O uso de microcontroladores no desenvolvimento de aplicações em eletrônica foi se tornando cada vez mais utilizado pelas diversas vantagens que são incorporadas neste tipo de circuito integrado. Várias foram as famílias de microcontroladores que foram implementadas com o passar dos anos. [38]

Variações na capacidade de processamento e armazenamento, número de portas de entrada e saída de dados ou variações nos tipos de dispositivos de comunicação externa são algumas das principais diferenças entre os diversos microcontroladores que são disponíveis atualmente no mercado. Porém, de forma geral, tais diferenças não eliminam uma das características básicas que impulsionou a utilização de microcontroladores, que é a capacidade de se realizar um processamento de forma simples, eficiente e barata. [38]

O microcontrolador MSP 430, como tantos outros, possui vários módulos que podem ser utilizados para as mais diversas aplicações. Tais módulos são controlados por um conjunto de registradores, os quais servem como orientação à unidade central de processamento (CPU) de quais os comandos se devem realizar ou quais módulos devem ou não estar habilitados.

\subsection{1 - Características básicas do microcontrolador MSP 430}

O Microcontrolador, produzido pela Texas Instruments, foi escolhido devido às diversas vantagens associadas ao produto. Primeiramente, o fato de possuir um módulo que faz a conversão do sinal analógico para digital (ADC12) foi essencial para a viabilidade do projeto. Outro fator de extrema importância foi a existência de módulos que permitem a comunicação com dispositivos e componentes externos (USART).

Como ferramenta de desenvolvimento, o MSP 430 possui uma interface JTAG (Joint Test Action Group), o qual permite um monitoramento de todas as variáveis e registradores de forma instantânea e contínua, de acordo com o andamento do processamento. Tal fator facilita a elaboração de programas e deteç̧ão de possíveis erros, que possam estar afetando os objetivos reais de processamento. 
Vale ressaltar também que o microcontrolador foi adquirido através de amostra grátis do fabricante, o que acaba sendo um facilitador nas pesquisas em diversas aplicações e uma forma de se gerar um número maior de usuários. Tal incentivo, de certa forma, vem ocasionando um aumento cada vez maior de documentos sobre soluções de problemas e aplicações gerais dos diversos módulos do microcontrolador.

O MSP 430 é formado por uma moderna unidade central de processamento, a qual trabalha em tecnologia RISC de 16 bits, além de possuir um sistema de relógio flexível. Em sua memória, estão mapeados periféricos analógicos e digitais, os quais oferecem soluções para os mais diversos problemas e aplicações. As principais características do microcontrolador são: [8]

$\checkmark$ Arquitetura de baixo consumo de energia, que prolonga a vida útil de baterias; [8]

$\checkmark$ Alta performance dos módulos analógicos, ideal para medições com precisão;

- Conversor Analógico-Digital (12 bits ou 10 bits);

- Sensor de temperatura;

$\checkmark$ Unidade Central de Processamento de 16 bits

- Grande conjunto de registradores;

- Projeto compacto e centralizado, o que reduz o consumo de energia e o custo;

- Otimização, que permite uma programação moderna de alto-nível;

- Alta capacidade do vetor de interrupções;

$\checkmark$ Memória Flash programável, a qual permite mudanças no código de forma flexível, além de atualizações e monitoramento de dados.

\section{2 - ENTRADAS E SAÍDAS (DISPOSITIVOS I/O)}

Uma das principais vantagens do uso do MSP 430 é a presença de seis portas de entrada e saída de dados (portas I/O). Cada uma das seis portas (de P1 a P6) possuí oito pinos que são utilizados para a comunicação de dados. Tais pinos podem ser configurados individualmente para trabalharem na direção de entrada ou saída. 
As portas P1 e P2 possuem características especiais, pois têm a capacidade de trabalhar com interrupções, sendo que cada um dos pinos de tais portas pode ser ativado e configurado para gerar uma interrupção em uma borda de subida ou de descida no respectivo pino.

\section{3 - REGISTRADORES (OPERAÇÕES DIGITAIS DE I/O)}

Os dispositivos de entrada e saída do MSP 430 são configurados por meio de software. Tais dispositivos funcionam através da observação do estado de alguns registradores, que indicam a função e o modo de operação de cada um dos pinos.

Cada porta possui diversos registradores que controlam as diversas funções possíveis que ela pode exercer. Por isso, uma breve explicação será dada para ilustrar as peculiaridades de alguns dentre os registradores principais:

\subsection{1 - Registrador de direção de dados PxDIR}

No MSP 430 existem seis registradores que são responsáveis em coordenar o tráfego de entrada e saída de dados. Tais registradores (P1DIR, P2DIR, P3DIR, P4DIR, P5DIR, P6DIR) possuem oito bits, que correspondem a cada um dos oito pinos de cada uma das seis portas do microcontrolador (Portas P1, P2, P3, P4 P5 e P6).

Cada bit de cada um dos registradores PxDIR seleciona a direção de tráfego de dados (entrada ou saída) do correspondente pino da porta, independente da função que foi estabelecida para o respectivo pino. A Tabela 4.1 indica como a modificação de cada bit do registrador afeta o funcionamento de cada pino das portas de entrada e saída de dados.

Tabela 4.1 - Operação do registrador PxDIR

\begin{tabular}{|c|l|}
\hline Nível Lógico & \multicolumn{1}{c|}{ Direção de Dados } \\
\hline Bit $=0$ & $\begin{array}{l}\text { O respectivo pino é configurado } \\
\text { como entrada de dados }\end{array}$ \\
\hline Bit $=1$ & $\begin{array}{l}\text { O respectivo pino é configurado } \\
\text { como saída de dados }\end{array}$ \\
\hline
\end{tabular}

A Figura 4.1 ilustra um exemplo de ação efetuada ao se modificar o valor do bit 4 do registrador P5DIR. Com isso, o pino P5.4, pertencente a porta P5 passará a funcionar no sentido de saída de dados. 


\section{Registrador P5DIR}

\begin{tabular}{|c|c|c|c|c|c|c|c|} 
bit 7 & bit 6 & bit 5 & bit 4 & bit 3 & bit 2 & bit 1 & bit 0 \\
- & - & - & 1 & - & - & - & - \\
\hline
\end{tabular}

Caso opino P5.4 tenha sido selecionado com o rível lógico I

o pino P5. 4 será habilitado

como pino de saída de dados

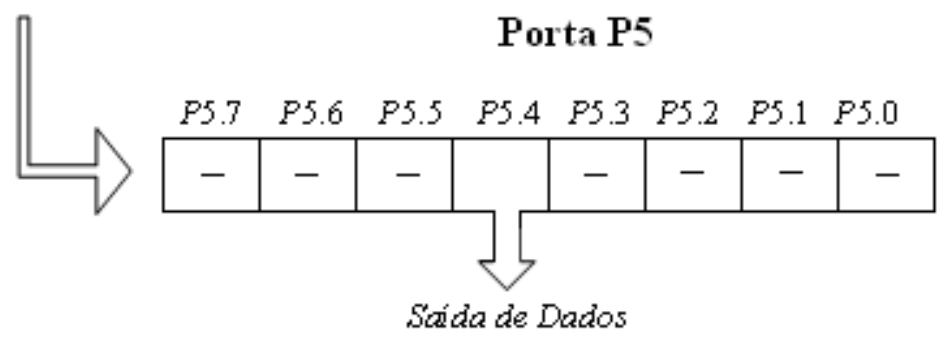

Figura 4.1 - Exemplo de operação do registrador PxDIR.

\subsection{2 - Registrador de entrada PxIN}

Através do uso deste registrador, é possível fazer a leitura de um sinal de entrada no pino correspondente, quando o pino é configurado como um dispositivo I/O. Da mesma forma que no caso abordado na seção 4.3.1 sobre o registrador PxDIR, no caso de PxIN também existem seis diferentes registradores que correspondem às seis diferentes portas de entrada e saída de dados do microcontrolador. Sendo assim, a Tabela 4.2 (Operação do registrador PxIN) demonstra como o valor de PxIN é modificado de acordo com o valor na entrada do MSP 430.

Tabela 4.2 - Operação do registrador PxIN

\begin{tabular}{|c|c|}
\hline Nível Lógico & Estado da Entrada \\
\hline Bit $=0$ & A entrada está em nível lógico baixo \\
\hline Bit $=1$ & A entrada está em nível lógico alto \\
\hline
\end{tabular}

Na Figura 4.2 é possível observar a ilustração do registrador P4IN sendo atualizado de acordo com o valor na entrada da porta P4.

\section{Registr ador P4IN}

\begin{tabular}{|c|c|c|c|c|c|c|c|} 
bit 7 & bit 6 & bit 5 & bit 4 & bit 3 & bit 2 & bit 1 & bit 0 \\
\hline- & - & - & - & 1 & - & - & - \\
\hline
\end{tabular}

Os bits de $P 4$ N são atualizados de acordo com as entradas na Porta P4

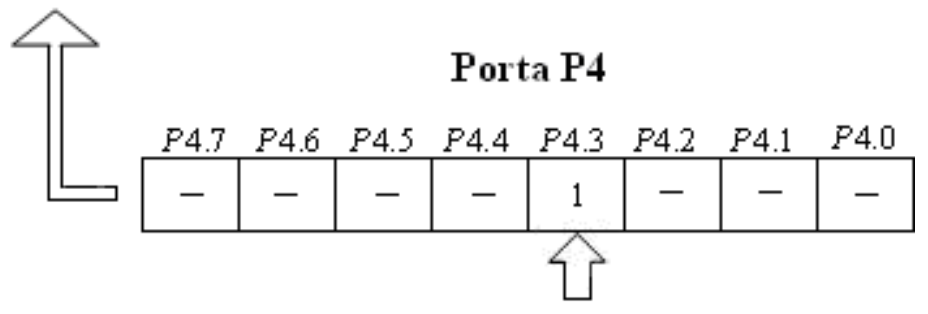

Entrada de dados

Figura 4.2 - Exemplo de operação do registrador PxIN 


\subsection{3 - Registrador de saída PxOUT}

Tais registradores são utilizados para a comunicação de saída de dados por parte do MSP 430. Caso um determinado pino do microcontrolador seja configurado como pino de saída, o valor lógico produzido em tal pino será atualizado de acordo com atualizações no bit correspondente em PxOUT. A Tabela 4.3 (Operação do registrador PxOUT) demonstra como o valor de PxOUT modifica o pino correspondente da porta em questão.

Tabela 4.3 - Operação do registrador PxOUT

\begin{tabular}{|c|c|}
\hline Nível Lógico & Estado da Saída \\
\hline Bit $=0$ & Saída em nível lógico 0 \\
\hline Bit $=\mathbf{1}$ & Saída em nível lógico 1 \\
\hline
\end{tabular}

Na Figura 4.3 é possível observar a ilustração do registrador P4OUT atualizando o pino correspondente da porta $\mathrm{P} 4$, de acordo com as modificações realizadas.

\section{Registrador P4OUT}

\begin{tabular}{|c|c|c|c|c|c|c|c|} 
bit 7 & bit 6 & bit 5 & bit 4 & bit 3 & bit 2 & bit 1 & bit 0 \\
\hline- & - & - & - & 1 & - & - & - \\
\hline
\end{tabular}

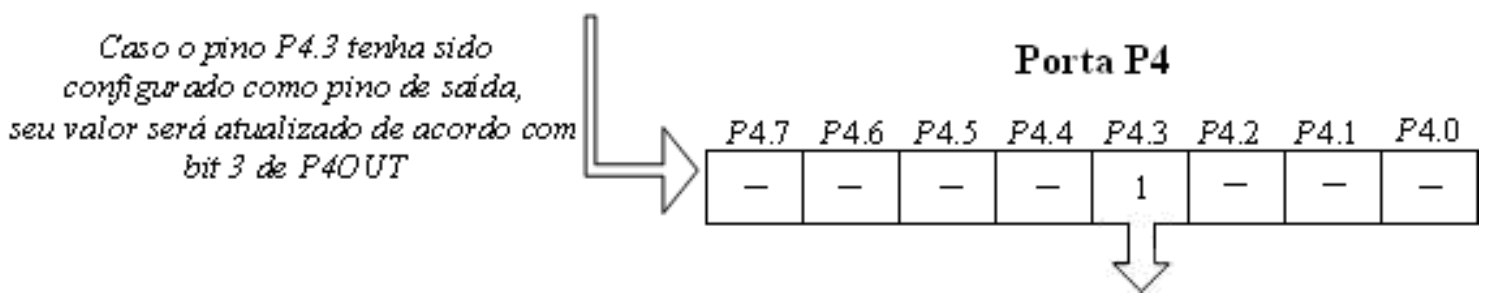

Figura 4.3 - Exemplo de operação do registrador PxOUT

\subsection{4 - Registrador de habilitação de interrupção P1IE e P2IE}

Cada um dos bits dos registradores P1IE e P2IE é capaz de ativar ou desabilitar a capacidade do pino associado ao bit de gerar ou não interrupções. Lembrando que somente as portas $\mathrm{P} 1$ e P2 possuem a peculiaridade de poder gerar interrupções. A Tabela 4.4 (Operação do registrador PxIE) demonstra como o valor de PxIE permite ou não que um determinado pino gere interrupções.

Tabela 4.4 - Operação do registrador PxIE

\begin{tabular}{|c|c|}
\hline Nível Lógico & Estado da Interrupção \\
\hline Bit $=0$ & Sem permissão para gerar interrupção \\
\hline Bit $=\mathbf{1}$ & Permissão para gerar interrupção \\
\hline
\end{tabular}

Na Figura 4.4 é possível visualizar a demonstração de como o registrador P2IE atua em pinos separados, habilitando e desabilitando a permissão de se gerar interrupções. 


\section{Registrador P2IE}

\begin{tabular}{|c|c|c|c|c|c|c|c|}
\hline bit 7 & bit 6 & bit 5 & bit 4 & bit 3 & bit 2 & bit 1 & bit 0 \\
\hline- & 1 & - & - & - & - & 0 & - \\
\hline
\end{tabular}

\section{Porta P2}

De acordo com os valores de P2IE, se fornece permissóes para a porta $P 2$ de gerar ou não interrup̧ões.

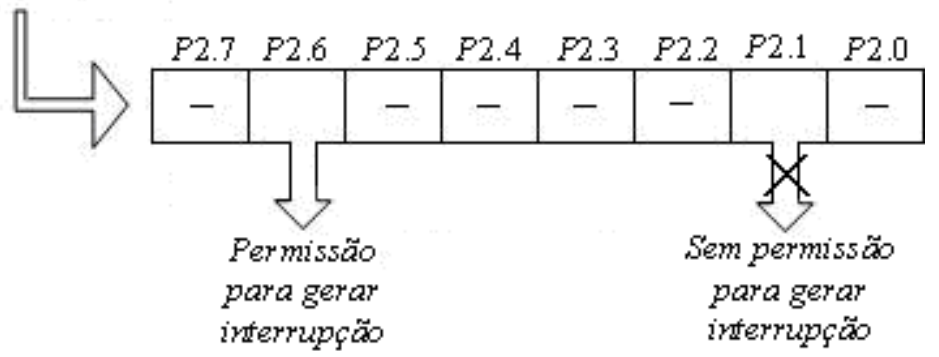

Figura 4.4 - Exemplo de operação do registrador PxOUT

\subsection{5 - Registrador de seleção de função PxSEL}

Os pinos das portas de entrada e saída de dados são frequentemente multiplexadas para trabalharem com outros módulos periféricos. Cada bit dos registradores PxSEL é usado para selecionar a função que cada um dos pinos do respectivo registrador irá exercer.

Tabela 4.5 - Operação do registrador PxSEL

\begin{tabular}{|c|c|}
\hline Nível Lógico & Função do Pino \\
\hline Bit $=0$ & $\begin{array}{c}\text { Função de Entrada e Saída } \\
\text { (I/O) é selecionada }\end{array}$ \\
\hline Bit $=1$ & $\begin{array}{c}\text { Função para trabalhar como } \\
\text { módulo periférico é } \\
\text { selecionada }\end{array}$ \\
\hline
\end{tabular}

Tanto a Tabela 4.5 (Operação do registrador PxSEL), quanto a Figura 4.5 (Exemplo de operação do registrador PxSEL) ilustram como a modificação dos bits no registrador irão afetar a utilização do respectivo pino na porta.

\section{Registrador P5SEL}

\begin{tabular}{|c|c|c|c|c|c|c|c|} 
bit 7 & bit 6 & bit 5 & bit 4 & bit 3 & bit 2 & bit 1 & bit 0 \\
\hline- & - & - & 0 & - & - & - & - \\
\hline
\end{tabular}

Caso o pino bit 4 tenha sido selecionado com o nível lógico 0 o pino P5. 4 irá funcionar como dispositivo de entrada e saída de dados

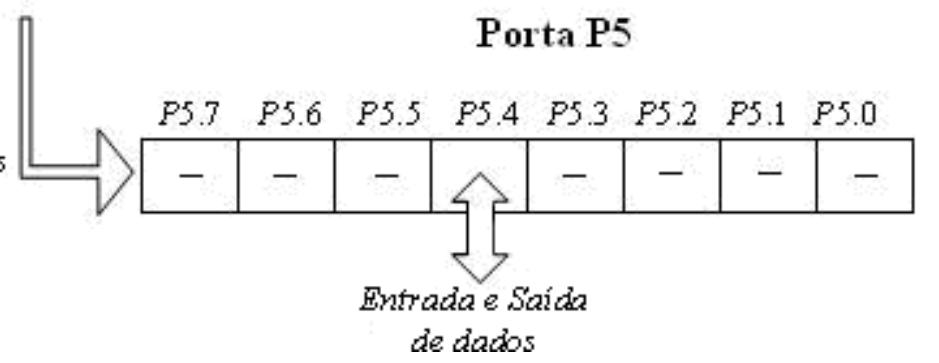

Figura 4.5 - Exemplo de operação do registrador PxSEL 
Vale observar que ao se selecionar o nível lógico PxSELx como 1, o determinado pino não tem a sua direção de entrada ou saída ajustada automaticamente. Em tal caso, os bits de outro registrador, PxDIRx, devem ser configurados de acordo com a direção em qual os dados irão trafegar.

Outra importante observação sobre o registrador PxSEL é que este pode vir a desabilitar a utilização de interrupções por parte das portas P1 e P2. Isso ocorre quando determinados bits de P1SEL ou P2SEL estiverem selecionado com o nível lógico 1. Portanto, sinais de dados nestes pinos não serão capazes de gerar interrupções em P1 ou em P2, independente do estado do estado do bit correspondente em P1IE e em P2IE.

\section{4 - CONVERSOR ANALÓGICO DIGITAL DE 12 BITS}

O MSP 430 possui um módulo conversor analógico digital (ADC12) que é capaz de fazer rápidas conversões de um sinal analógico para um sinal digital de 12 bits. Tal módulo é composto por um gerador de tensão de referência, bem como de 16 registradores de conversão e controle. Tais registradores permitem que o MSP 430 realize 16 conversões analógico-digital e armazene tais amostras, sem que seja necessária qualquer intervenção da CPU. As principais características do ADC12 são: [5]

$\checkmark$ Taxa de conversão superior a 200 mil amostras por segundo;

$\checkmark$ Velocidade Programável (5,2 ou $1 \mu s$ ), o que permite uma melhor relação entre consumo e velocidade de conversão;

$\checkmark$ Processo de conversão iniciado por software, pelo Timer A (seção 4.5) ou Timer B;

$\checkmark$ Possibilidade de uso de referência tanto interna quanto externa, selecionado por software;

$\checkmark$ Quatro diferentes modos de conversão: um único canal, único canal repetido, seqüência de canais e seqüência repetida de canais;

$\checkmark$ Sample-and-hold com tempo de amostragem programável controlado por software ou por temporizador;

$\checkmark$ Gerador de tensão de referência interna (1,5 V ou 2,5 V) selecionado por software;

$\checkmark$ Oito canais de conversão que podem ser configurados individualmente;

$\checkmark$ Registrador vetor de interrupção que indica qual dos canais gerou interrupção no conversor. 
Como pode ser percebido, a maioria das características do modulo ADC12 é configurado através da utilização de software. Tal processo de conversão possui um limite de tensão superior e outro limite de tensão inferior $\left(V_{R_{+}}\right.$e $\left.V_{R_{-}}\right)$os quais delimitam a faixa de operação do ADC12. Tais limites também são programados por software, sendo que a saída digital será máxima (0FFFh) quando o sinal de entrada for igual ou maior ao valor de $V_{R+}$, e será mínima $(0000 \mathrm{~h})$ quando o mesmo sinal de entrada for igual ou menor do que o valor $V_{R^{-}} \cdot[5]$

O canal de entrada e os limites de referência $\left(V_{R_{+}}\right.$e $\left.V_{R_{-}}\right)$são definidos na memória do controle de conversão (conversion-control memory). O resultado da conversão $\left(N_{A D C}\right)$ pode ser expresso pela seguinte fórmula:

$$
N_{A D C}=4095 \cdot \frac{(\text { Tensão de Entrada })-V_{R-}}{V_{R+}-V_{R-}}
$$

O núcleo do ADC12 pode ser configurado por dois registradores, ADC12CTL0 e ADC12CTL1. A conversão é habilitada com o bit ADC12ON, que faz parte do registrador ADC12CTL0. Outro bit essencial de tal registrador é o ENC, o qual deve estar habilitado ( $E N C=1$ ) para que qualquer conversão aconteça. Com pouquíssimas exceções, os bits dos registradores de controle ADC12CTL0 e ADC12CTL1 podem ser modificados no caso de ENC estar desabilitado $(E N C=0)$. [8]

\subsection{1 - Seleção do Relógio do Conversor}

O sinal ADC12CLK é utilizado como o relógio de conversão, para gerar o período de amostragem quando o modo de amostragem for ativado. Várias das configurações relacionadas ao relógio do conversor são feitas pelo programador através de modificações nos dois principais registradores do conversor analógico digital, ADC12CTL0 e ADC12CTL1, os quais serão mais bem abordados na seção 4.4.2.

Uma forma simples de visualizar o funcionamento do relógio do conversor ADC12 pode ser feita com o auxílio da Figura 4.6, a qual possui um funcionamento relativamente simples. 
$\checkmark$ Os bits ADC12SSELx (pertencentes à ADC12CTL1) selecionam a fonte do sinal de relógio (ADC12CLK), a qual pode ser proveniente de 4 possíveis escolhas: ACLK, MCLK, SMCLK ou um oscilador interno ADC12OSC;

$\checkmark$ Tal sinal pode ser dividido de 1 até 8, através de seleção dos bits ADC12DIVx;

$\checkmark$ Vale ressaltar que o relógio escolhido para ADC12CLK deve continuar ativo até o final da conversão. Caso o relógio seja removido durante o processo, a operação não será completada e qualquer resultado será inválido.

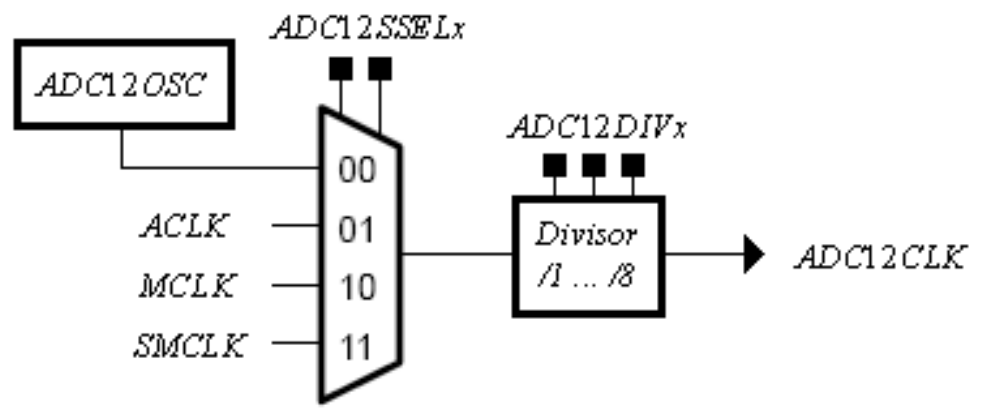

Figura 4.6 - Seleção do relógio do conversor analógico digital

\subsubsection{Registradores de Controle do Conversor Analógico Digital}

Como abordado anteriormente, o processo de conversão analógico digital é controlado por diversos registradores, os quais servem como referência ao microcontrolador na escolha de quais operações se realizar, de acordo com o modo de operação escolhido.

Os dois principais registradores de controle são o ADC12CTL0 e o ADC12CTL1. A configuração e localização dos respectivos bits de ADC12CTL0 podem ser vistas na Figura 4.7, ilustrada abaixo.

\begin{tabular}{|c|c|c|c|c|c|c|c|}
\hline \multicolumn{8}{|c|}{ Registrador ADC12CTLO } \\
\hline 15 & 14 & 13 & 12 & 11 & 10 & 9 & 8 \\
\hline \multicolumn{4}{|c|}{$S T H 1 x$} & \multicolumn{4}{|c|}{$S H T 0 x$} \\
\hline 7 & 6 & 5 & 4 & 3 & 2 & 1 & 0 \\
\hline$M S C$ & $\begin{array}{l}R E F \\
2 \_5 V\end{array}$ & $R E F O N$ & ${ }_{O N}^{A D C 12}$ & $\begin{array}{c}A D C 12 \\
O V I E\end{array}$ & \begin{tabular}{|l|} 
ADC12 \\
TOVIE
\end{tabular} & $E N C$ & $\underset{S C}{A D C 12}$ \\
\hline
\end{tabular}

Figura 4.7 - O registrador ADC12CTL0

Uma explicação resumida da função exercida pelos principais bits do registrador ADC12CTL0 pode ser visualizada a seguir: 
$\checkmark$ SHTx (Sample-and-Hold Time): Tais bits definem o número de ciclos do sinal de relógio do conversor (ADC12CLK) que serão utilizados para realizar a amostragem.

$\checkmark$ MSC: Habilitação de múltipla amostragem e conversão;

$\checkmark$ REFON: Habilitação da geração de tensão de referência;

$\checkmark$ REF2_5: Gerador de tensão de referência (REFON também deve estar habilitado);

$\checkmark$ ADC12ON: Habilitação do conversor analógico digital;

$\checkmark$ ENC: Habilita o processo de conversão;

$\checkmark$ ADC12SC (Start Conversion): Inicia o processo de conversão;

A configuração e localização dos respectivos bits do registrador ADC12CTL1 pode ser acompanhada na Figura 4.8 (O registrado ADC12CTL1).

\section{Registrador ADC12CTL1}

\begin{tabular}{|c|c|c|c|c|c|c|c|}
\hline 15 & 14 & 13 & 12 & 11 & 10 & 9 & 8 \\
\hline \multicolumn{4}{|c|}{ CSTARTADDx } & \multicolumn{2}{|c|}{ SHSX } & $S H P$ & ISSH \\
\hline 7 & 6 & 5 & 4 & 3 & 2 & 1 & 0 \\
\hline \multicolumn{3}{|c|}{$A D C 12 D I V x$} & \multicolumn{2}{|c|}{$A D C 12 \operatorname{SSELX}$} & \multicolumn{2}{|c|}{ CONSEQx } & $\begin{array}{c}A D C 12 \\
B U S Y\end{array}$ \\
\hline
\end{tabular}

Figura 4.8 - O registrador ADC12CTL1

Uma explicação resumida da função exercida pelos principais bits do registrador ADC12CTL1 pode ser visualizada a seguir:

$\checkmark$ CSTARTADDx (Conversion Start Adress): Seleciona qual o registrador de memória do ADC12 será utilizado no armazenamento dos dados da conversão;

$\checkmark$ ADC12DIVx (Clock Divider): Como explicado na seção 4.4.1, tais bits selecionam o divisor do relógio usado na conversão;

$\checkmark$ ADC12SSELx (ADC12 Clock Source Select): Seleciona a fonte do relógio usada pelo sinal ADC12CLK (explicado na seção 4.4.1);

$\checkmark$ CONSEQx: Seleciona o modo e o número de conversões;

$\checkmark$ ADC12BUSY: Indica que um processo de amostragem ou uma operação de conversão está sendo realizada.

Outro conjunto de registradores de extrema importância é o ADC12MEMx, os quais são usados para o armazenamento de dados resultantes do processo de conversão. Como o conversor faz uma codificação em 12 bits, somente os bits de 0 a 11 são utilizados no armazenamento. $\mathrm{O}$ restante permanecerá sempre em zero. Tal configuração pode ser 
melhor observada na Figura 4.9 (O registrador ADC12MEMx), ilustrada abaixo:

Registrador ADC12MEMx

\begin{tabular}{|c|c|c|c|cccc|}
\hline 15 & 14 & 13 & 12 & 11 & 10 & 9 & 8 \\
\hline 0 & 0 & 0 & 0 & Resultados da Conversão \\
\hline 7 & 6 & 5 & 4 & 3 & 2 & 1 & 0 \\
\hline \multicolumn{7}{|c|}{ Resultados da Conversão } \\
\hline
\end{tabular}

Figura 4.9 - O registrador ADC12MEMx.

\subsection{3 - Gerador de Tensão de Referência}

Como explicado anteriormente nas características básicas do conversor analógico digital (seção 4.1.1), o módulo ADC12 possui um gerador de tensão de referência que é construído com dois níveis de tensão selecionáveis: $1,5 \mathrm{~V}$ e 2,5 V. Cada uma dessas tensões pode ser usada internamente ou externamente (no pino $V_{R E F+}$ ). Configurando o bit REFON (presente no registrador ADC12CTL0) com nível lógico 1, habilita-se a referência interna. Quando o bit REF2_5V for igual a 1, a referência interna será 2,5V. Caso contrário, se o mesmo bit for igual a 0 , a referência interna será $1,5 \mathrm{~V}$. O fluxograma de tal processo poder visto na Figura 4.10, ilustrada abaixo:

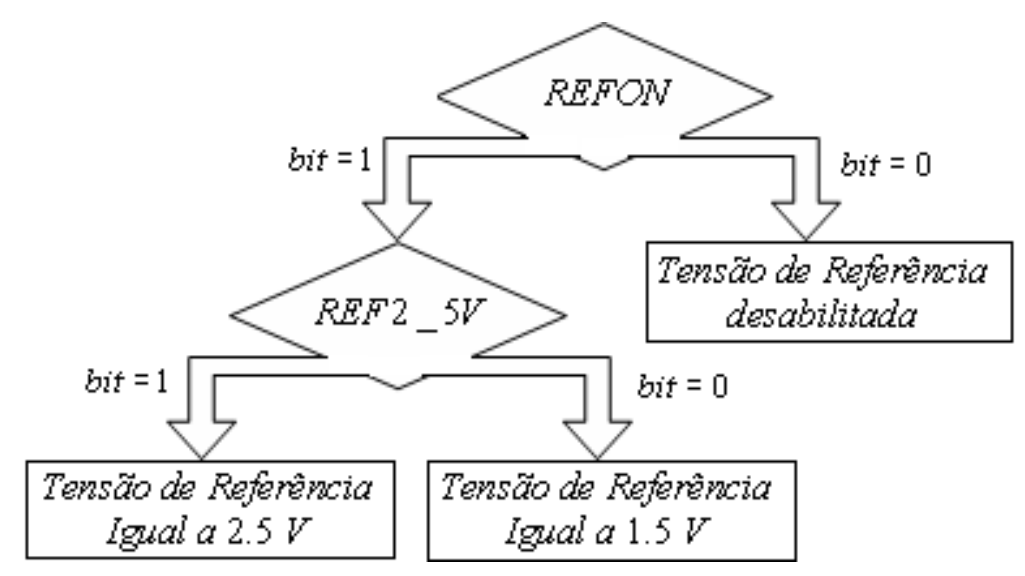

Figura 4.10 - Fluxograma do processo de geração de tensão de referência

\section{5 - O CONTADOR/TEMPORIZADOR TIMER A}

O Timer A é um contador/temporizador de 16 bits com diversas características que podem ser trabalhadas em conjunto com outros módulos do MSP 430. Suas principais funções incluem:

$\checkmark$ Um contador/temporizador assíncrono de 16 bits com quatro modos de operação;

$\checkmark$ Contador progressivo/regressivo com módulo programável e capacidade de 
interrupção;

$\checkmark$ Capacidade de trabalhar a partir de diversas fontes de clock interno e externo, os quais são selecionáveis;

$\checkmark$ Três registradores de CCP - Captura/Comparação/PWM, capazes de trabalhar no modo de captura (medição do período de sinais), comparação (geração de pulsos que possuem largura programável) e PWM (geração de sinais de freqüência e ciclo ativo programáveis);

$\checkmark$ Registrador Vetor de Interrupções para decodificação rápida de todas as interrupções originárias pelo contador Timer A;

$\checkmark$ Possibilidade de iniciar uma conversão A/D.

O módulo do Timer A é configurado através de software. O princípio de operação é bastante simples. O coração do funcionamento do sistema é o registrador contador de 16 bits TAR, o qual incrementa ou decremeta (dependendo do modo de operação) de acordo com a borda de subida ou descida de um sinal de relógio, que pode ser selecionado entre quatro diferentes fontes (TACLK (clock externo), ACLK, SMCLK ou INCLK).

O registrador TAR pode ser lido através de software, o que facilita o monitoramento da contagem. Outra característica importante é o fato de que o mesmo registrador TAR ser capaz de gerar interrupção, quando este excede o seu limite de contagem. A direção de contagem e o modo de operação do TAR é definida pela seleção dos bits MCx (pertencentes ao registrador TACTL), conforme Tabela 4.6 (Modo de operação do TAR).

Tabela 4.6 - Modo de operação do TAR

\begin{tabular}{|c|c|l|}
\hline MCX & Modo & \multicolumn{3}{|c|}{ Descrição } \\
\hline 00 & Contagem Parada & $\begin{array}{l}\text { Contagem do TAR permanece parada, } \\
\text { mantendo seu último valor. Nenhum } \\
\text { incremento ou decremento ocorre. }\end{array}$ \\
\hline 01 & Contagem de Módulo & $\begin{array}{l}\text { O contador TAR conta repetidamente de zero } \\
\text { até atingir o valor programado no registrador } \\
\text { TACCR0 (módulo de contagem) }\end{array}$ \\
\hline 10 & Contagem Contínua & $\begin{array}{l}\text { O contador TAR conta repetidamente de zero } \\
\text { (00000h) ao valor máximo (0xFFFFh) }\end{array}$ \\
\hline 11 & $\begin{array}{l}\text { Contagem } \\
\text { Progressiva/ } \\
\text { Regressiva }\end{array}$ & $\begin{array}{l}\text { O contador TAR conta repetidamente de zero } \\
\text { ao valor programado no registrador } \\
\text { TACCR0 e depois passa a contar } \\
\text { regressivamente até zero. }\end{array}$ \\
\hline
\end{tabular}




\section{6 - INTERFACE SERIAL UNIVERSAL}

O MSP 430 possui dois módulos independentes de interface serial síncrona/assíncrona universal (USART0 e USART1) os quais permitem a comunicação entre o microcontrolador e outros equipamentos e dispositivos, como computadores, dispositivos de comunicação e outros microcontroladores.

O módulo de comunicação serial incluído no MSP 430 suporta tamanhos de 7 ou 8 bits, geração e detecção de paridade e seleção do número de bits de parada (1 ou 2). Também estão presentes circuitos que funcionam na detecção de erros de comunicação e para o suporte a endereçamento em sistemas que são multiprocessados.

A USART também é formada por dois registradores de deslocamento, separados e independentes para transmissão e recepção dos dados. Além de todas essas funcionalidades, a USART ainda possui um circuito gerador de clock (baude-rate) o qual possibilita o trabalho com diversas velocidades de comunicação, a partir de uma das fontes de relógio disponíveis.

\subsection{1 - Modo Assíncrono}

Um dos possíveis modos de comunicação da interface serial é o modo assíncrono. No presente projeto, ele foi usado para o envio de dados do microcontrolador para o computador onde se encontram os aplicativos de monitoramento.

O formato de transmissão de um determinado caractere por modo assíncrono iniciase por um bit de partida (Start) o qual é seguido pelo bit menos significativo do caractere $(L S B)$ e em seqüência os demais bits em ordem crescente. Como explicado anteriormente, a USART pode trabalhar tanto com 7 bits quanto com 8 bits, o que é definido por software.

Após a transmissão do bit mais significativo do caractere, seguem-se dois bits opcionais, que são um bit de endereçamento (Ende*) e um bit de paridade (Par*). Após isso, é transmitido um bit de parada (Stop) e um eventual e opcional segundo bit de parada (Stop*). Tal formato pode ser visualizado na Figura 4.11, ilustrada a seguir: 


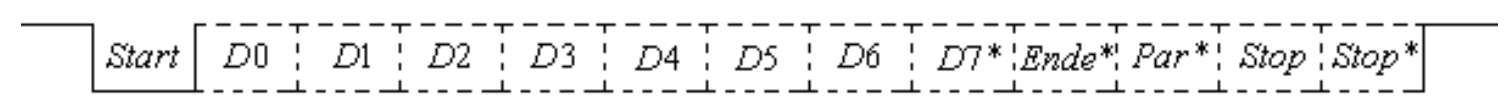

Figura 4.11 - Formato de envio de dados por modo serial assíncrono.

\subsection{2 - Modo Síncrono SPI}

Outro modo de comunicação, que foi utilizado no presente projeto, o qual visa a interconexão da interface serial universal do MSP430 com sistemas externos é através de do modo síncrono SPI (Serial Peripheral Interface). Tal protocolo é configurado e selecionado através de programa e utiliza três ou quatro pinos (SIMO, SOMI, UCLK e STE) para a comunicação externa. Uma descrição resumida dos pinos pode ser dada a seguir:

$\checkmark$ SIMO (Slave In Master Out): No caso do microcontrolador operar no modo "mestre", o pino SIMO será de saída de dados. Caso o MSP esteja operando no modo "escravo", tal pino será de entrada de dados;

$\checkmark$ SOMI (Slave Out Master In): No caso do microcontrolador operar no modo "mestre", o pino SOMI será de entrada de dados. Caso o MSP esteja operando no modo "escravo", tal pino será de saída de dados;

$\checkmark$ UCLK (USART SPI Clock): No caso do microcontrolador operar no modo “mestre”, o pino UCLK será a saída do relógio de comunicação. Caso o MSP esteja operando no modo "escravo", tal pino será a entrada do relógio de comunicação.

$\checkmark$ STE (Slave Transmit Enable): Pino adicional que é utilizado para habilitar um determinado dispositivo de receber e transmitir dados. Tal pino é configurado pelo "mestre" da comunicação.

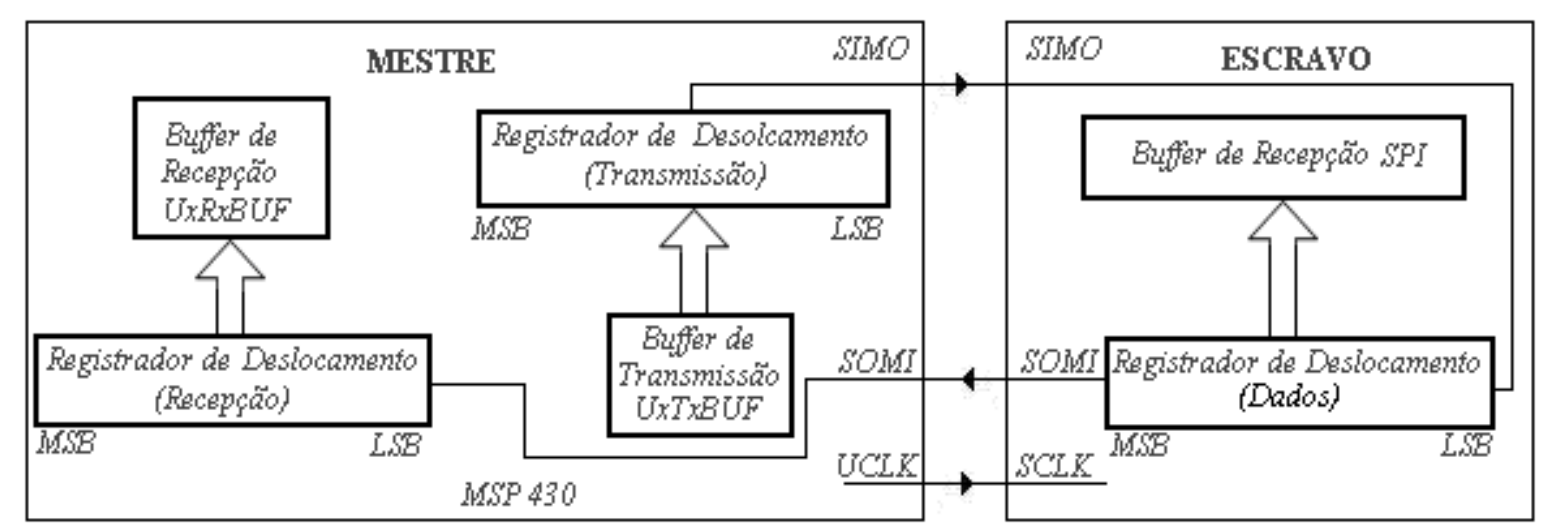

Figura 4.12 - Exemplo de comunicação por modo síncrono SPI, MSP430 como “mestre”.

A Figura 4.12 ilustra um exemplo de comunicação por modo síncrono SPI, sendo que em tal caso o microcontrolador está operando como "mestre" e um dispositivo padrão 
como "escravo". É possível perceber o sentido das comunicações e o processo de armazenamento de dados (buffers).

O modo síncrono SPI de comunicação serial foi utilizado no presente projeto para o envio de dados a alguns dispositivos pertencentes ao Sistema de controle de LEDs (seção 5.2) e ao Módulo de adequação do sinal à faixa dinâmica de conversão (seção 5.4.3), os quais serão melhor explicado adiante. Tal escolha se deve a possibilidade de comunicação de diversos dispositivos utilizando o mesmo sinal e o mesmo barramento de dados e sincronismo, sendo necessário apenas um pino adicional para o endereçamento do dispositivo.

\section{7 - PROGRAMAÇÃO DO MSP 430}

Como pode ser visto nas descrições e especificações do sistema (Capitulo 3), o microcontrolador MSP 430 exerce um papel central na análise, controle, armazenamento e captação dos sinais de oximetria de pulso.

Todo o gerenciamento de informações é feito de acordo com instruções dos códigos de programa que foram implementados para o sistema. Tais instruções atuam nas mais diversas partes do projeto, tentando controlar a qualidade do sinal, para que se obtenha uma maior resolução e conseqüentemente um valor o mais próximo possível da oxigenação sanguínea.

A primeira configuração realizada foi a escolha do relógio do microcontrolador. Para tal, foi utilizado um sinal de relógio proveniente de um cristal externo com frequiência de $f_{C L K}=8 \mathrm{MHz}$, a qual permitirá uma alta velocidade de processamento e consequentemente a possibilidade de se trabalhar com um número maior de dispositivos simultaneamente. O mesmo sinal de relógio será utilizado em outros módulos internos do MSP430, como o Timer A e o módulo ADC12.

\subsection{1 - Geração de onda quadrada necessária para os sinais de controle}

Para um funcionamento adequado do Sistema de Geração de Ondas de Controle (seção 5.1), se torna necessário o fornecimento de uma onda quadrada de frequiência 
$f_{C T L}=4,8 \mathrm{kHz}$ por parte do MSP430.

A rotina para o fornecimento foi implementada utilizando o valor do tempo de duração de 1 (um) período do sinal de relógio escolhido para sincronizar a contagem do Timer A, que neste caso foi o cristal externo com freqüência $f_{C L K}=8 \mathrm{MHz}$. Sendo assim:

$$
\begin{gathered}
\text { Intervalo de contagem }=\tau_{C L K} \\
\tau_{C L K}=\frac{1}{f_{C L K}} \rightarrow \tau_{C L K}=1,25 \cdot 10^{-7} \text { segundos }
\end{gathered}
$$

O procedimento utiliza o temporizador Timer A para fazer a contagem de quantos intervalos seriam necessários para completar meio periodo da onda de $4,8 \mathrm{kHz}$. Tal método pode ser visualizado através da Figura 4.13, ilustrada abaixo:

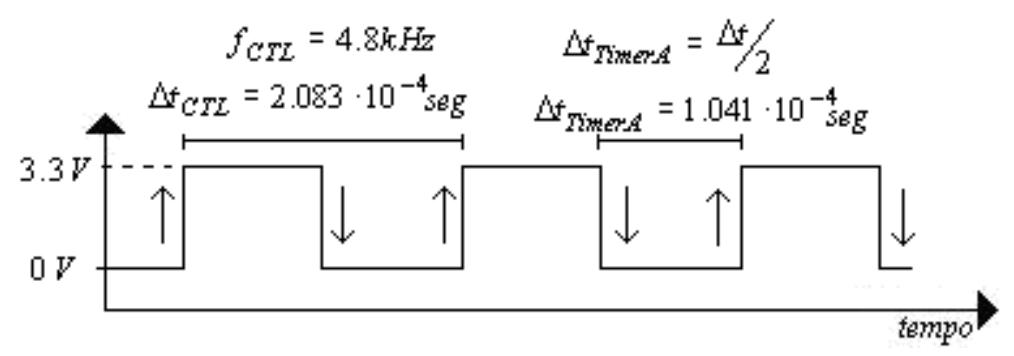

Figura 4.13 - Geração da onda quadrada de $4.8 \mathrm{kHz}$

Como $f_{C T L}=4,8 \mathrm{kHz}$, tem-se que o período da onda é igual a $\Delta t_{C T L}=2,083 \cdot 10^{-4} \mathrm{seg}$. Com isso, o Timer A deve realizar uma contagem de meio ciclo de onda, ou seja, $\Delta t_{\text {TimerA }}=1,041 \cdot 10^{-4} \mathrm{seg}$.

Neste momento, o Timer A deve proceder uma interrupção e inverter o pino onde a onda quadrada está sendo gerada (pino P1.1), como ilustrado na Figura 4.13. O número de contagens pode ser calculado pela relação linear ilustrada na equação 4.3.

$$
\begin{gathered}
\frac{1 \text { contagem }}{x} \leftrightarrow \frac{1.25 \cdot 10^{-7} \text { segundos }}{1.041 \cdot 10^{-4} \text { segundos }} \\
x=\frac{(1 \text { contagem }) \cdot\left(1,041 \cdot 10^{-4} \text { segundos }\right)}{\left(1,25 \cdot 10^{-7} \text { segundos }\right)} \rightarrow x=833 \text { contagens }
\end{gathered}
$$

O esquemático desta rotina pode ser visualizada na Figura 4.14 (Esquemático do método de geração de onda quadrada de $4,8 \mathrm{kHz}$ ). 


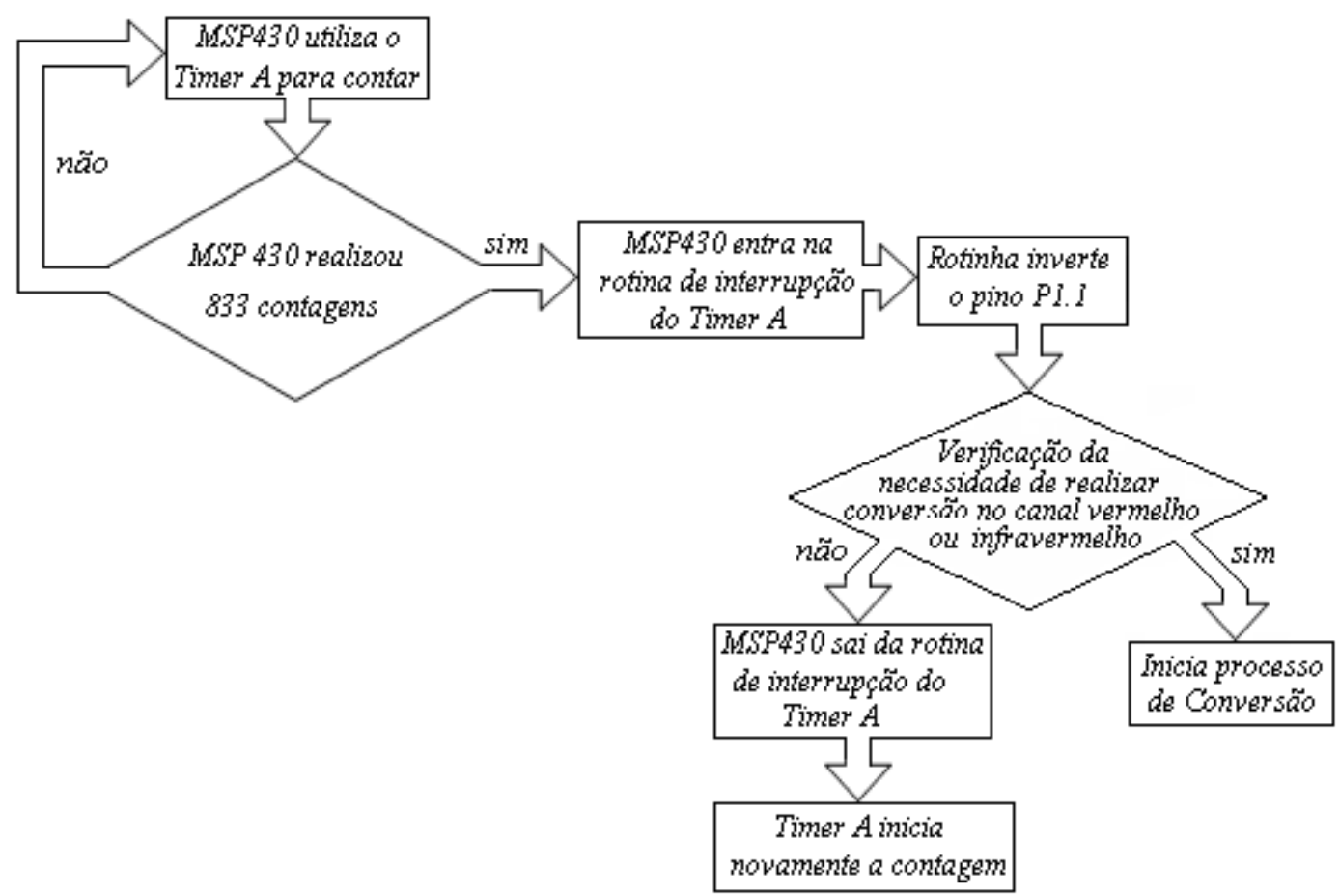

Figura 4.14 - Esquemático do método de geração de onda quadrada de $4.8 \mathrm{kHz}$

Como pode ser observado, o Timer A também é utilizado para a verificação de quais os momentos devem ser iniciados os processos de conversão. Tal fato pode ser explicado através da Figura 4.19, a qual demonstra a onda CLK e 32 inversões do pino P1.1. Os momentos em que são realizadas as conversões são controlados pelo sistema de geração de ondas de controle, o qual será abordado na seção 5.1. De princípio, pode-se adiantar que dentro desta janela, a conversão do sinal proveniente do LED vermelho é feita na inversão número 8 e a conversão do sinal do LED infravermelho na inversão número 20.

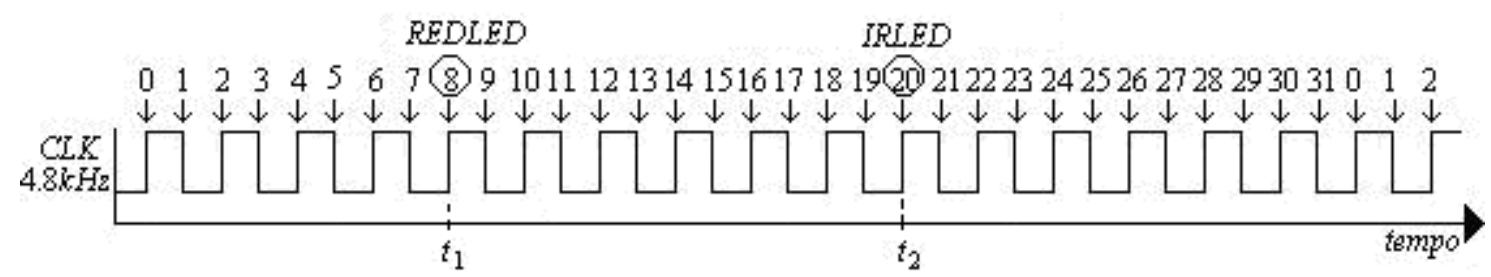

Figura 4.15 - Janela de 32 inversões do pino P1.1 e ilustração dos momentos em que são realizadas as conversões analógico-digital de cada LED

\subsection{2 - Programação da interface serial universal}

No presente projeto, o MSP 430 utiliza a interface serial para se comunicar com diversos dispositivos e com o microcomputador. As configurações dos dois módulos independentes, USART0 e USART1, são feitas de forma distinta, pois elas serão usadas 
em modos diferentes.

A USART0 foi utilizada para o envio de dados para o microcomputador para a conseqüente visualização dos resultados obtidos nos aplicativos de monitoramento (seção 5.5). Na configuração estabelecida para tal modo, optou-se por uma velocidade de envio de dados de 115.200 bits por segundo, com palavras de 8 bits, mais dois bits de parada. A Tabela 4.7 ilustra as modificações que foram realizadas nos registrador de controle UOCTL (USART1 Control Register) para que a interface serial operasse como desejado:

Tabela 4.7 - Configuração da USART0 para modo assíncrono

\begin{tabular}{|c|c|l|}
\hline $\begin{array}{c}\text { Bit do Registrador } \\
\text { U0CTL }\end{array}$ & $\begin{array}{c}\text { Valor lógico } \\
\text { do bit }\end{array}$ & \multicolumn{1}{c|}{ Resultado } \\
\hline PENA & 0 & Desabilita o bit de parada \\
\hline CHAR & 1 & Comprimento da palavra de 8bits \\
\hline SSEL1 / SSEL0 & $1 / 1$ & Seleciona o SMCLK como fonte do relógio \\
\hline SPB & $\mathbf{1}$ & Palavra com dois bits de parada \\
\hline
\end{tabular}

Outras modificações devem ser realizadas nos registradores U0BR0 e U0BR1 (USART Baud Rate Control Register) para se conseguir o valor de velocidade de transmissão de dados desejado, como ilustrado na Tabela 4.8:

Tabela 4.8 - Configuração da velocidade de transmissão da USART1

\begin{tabular}{|c|c|c|}
\hline Registrador & $\begin{array}{c}\text { Valor do Código } \\
\text { Binário }\end{array}$ & Significado \\
\hline U0BR0 & 010000101 & $\begin{array}{c}\text { O valor da fonte de relógio é dividido por 69, } \\
\text { para se conseguir a transmissão em 115.200 } \mathrm{pps} \text {. }\end{array}$ \\
\hline U0BR1 & $\mathbf{0 0 0 0 ~ 0 0 0 0}$ &
\end{tabular}

A USART1, por sua vez, foi usada no modo síncrono SPI para o envio de dados aos dispositivos que são controlados pelo MSP 430, como conversores D/A e potenciômetros digitais. Na configuração estabelecida para tal modo, optou-se por uma velocidade de envio de dados de $500 \mathrm{kbps}$, com palavras de 8 bits e com o microcontrolador operando no modo "mestre". A Tabela 4.9 ilustra as modificações que foram realizadas nos registrador de controle U1CTL (USART1 Control Register) para que a interface serial operasse como desejada:

Tabela 4.9 - Configuração da USART 1 para o modo SPI

\begin{tabular}{|c|c|l|}
\hline $\begin{array}{c}\text { Bit do Registrador } \\
\text { U1CTL }\end{array}$ & $\begin{array}{c}\text { Valor lógico } \\
\text { do bit }\end{array}$ & \multicolumn{1}{c|}{ Resultado } \\
\hline SYN & 1 & Habilitação do modo síncrono \\
\hline CHAR & 1 & Comprimento da palavra de 8 bits \\
\hline SSEL1 / SSEL0 & $1 / 1$ & Seleciona o SMCLK como fonte do relógio \\
\hline MM & $\mathbf{1}$ & Define o MSP como mestre \\
\hline
\end{tabular}


Outras modificações devem ser realizadas nos registradores U1BR0 e U1BR1 (USART Baud Rate Control Register) para se conseguir o valor de velocidade de transmissão de dados desejado, como ilustrado na Tabela 4.10:

Tabela 4.10 - Configuração da velocidade de transmissão da USART1

\begin{tabular}{|c|c|c|}
\hline Registrador & $\begin{array}{c}\text { Valor do Código } \\
\text { Binário }\end{array}$ & Significado \\
\hline U1BR0 & 00001000 & $\begin{array}{c}\text { O valor da fonte de relógio é dividido por 16, } \\
\text { para se conseguir a transmissão em 500 } \mathrm{kbps}\end{array}$ \\
\hline U1BR1 & $\mathbf{0 0 0 0 0 0 0 0}$ &
\end{tabular}

\subsection{3 - Configuração do conversor analógico digital ADC12}

No desenvolvimento do oxímetro de pulso, o módulo de conversão analógico digital ADC12 exerce um papel crucial, pois é através dele que o microcontrolador poderá receber dados do sistema e decidir quais as instruções realizar para se obter uma melhor qualidade do sinal captado.

Para o bom funcionamento de tal módulo, várias configurações devem ser realizadas, com o intuito de indicar o modo de operação e a sequiência de instruções a serem realizadas pelo microcontrolador. Por isso, algumas escolhas devem ser feitas, como por exemplo, o relógio a ser utilizado na conversão, o período de amostragem, quais os registradores serão utilizados para o armazenamento de dados captados, qual a fonte de referência de tensão, entre outros.

A Tabela 4.11 especifica algumas modificações que foram realizadas nos registradores ADC12CTL0 e ADC12CTL1 (ADC12 Control Register), para que o módulo ADC12 operasse como desejado:

Tabela 4.11 - Configuração do módulo ADC12

\begin{tabular}{|c|c|l|}
\hline $\begin{array}{c}\text { Bit do Registrador } \\
\text { ADC12CTL0 ou } \\
\text { ADC12CT1 }\end{array}$ & $\begin{array}{c}\text { Valor lógico } \\
\text { do bit }\end{array}$ & \multicolumn{1}{c|}{ Resultado } \\
\hline SHT0 & 0000 & $\begin{array}{l}\text { Define o tempo de amostragem como quatro } \\
\text { períodos de ADC12CLK }\end{array}$ \\
\hline REF2_5 & 1 & Gerador de tensão de Referência em $2.5 \mathrm{~V}$ \\
\hline REFON & 1 & Gerador de tensão de referência ligado \\
\hline ADC12ON & 1 & Módulo ADC12 ligado \\
\hline CSTARTADD & 0000 & $\begin{array}{l}\text { Configura o registrador ADC12MEM0 como o } \\
\text { endereço do resultado de conversão }\end{array}$ \\
\hline SHS & 0 & $\begin{array}{l}\text { Seleciona ADC12SC como fonte do tempo de } \\
\text { amostragem e inicia a conversão. }\end{array}$ \\
\hline ADC12DIV & $\mathbf{0}$ & Divisor do relógio de conversão igual a 1 \\
\hline
\end{tabular}




\subsection{4 - Rotina de detecção de máximos e mínimos do sinal recebido}

Essa função é essencial para o bom funcionamento do oxímetro. Nela, são extraídos os valores referentes ao máximo e mínimo locais da onda pletismográfica dos canais vermelho e infravermelho.

De porte desses valores, serão ajustados os valores de tensão retirados de cada canal através do conjunto conversor digital/analógico e amplificador de instrumentação, como também o ganho do sinal enviado ao conversor analógico/digital. Além disso, serão usados para o cálculo da saturação de oxigênio do sangue arterial, motivação maior desse projeto.

Com a intenção de manter sempre o sinal de entrada dentro da faixa de conversão do módulo ADC12, foram determinados limites inferior e superior como forma de indicação de que o sinal está se deslocando para fora da zona de conversão.

Assim, como o conversor analógico/digital fornece amostras de 0 a 4095, os valores 100 e 3995 foram escolhidos como limites inferior e superior, respectivamente. $\mathrm{Na}$ primeira parte da função, é verificado se a amostra atual está dentro da zona de conversão, ou seja, entre 100 e 3995.

Caso contrário, após 50 amostras fora da zona de conversão e dentro de uma janela de 2 segundos, a função ajusta o valor de tensão enviado ao conversor digital/analógico. A contagem de amostras encontradas acima ou abaixo dos limites é feita por duas variáveis, uma para cada caso. Mesmo estando dentro ou fora da faixa de conversão, um teste é feito para saber se a amostra atual é um máximo ou mínimo da janela, atualizando um desses valores caso positivo.

\subsection{5 - Rotina de cálculo do ganho fornecido ao sinal}

Nessa parte do programa, o ganho dos amplificadores do módulo de adequação do sinal a faixa dinâmica de conversão é ajustado num intervalo de 2 segundo, fazendo uso do mínimo e máximo encontrados na janela atual.

Primeiramente, é verificado se o máximo da janela é maior que o mínimo da 
mesma. Isso se faz necessário devido ao fato de que um desses valores é reiniciado a cada ajuste do conversor digital/analógico. Portanto, há casos em que o máximo é menor que o mínimo da janela, uma vez que um ajuste da tensão no final da janela pode ter sido forçado por deslocamento positivo do sinal de entrada.

Então, a diferença entre o máximo e mínimo, o valor pico-a-pico do sinal, é calculada, verificando se está dentro dos limites de um sinal ideal, que varia de 100 a 3500 . Caso esteja dentro dos limites, o novo ganho é determinado almejando-se um valor pico-apico desejado pré-fixado na inicialização do sistema. Se não estiver, ajustamos o valor de corrente enviada ao repectivo LED, no caso de ser menor que 100. Já se o valor pico-apico for maior que 3500, seu ganho atual é dividido para que o sinal de entrada possa voltar integralmente à faixa de conversão.

A Figura 4.20 traz um esquemático mais detalhado do funcionamento e operação da rotina de cálculo do ganho fornecido ao sinal.

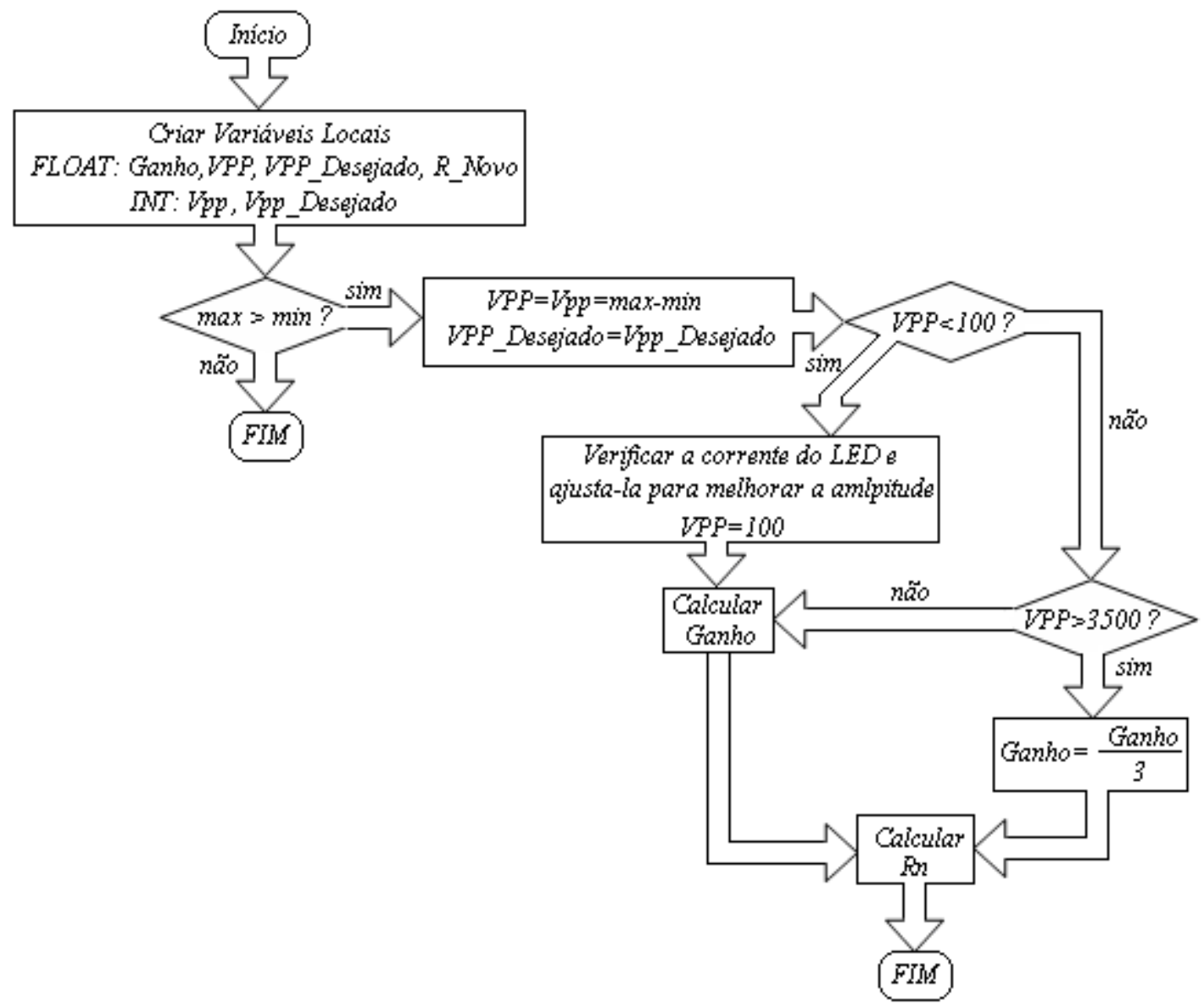

Figura 4.16 - Esquemático de funcionamento da rotina de cálculo do ganho fornecido ao sinal 


\subsection{6 - Rotina de cálculo do resistor do potenciômetro digital}

Após o cálculo do ganho de cada canal, o valor do resistor deve ser recalculado e atualizado no dispositivo. Assim, é verificado se o ganho extrapola os valores de ganho mínimo e máximo.

Se extrapolar, valores pré-determinados de resistor máximo, no caso de ganho mínimo, e de resistor mínimo, no caso de ganho máximo, são enviados aos potenciômetros e armazenados no MSP 430, visto que o valor do ganho é inversamente proporcional ao resistor acoplado ao amplificador de instrumentação INA118, o qual será abordado na seção 5.4.1. Do contrário, calcula-se o resistor para o ganho encontrado na função anterior.

\subsection{7 - Rotina de cálculo da saturação de oxigênio}

Essa função é realizada a cada 2 segundos, quando se completa uma janela de pesquisa do sinal. Através dos valores de máximo, mínimo, tensões retiradas através do conversor digital/analógico no instante de atualização do máximo e do mínimo e ganho do amplificador de instrumentação, os valores de máximo e mínimo são convertidos para seus valores reais, ou seja, em Volts.

Em seguida, encontra-se a divisão da componente pulsante pela componente nãopulsante do sinal vermelho e, também, para o sinal infravermelho, chamados de Razão vermelho e Razão infravermelho. Assim, calcula-se a razão das razões encontradas anteriormente. Então, verifica-se a equação a ser utilizada para o cálculo da saturação de oxigênio determinada pela faixa em que o valor dessa última razão se encontra. 


\section{5 - SISTEMAS E CIRCUITOS DO OXÍMETRO DE PULSO}

Como visto no Capítulo 3, o projeto completo do oxímetro de pulso é composto de diversos módulos e sistemas, os quais trabalham em conjunto no controle, recepção e monitoramento do sinal de oxigenação sanguínea.

O módulo principal é formado pelo microcontrolador MSP 430, o qual foi amplamente visto no Capítulo 4. Neste capítulo será feita uma abordagem acerca dos outros sistemas que completam o conjunto de circuitos, os quais foram nomeados por:

$\checkmark$ Sistema de Geração de Ondas de Controle

$\checkmark$ Sistema de Recepção

$\checkmark$ Sistema de Controle dos LEDs

$\checkmark$ Fonte analógica

\section{1 - SISTEMA DE GERAÇÃO DE ONDAS DE CONTROLE}

Devido o grande número de dispositivos que devem ser comandados no oxímetro de pulso, bem como o direcionamento das informações que são colhidas pelos sensores e circuitos de recepção do sinal, acaba tornando-se necessária a realização de um projeto de circuito que produza ondas de controle para sinalizar o tráfico de informações, bem como acionar ou desabilitar o funcionamento dos diversos componentes.

Tal circuito gerador de sinais de controle utiliza a onda quadrada de $4,8 \mathrm{kHz}$ produzida pelo MSP 430 para a formação de duas outras ondas periódicas que servirão como indicação de qual dos LEDs a informação está sendo recebida, bem como o conjunto de dispositivos que se encontram habilitados ou não. Tal formação pode ser vista na Figura 5.1, ilustrado abaixo:

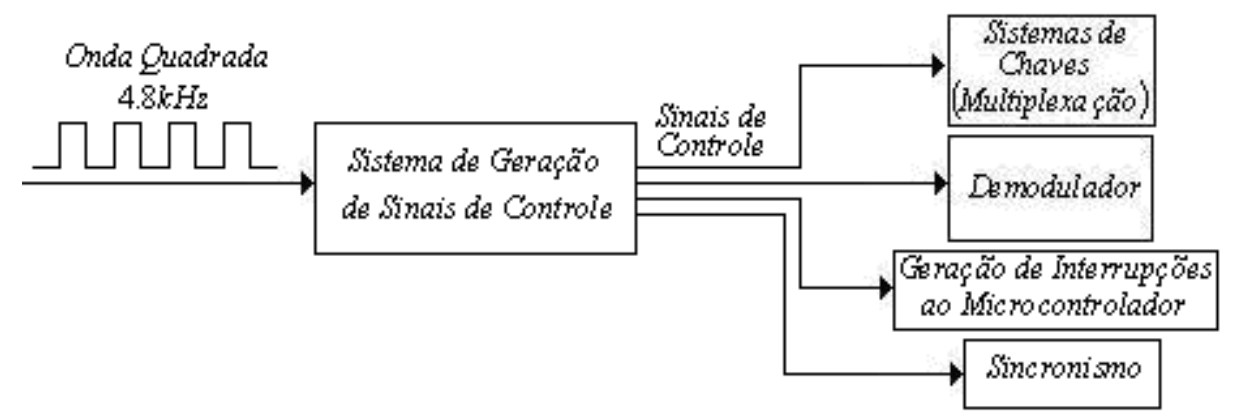

Figura 5.1 - Sistema de geração de sinais de controle. 
O primeiro módulo do circuito do projeto foi feito utilizando-se um contador digital síncrono de quatro bits (74LS161). A onda quadrada proveniente do microcontrolador MSP 430 é usada como relógio do contador (CLK), o qual, caso esteja ativado no modo de contagem, irá produzir quatro ondas diferentes nos seus pinos de saída $\left(Q_{A}, Q_{B}, Q_{C}\right.$ e $Q_{D}$ ). $\mathrm{O}$ formato de tais sinais, bem como a freqüência de cada um deles pode ser visto na Figura 5.2:

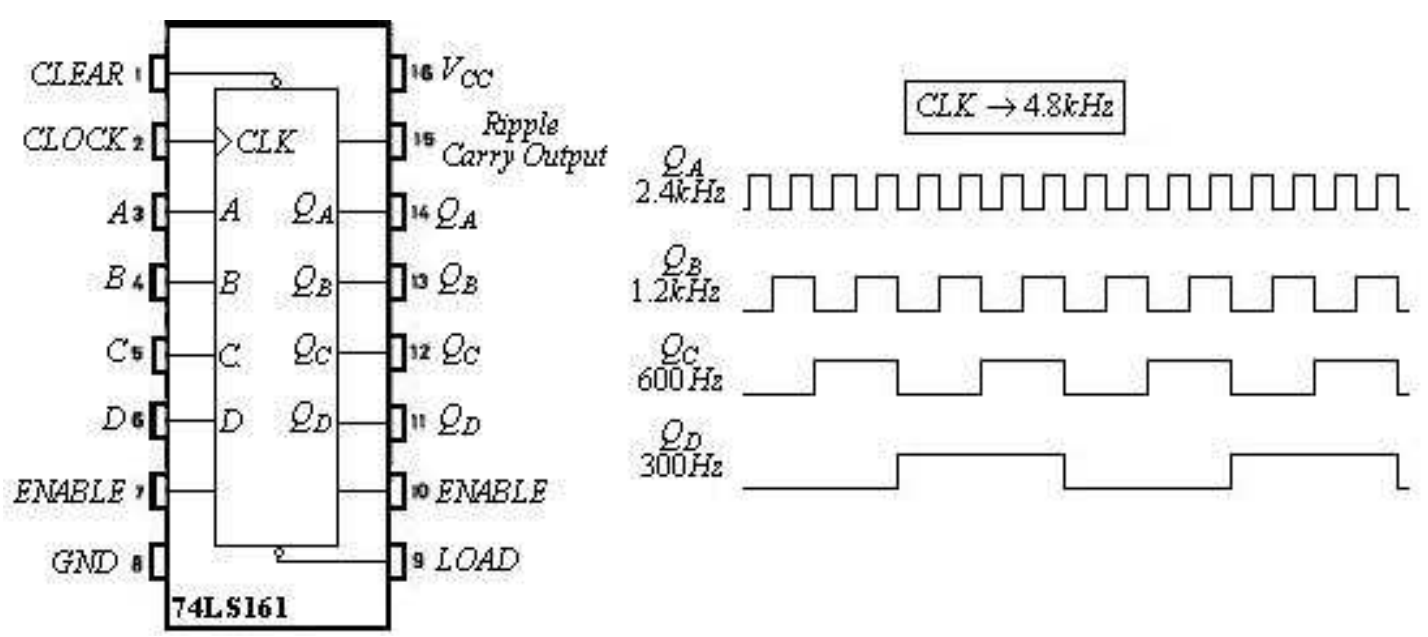

Figura 5.2 - Contador digital síncrono de quatro bits e ondas de saída.

Com tais sinais formados, é possível estabelecer algumas variáveis que, ao serem combinadas, indicarão em qual estágio de funcionamento o oxímetro de pulso está trabalhando.

Sendo assim, o sinal $Q_{B}$ indicará qual dos LEDs está em funcionamento. Caso o valor de $Q_{B}$ for igual a 0, o LED infravermelho (IRLED) é o componente em uso. Caso contrário, se $Q_{B}$ for igual a 1 , o vermelho (REDLED) será o que se encontra em uso. A Figura 5.3 ilustra o comportamento que foi adotado para $Q_{B}$.

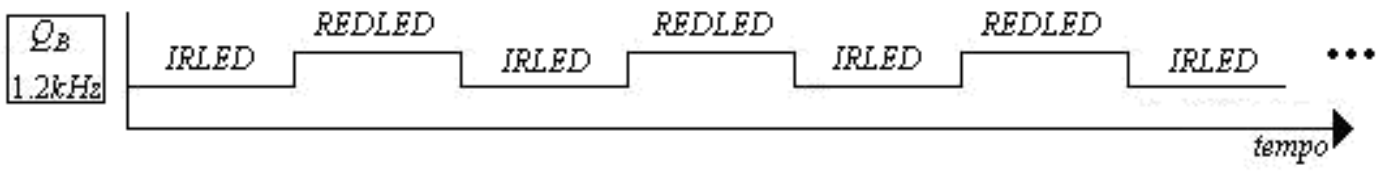

Figura 5.3 - Comportamento adotado para o sinal $\mathrm{Q}_{\mathrm{B}}$

Outra variável foi estabelecida usando-se a onda quadrada $Q_{A}$, a qual indicará se o LED se encontra ou não aceso. Sendo assim, se $Q_{A}$ for igual a 1 , servirá como indício de 
que algum dos dois LEDs se encontra ligado. Caso contrário, se $Q_{A}$ for igual a 0 , indicará que nenhum de ambos os LEDS está aceso. A Figura 5.4, ilustra o comportamento que foi padronizado para a onda $Q_{A}$.

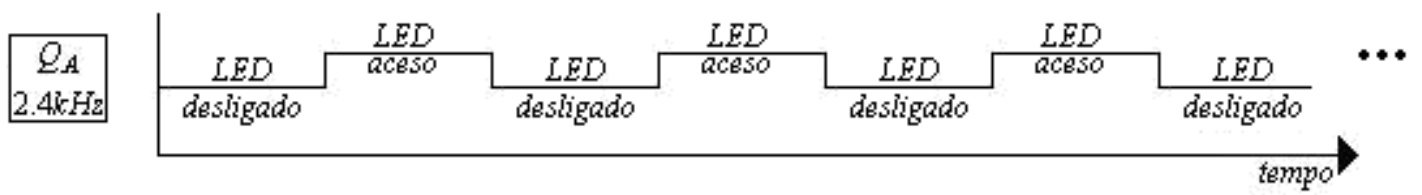

Figura 5.4 - Comportamento adotado para o sinal $\mathrm{Q}_{\mathrm{A}}$

Com isso, através da utilização de álgebra booleana, consegue-se juntar as informações provenientes das ondas $Q_{A}$ e $Q_{B}$ para saber em que estágio o oxímetro está operando. Sendo assim, caso se queira saber se o LED vermelho se encontra aceso, basta observar todos os instantes em que o valor lógico das ondas $Q_{A}$ e $Q_{B}$ se encontra em nível alto.

Tal fato pode ser exemplificado nos mapas de Karnaugh vistos na Figura 5.5 (Operações booleanas com ondas de saída do contador síncrono), onde também é possível analisar o resultado de tal processo em um gráfico em função do tempo:
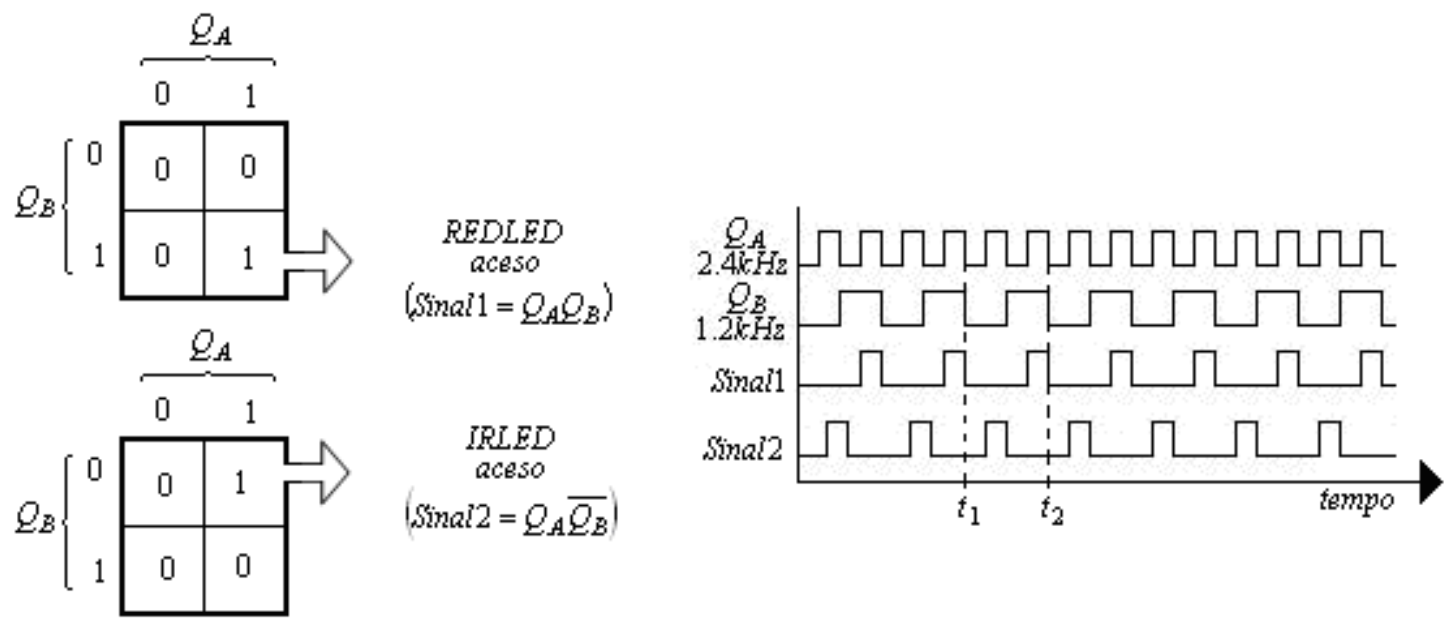

Figura 5.5 - Operações booleanas com ondas de saída do contador síncrono

A implementação de tais funções (Sinal1 e Sinal2) foi realizada através do uso de portas lógicas NÃO-E. A Tabela 5.1 ilustra as possíveis respostas de entrada e saída da porta NÂO-E.

Tabela 5.1 - Tabela verdade da porta lógica NÂO-E

\begin{tabular}{|c|c|c|}
\hline Entrada 1 & Entrada 2 & Saída \\
\hline 0 & 0 & $\mathbf{1}$ \\
\hline 0 & 1 & $\mathbf{1}$ \\
\hline 1 & 0 & $\mathbf{1}$ \\
\hline
\end{tabular}




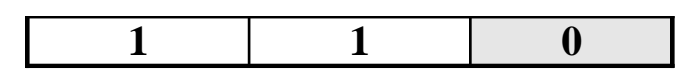

É possível perceber claramente que caso uma das entradas for igual a 1, a saída será o inverso do valor lógico da outra entrada. Com isso, implementou-se o circuito ilustrado na Figura 5.6 (Circuito gerador de ondas de controle).

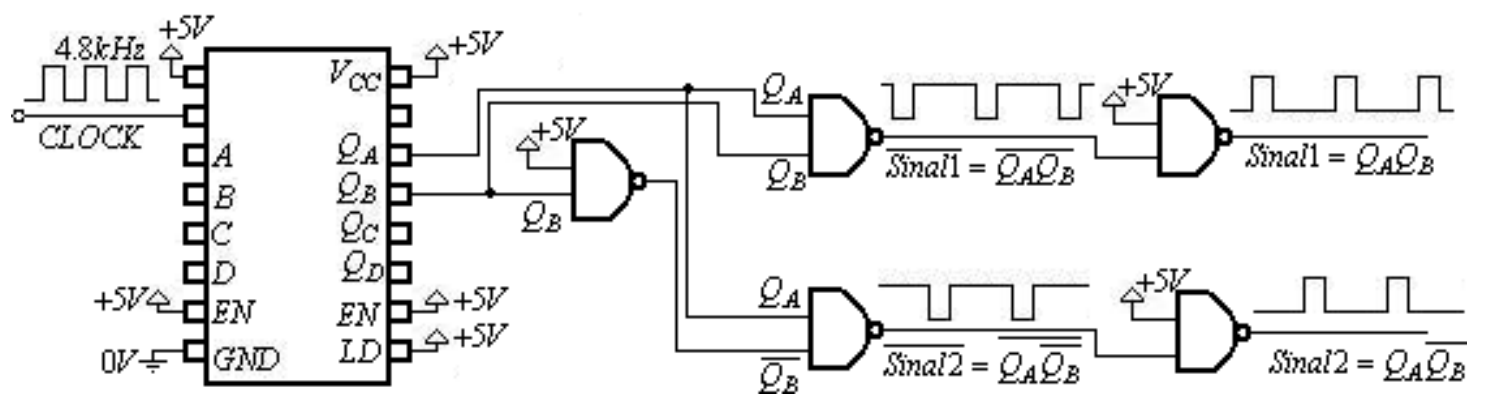

Figura 5.6 - Circuito gerador de ondas de controle

Como o sistema de controle dos LEDs (apresentado na seção 5.2) utiliza lógica invertida, houve a necessidade de se gerar as ondas $\overline{\text { Sinal1 }}$ e $\overline{\text { Sinal2 }}$.

\section{2 - SISTEMA DE CONTROLE DOS LEDS}

Um dos módulos mais importantes do funcionamento do oxímetro de pulso implementado é o circuito responsável pelo controle de acionamento e controle de corrente enviada para cada um dos LEDs. Tal circuito é formado por partes analógicas e digitais, as quais alteram automaticamente o LED em operação, bem como o valor de corrente enviada para cada um dos LEDs de acordo com a absorção de luz pelos tecidos do corpo do paciente. Um esquemático reduzido pode ser visto na Figura 5.7, ilustrando os módulos de tal sistema, bem como a comunicação com os LEDs e microcontrolador.

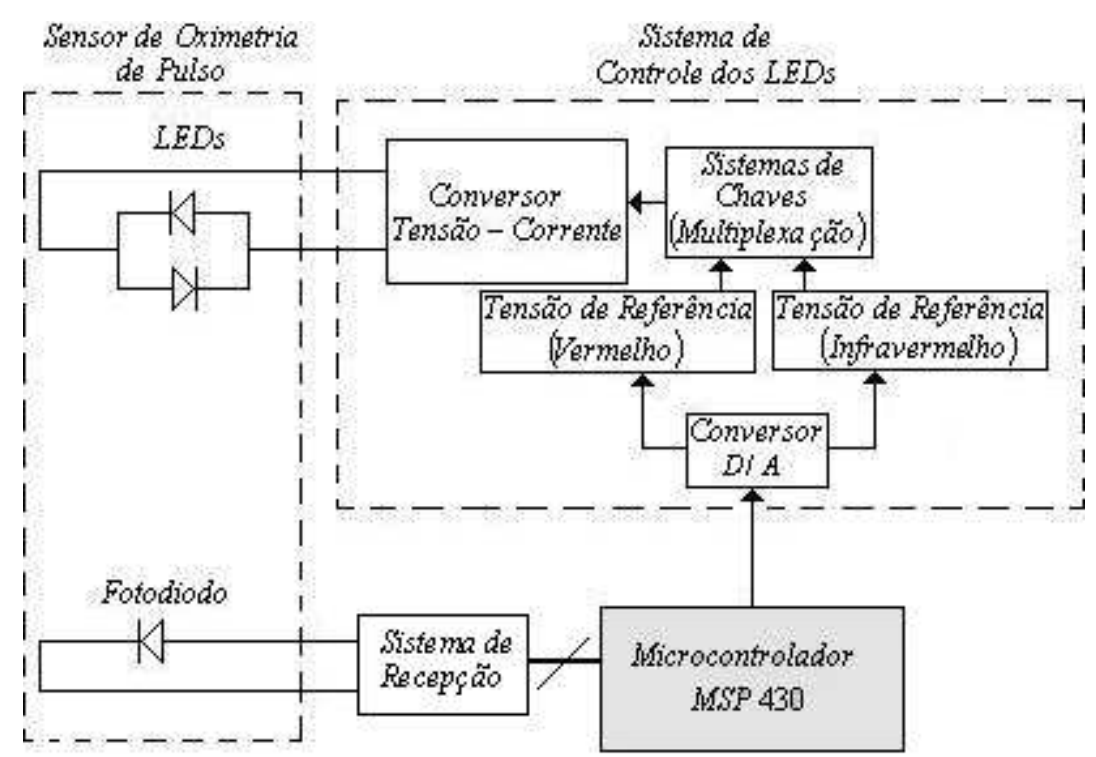


Figura 5.7 - Esquemático do circuito e das comunicações do sistema de controle dos LEDS

Toda essa análise descrita acima é feita através de processamento realizado pelo microcontrolador MSP 430. Fatores como a pigmentação e espessura da pele, comprimento do caminho ótico pelo dedo, dentre muitos outros determinam a absorção de luz pelos tecidos.

O microprocessador analisa primeiramente se o fotodiodo está recebendo uma quantidade apropriada de luz, suficiente para excitar, mas não saturar o fotodiodo. $\mathrm{O}$ microprocessador então retorna uma tensão de referência que alimenta o circuito de controle dos LEDs, o qual irá ajustar a corrente apropriadamente.

Tal circuito desenvolvido pode ser melhor observado na Figura 5.8, ilustrada abaixo. Primeiramente, é possível perceber que o MSP controla a tensão de referência através do envio de dados a um conversor digital-analógico de oito bits (TLC5620) através de comunicação serial SPI.

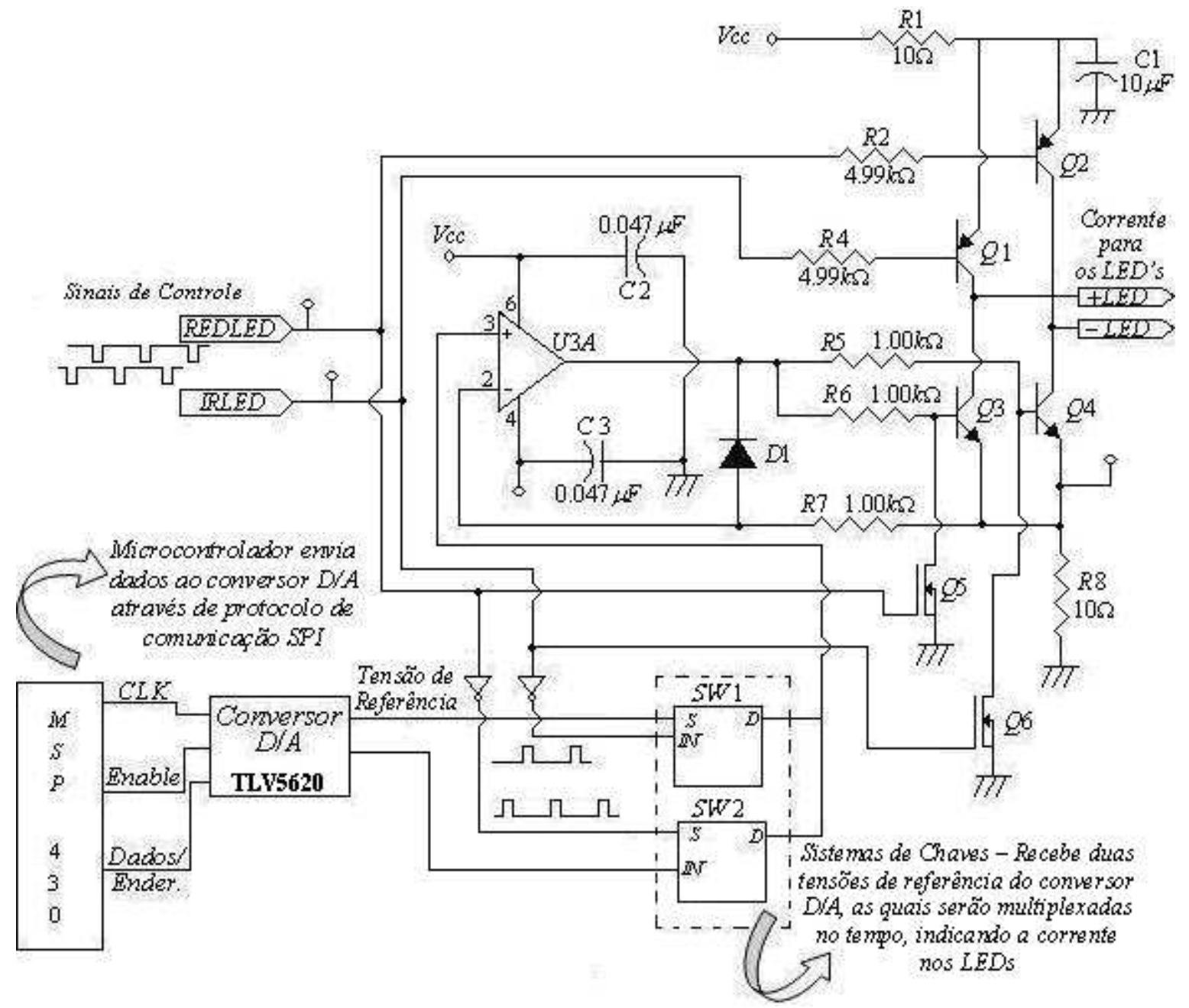


O conversor DA, por conseguinte, produz tal tensão de referência, a qual é enviada ao circuito de controle dos LEDs por um sistema de chaves digitais (SW1 e SW2), que é responsável pelo chaveamento seletivo de tensão de referência, ajustando de forma dinâmica e automática a corrente de acordo com o LED em operação no oxímetro de pulso. Em determinados momentos a tensão enviada servirá para gerar a corrente no LED vermelho. Em outros casos, irá gerar a corrente no LED infravermelho.

Os sinais de controle REDLED e IRLED são provenientes do circuito de geração de ondas de controle ( $\overline{\text { Sinal1 }}$ e $\overline{\text { Sinal2 }}$ ) que é mais amplamente explicado na seção 5.1. Tais sinais controlam a abertura ou fechamento das chaves $S W 1$ e $S W 2$, bem como a rede de transistores que irão ser responsáveis por drenar a corrente ao LED em operação.

Como pode ser visto no gráfico observado na Figura 5.5, o qual ilustra o comportamento das ondas Sinall e Sinal2 ao longo do tempo, é possível perceber que os LEDs vermelho e infravermelho nunca estão ativos ao mesmo tempo, apesar de em alguns momentos dos ciclos de chaveamento eles estarem ambos desligados, fato que poderia ser utilizado para a detecção da luz ambiente pelo fotodiodo.

\subsection{1 - Habilitação do LED vermelho}

Quando o sinal REDLED ( $\overline{\text { Sinal1 }})$ está em nível lógico baixo (0V) e o sinal IRLED ( $\overline{\text { Sinal2 }}$ ) em nível lógico alto, é possível perceber que a chave $S W 1$ se encontra fechada, colocando assim a tensão de referência do LED vermelho na entrada não inversora do amplificador operacional.

$\mathrm{Na}$ rede de transistores, essa configuração de REDLED e IRLED irá ativar e desabilitar diversos componentes, como pode ser explicado a seguir:

$\checkmark$ Com REDLED em nível lógico baixo, o transistor Q2 passa a atuar na região ativa, permitindo que a corrente flua da alimentação $V_{C C}$ para o anodo do LED vermelho, acendendo tal LED.

$\checkmark$ Com REDLED em nível lógico baixo, o transistor Q5 é cortado, o que permite Q3 
conduzir a corrente proveniente do LED através de R8, o qual é chamado de resistor de verificação de corrente dos LEDs.

$\checkmark$ Com IRLED em nível lógico alto, Q1 é cortado, desabilitando a condução de corrente. Outra consequiência de tal situação é o transistor Q6 passar a conduzir, o que leva a base do transistor Q4 para o nível do terra.

$\checkmark$ O caminho de corrente para tal configuração inicia-se no $V_{C C}$, passa por Q2, pelo LED vermelho, por Q3 e R8.

$\checkmark$ A tensão sobre o resistor de verificação de corrente dos LEDs, R8, é usada como realimentação na entrada do amplificador operacional, o qual a compara com a tensão de referência proveniente do sistema de chaves, alterando a corrente fornecida a Q3.

\subsection{2 - Habilitação do LED infravermelho}

Quando o sinal IRLED ( $\overline{\text { Sinal2 }}$ ) está em nível lógico baixo $(0 \mathrm{~V})$ e o sinal REDLED ( $\overline{\text { Sinal1 }}$ ) em nível lógico alto, é possível perceber que a chave $S W 2$ se encontra fechada, colocando assim a tensão de referência do LED infravermelho na entrada não inversora do amplificador operacional.

$\mathrm{Na}$ rede de transistores, essa configuração de REDLED e IRLED irá ativar e desabilitar diversos componentes, como pode ser explicado a seguir:

$\checkmark$ O sinal REDLED em nível lógico alto faz com que o transistor Q2 fique na região de corte e Q5 na região ativa, cortando assim o transistor Q3.

$\checkmark$ IRLED em nível lógico baixo coloca o transistor Q1 na região de condução, permitindo que a corrente flua para o anodo do LED infravermelho, acendendo tal LED.

$\checkmark$ Q6 também é cortado, o que permite que a tensão na base de Q4 seja fornecida pelo amplificador operacional até que o transistor Q4 conduza.

$\checkmark$ O caminho de corrente neste caso inicia-se no $V_{C C}$, passa por Q1, pelo LED infravermelho, por Q4 e R8.

$\checkmark$ A tensão sobre o resistor de verificação de corrente dos LEDs, R8, é usada como realimentação na entrada do amplificador operacional, o qual a compara com a tensão de referência proveniente do sistema de chaves, alterando a corrente fornecida a Q4. 


\subsection{3 - LED vermelho e LED infravermelho desabilitados}

Com ambos os sinais IRLED e REDLED em nível lógico alto, ambas as chaves SW1 e SW2 são abertas e toda a rede de transistores é cortada, o que desabilita o transporte de corrente para os LEDs.

\section{3 - SENSOR DE OXIMETRIA DE PULSO}

Uma parte bastante simples, mas de extrema importância no oxímetro de pulso se refere ao sensor de oximetria. Várias qualidades são necessárias para um bom funcionamento do aparelho como um todo.

No presente projeto, foi utilizado um sensor modelo DS-100A, que pode ser reaproveitado e faz parte de uma linha de sensores do fabricante Nellcor (Reusable Sensors Nellcor). Tal dispositivo é formado por um encapsulamento, o qual diminui o ruído no sinal. Outra característica importante é a existência de LEDs vermelho e infravermelho de alta qualidade.

Como explicado anteriormente, o sensor recebe uma corrente proveniente do sistema de controle dos LEDs, o qual é controlado pelo microcontrolador MSP 430. Com isso, os LEDs irão acender alternadamente, emitindo luz em dois comprimentos de onda distintos (vermelho e infravermelho), os quais são captados por um fotodiodo na outra extremidade do dedo.

De acordo com o nível de oxigenação do sangue arterial, e conseqüentemente da coloração apresentada pelas moléculas de hemoglobina, haverá mais ou menos absorção de luz por parte das células que compõem o dedo do paciente e essa variação é captada pelo fotodiodo.

Um esquemático das conexões que formam a ligação do sensor com outros sistemas pode ser visto na Figura 5.9, onde também é possível visualizar o sensor DS$100 \mathrm{~A}$ em conjunto com o seu respectivo encapsulamento. 


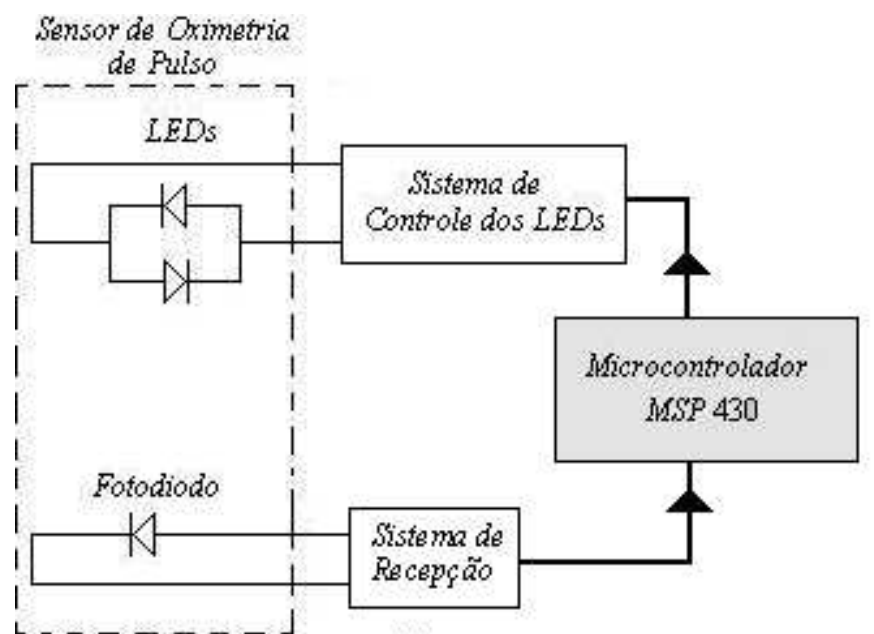

(a)

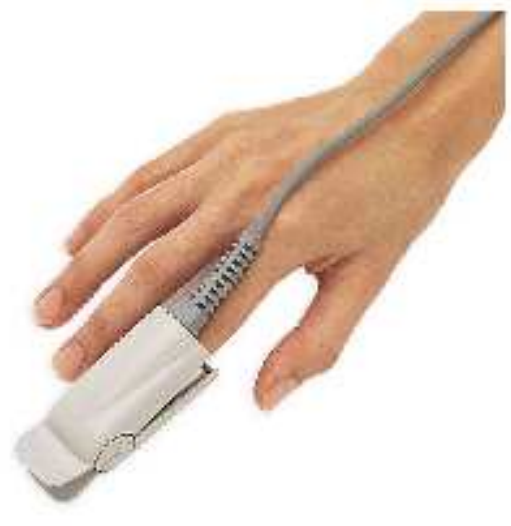

(b)

Figura 5.9 - a) Esquemático das conexões do sensor de oximetria; b) Ilustração do sensor DS-100A

O fotodiodo produz uma corrente que é proporcional à luz incidida. Tal corrente varia de acordo com o nível de oxigenação, devido à mudança na coloração do sangue, e conseqüentemente a mudança na luz absorvida pelo dedo. Tal corrente é então enviada ao sistema de recepção, o qual é detalhado na seção 5.4.

\section{4 - SISTEMA DE RECEPÇÃO}

Como explicado anteriormente, o sistema de recepção é responsável pela captação do sinal proveniente do fotodiodo, bem como a amplificação, filtragem e adequação de tal sinal aos limites de tensão estabelecidos para o conversor analógico digital (ADC12) do microcontrolador.

Tal sistema é composto por diversos módulos, os quais possuem características específicas e trabalham em conjunto na melhoria do sinal, tentando diminuir ao máximo as componentes de ruído, preservando as características que serão usadas pelo oxímetro de pulso no cálculo da taxa de oxigenação sanguínea.

\subsection{1 - Módulo de pré-amplificação e demodulação.}

O primeiro módulo pertencente ao sistema de recepção é responsável pela préamplificação e pela separação dos sinais provenientes do LED vermelho e do LED infravermelho. Um esboço de tal módulo pode ser visto na Figura 5.10, ilustrada abaixo: 


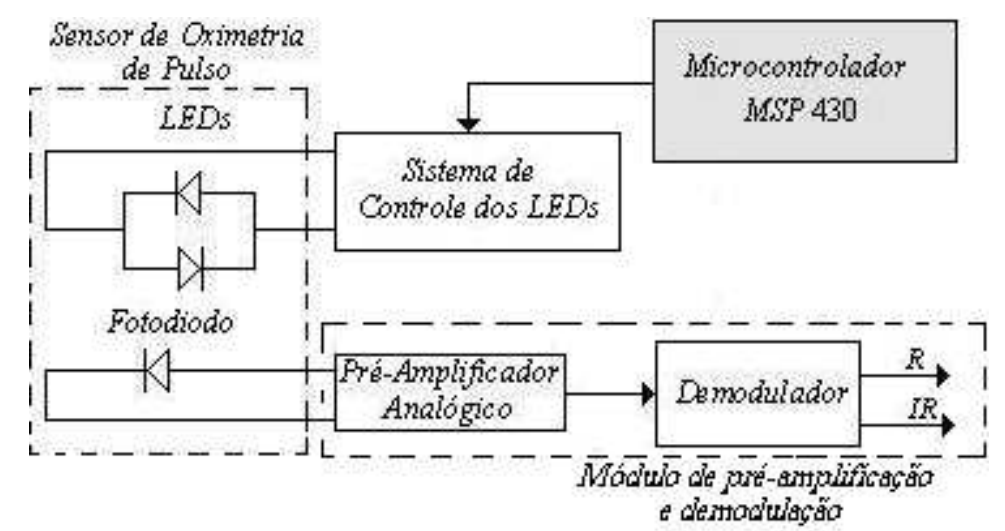

Figura 5.10 - Esquemático das conexões do módulo de pré-amplificação e demodulação.

Devido ao fato de que o fotodiodo gerar como saída um sinal de corrente, se torna necessária a utilização de um circuito de amplificação que converta tal sinal de corrente em um sinal de tensão, para que este possa ser usado pelo oxímetro de pulso. Amplificadores de transimpedância são circuitos lineares que se encaixam em tal situação, pois com um sinal de corrente em sua entrada, geram um sinal de tensão. Atualmente, tais circuitos são os mais utilizados como módulos de pré-amplificação em oxímetros comercializados.

Uma configuração de circuito de transimpedância pode ser vista na Figura 5.11. Em tal caso, a corrente gerada no fotodiodo é convertida em um sinal de tensão na saída do amplificador. Pelo "terra virtual", o amplificador operacional mantém uma tensão de $0 \mathrm{~V}$ nos terminais do fotodiodo. A corrente gerada pelo fotodiodo flui pelo resistor de realimentação, gerando uma tensão na saída que é proporcional à intensidade de luz.

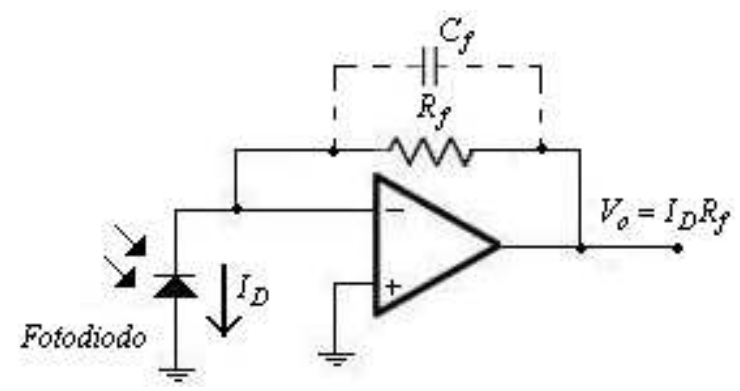

Figura 5.11 - Circuito típico de transimpedância com fotodiodo.

Um capacitor pode ser usado na realimentação do circuito, em paralelo com o resistor, como ilustrado na Figura 5.11. Tal dispositivo minimiza o ganho da função de transferência do circuito, mas diminui consideravelmente os ruídos. Um cuidado muito especial deve ser tomado na escolha do capacitor, pois ele pode afetar no processo de habilitação dos LEDs, introduzindo um filtro passa-baixa, onde não seja possível distinguir 
na saída do amplificador qual sinal é proveniente do LED vermelho e qual é proveniente do LED infravermelho.

Uma configuração mais elaborada de um circuito de transimpedância pode ser vista na Figura 5.12. Não fica difícil perceber que tal circuito possui dois módulos semelhantes ao mostrado na Figura 5.11. Porém, como neste caso a corrente produzida pelo fotodiodo atravessa cada um de tais módulos em sentidos opostos, a tensão na saída do módulo superior ( $\left.V_{o 1}\right)$ será o inverso da do módulo inferior $\left(V_{o 2}\right)$, como ilustrado.

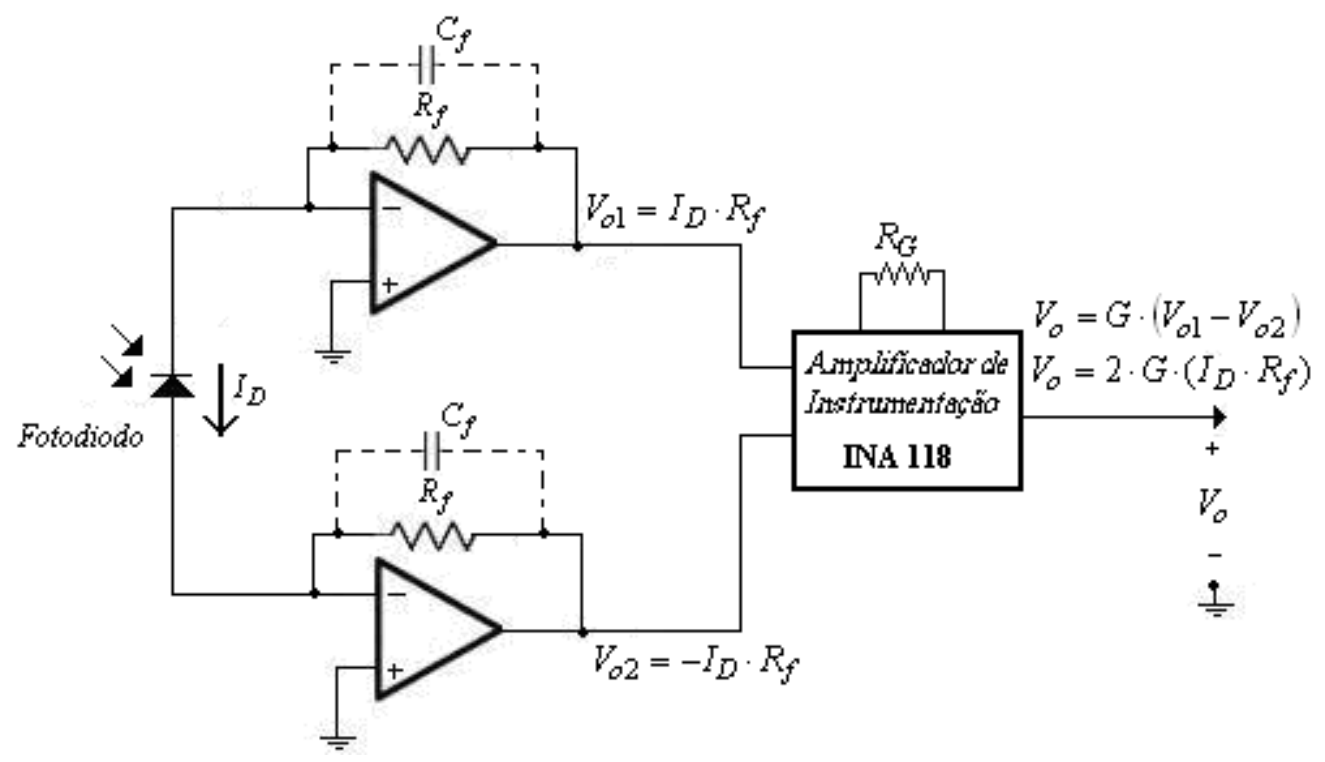

Figura 5.12 - Circuito de transimpedância com módulo diferencial.

Tais tensões são então introduzidas nas entradas de um amplificador de instrumentação INA 118, o qual possui características específicas de funcionamento que são controladas de acordo com o valor de resistência acoplado em seus terminais.

Tal dispositivo opera fazendo uma subtração dos dois sinais introduzidos nos seus terminais de entrada, que no presente caso são $V_{o 1}$ e $V_{o 2}$. Na tensão de saída $\left(V_{o}\right)$ pode ser dado um ganho ao resultado da subtração, como exemplificado na equação 5.1

$$
V_{o}=G \cdot\left(V_{o 1}-V_{o 2}\right)
$$

Tal ganho, como adiantado, varia de acordo com o valor de resistência que deve ser acoplado ao amplificador de instrumentação. A expressão matemática que ilustra a relação entre ganho e resistência pode ser observada na equação 5.2:

$$
G=1+\frac{50 k \Omega}{R_{G}}
$$


Na figura 5.13, pode ser visto um esquemático das ligações internas que compõem o amplificador de instrumentação INA118, bem como a atuação do resistor de acoplamento:
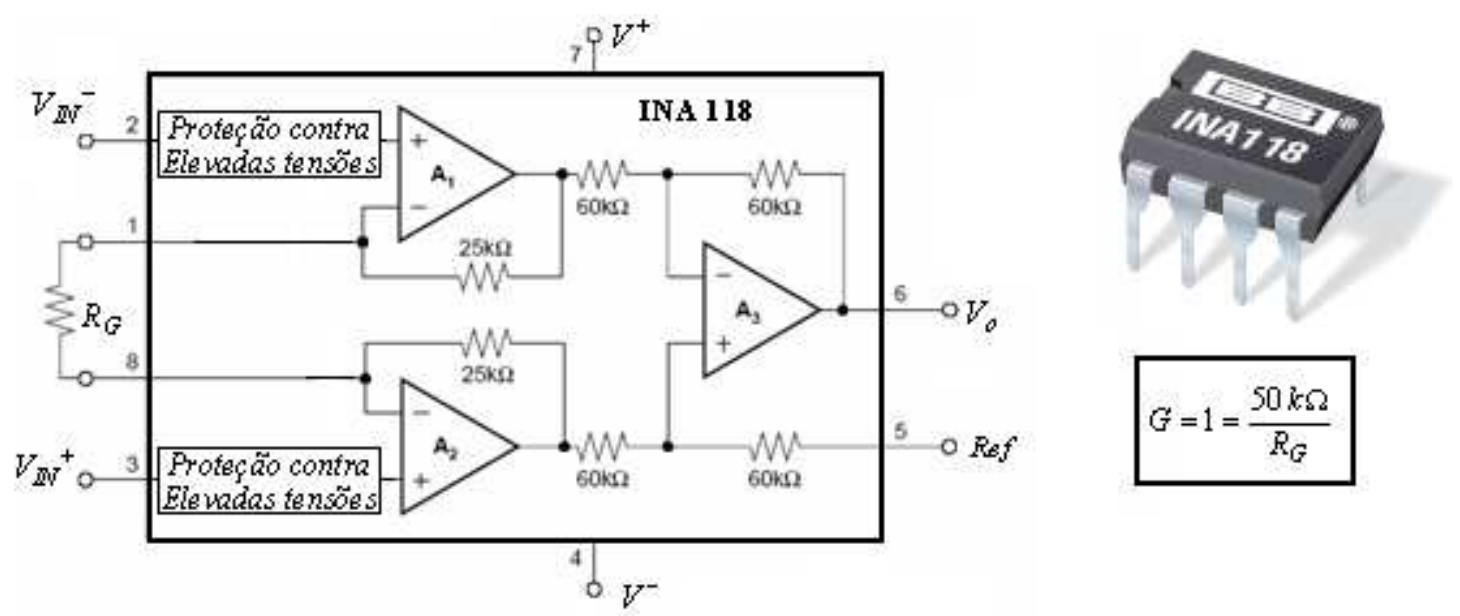

Figura 5.13 - O amplificador de instrumentação INA 118

Para a escolha dos valores que compõem o circuito da Figura 5.12, foram feitas análises matemáticas e experimentais de como cada componente afetaria o sinal captado pelo sensor de oximetria.

Com isso, percebeu-se que quanto maior o valor da resistência $R_{f}$, maior seria o ganho fornecido. Porém, tal aumento de ganho era acompanhado de um incremento de ruído associado ao sinal. Por isso, resolveu-se adotar um valor intermediário de $R_{f}=100 \mathrm{k} \Omega$, pois tanto o ganho quanto a influência de ruído foram considerados satisfatórios para o bom funcionamento do sistema.

Outro comportamento analisado foi como o valor da capacitância $C_{f}$ afetaria o sinal. Percebeu-se que para valores da ordem de $0,01 \mu F$ ou superiores, a impedância resultante da ligação em paralelo de $R_{f}$ e $C_{f}$ atuava como um filtro passa-baixa que afetava todo o sinal de recepção. Como o sinal captado no módulo de transimpedância é um composto resultante do processo de acionamento dos LEDs vermelho e infravermelho, deve-se tomar um cuidado crítico na escolha do valor de tal capacitância, para que esta não misture as informações provenientes da ligação de cada LED em separado.

Tal observação pode ser constatada na Figura 5.14, a qual ilustra dois 
comportamentos distintos de acordo com o chaveamento seletivo dos LEDs.

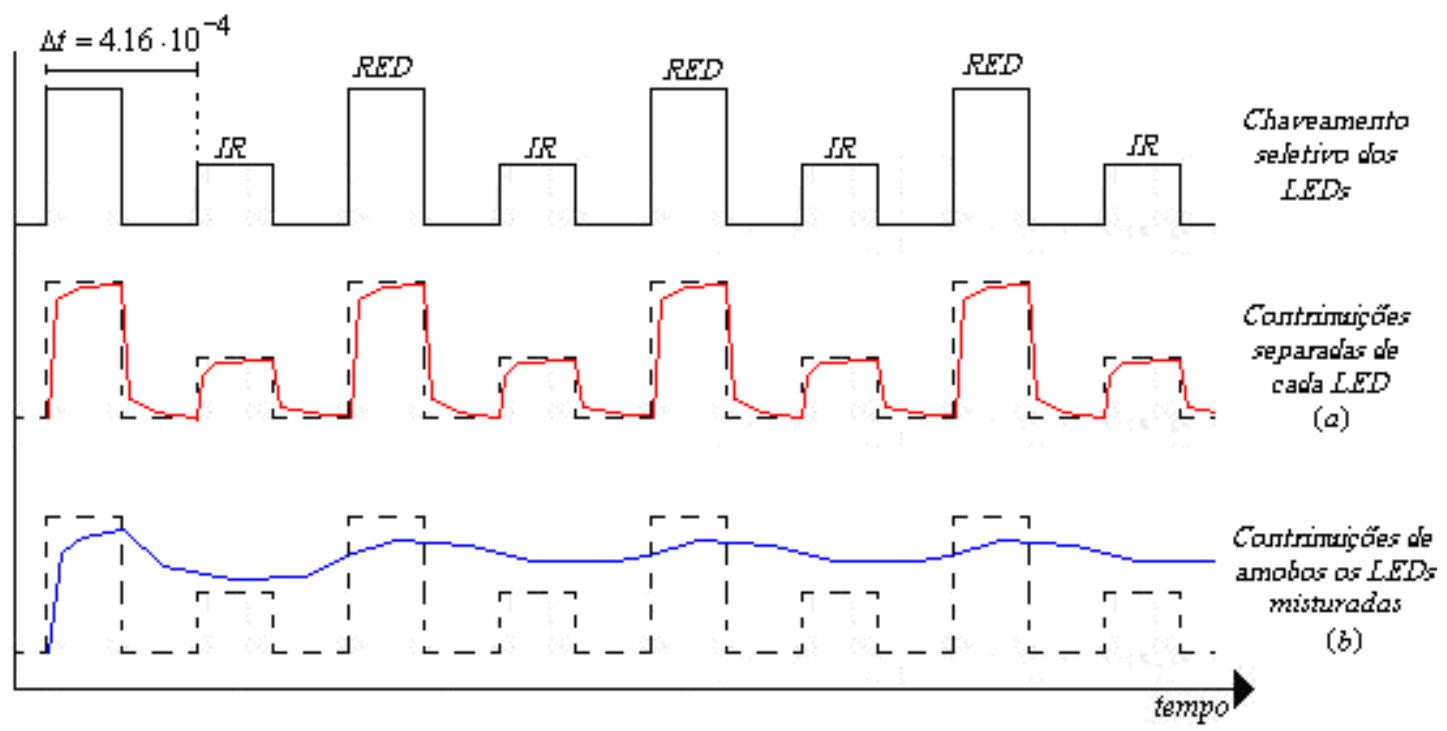

Figura 5.14 - Eleito da escolha da capacitância $C_{f}$ na recepção do sinal.

No primeiro caso (“a”), fica fácil observar que o sinal possui um tempo de subida relativamente curto, o que facilita a detecção da contribuição em separado de cada um dos LEDs. Já no segundo caso ("b”), é possível perceber uma situação hipotética de como o capacitor afetaria a capacidade do módulo de transimpedância de acompanhar o chaveamento seletivo. Em tal caso, devido ao alto tempo de subida, o sinal de saída acaba misturando as informações provenientes dos LEDs vermelho e infravermelho. Por isso, tal comportamento se torna indesejável para o bom funcionamento do sistema de recepção.

Sendo assim, o valor de capacitância $C_{f}$ é determinado através do tempo de subida do filtro associado à impedância resultante da ligação em paralelo com $R_{f}$. Tal valor deve ser relativamente superior à freqüência dos pulsos do chaveamento seletivo ( $f=2,4 \mathrm{kHz}$ e $\left.\Delta t=4,16 \cdot 10^{-4}\right)$. A partir de tal constatação, escolheu-se como valor de capacitância $C_{f}=220 p F$, o qual gera como constante de tempo:

$$
\tau_{\text {subida }}=R_{f} \cdot C_{f} \rightarrow \tau_{\text {subida }}=22 \mu s
$$

A freqüência de corte associada a tal tempo de subida pode ser calculada de acordo com o ilustrado na equação 5.4:

$$
\begin{gathered}
f_{c}=\frac{1}{2 \pi \cdot\left(R_{f} \cdot C_{f}\right)} \rightarrow f_{c}=\frac{1}{2 \pi \cdot\left(22 \cdot 10^{-6}\right)} \\
f_{c}=7,23 \mathrm{kHz}
\end{gathered}
$$


Por último, o valor da resistência $R_{G}$ acoplada ao amplificador de instrumentação foi escolhido para $R_{G}=2,2 \mathrm{k} \Omega$. Com isso, o ganho fornecido pelo INA118 ao sinal resultante pode ser analisado de acordo com a equação 5.6:

$$
G=1+\frac{50 \mathrm{k} \Omega}{R_{G}} \rightarrow G=23,72 \mathrm{~V} / \mathrm{V}
$$

Outra parte importante do presente módulo se refere à demodulação do sinal, onde se separam as ondas de acordo com o LED em operação. Em tal parte, foi utilizado um sistema de chaveamento, da mesma forma do que foi implementado no sistema de controle dos LEDs.

Tal módulo de demodulação trabalha abrindo e fechando chaves analógicas (HCC4066), as quais podem ser vistas na Figura 5.15. Para o controle de tais chaves, foram utilizados os sinais provenientes do sistema de geração de sinais de controle: Sinall e Sinal2 (seção 5.1).
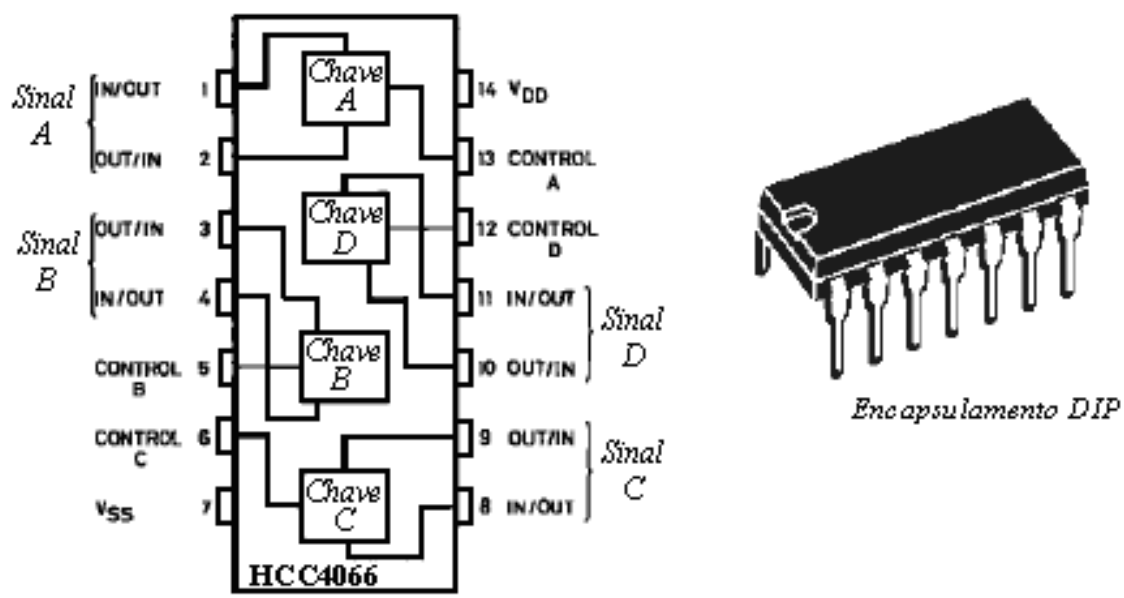

Figura 5.15 - Chaves digitais para transmissão e multiplexação de sinais analógicos e digitais

Terminada a separação de sinais, eles serão tratados de forma diferentes, com filtros, amplificadores e processamentos específicos. Tais sinais serão então enviados à dois filtros passa-baixa de Butterworth de segunda ordem, com freqüência de corte de $24 \mathrm{~Hz}$, os quais serão melhor abordados na seção 5.4.2.

\subsection{2 - Filtro passa-baixa com freqüência de corte de $24 \mathrm{~Hz}$}

Um segundo módulo do sistema de recepção se refere à filtragem dos sinais 
vermelho e infravermelho, os quais foram separados pelo módulo de demodulação. Tal filtragem se torna necessária para a diminuição dos ruídos associados ao processo de captação do sinal, bem como a redução dos efeitos da componente de frequiência proveniente da rede elétrica $(60 \mathrm{~Hz})$ e diminuição dos efeitos do processo de chaveamento realizado durante a demodulação do sinal.

Para a implementação de tal filtro, foi feita uma avaliação do sinal e das componentes mais significativas para a sua reconstrução. Sendo assim, constatou-se que a banda do sinal ficava concentrada na faixa entre o valor de $0,3 \mathrm{~Hz}$ e $16 \mathrm{~Hz}$. Sendo assim, foi implementado um filtro do tipo Sallen-Key, de segunda ordem com freqüência de corte de $24 \mathrm{~Hz}$. A configuração de tal circuito pode ser vista na Figura 5.16, ilustrada abaixo:

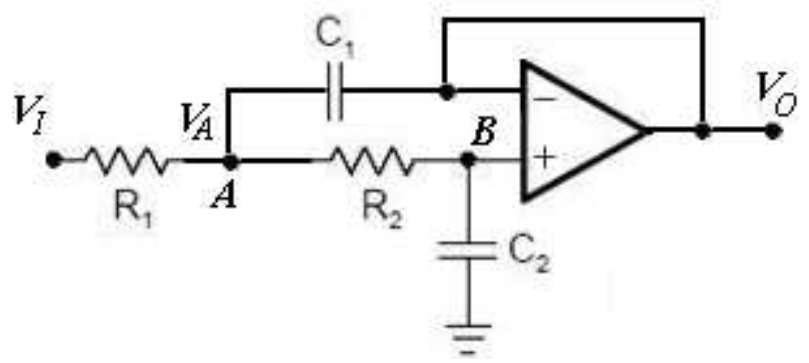

Figura 5.16 - Configuração de Filtro passa-baixa de segunda ordem, tipo Sallen-Key

A resolução da função de transferência deste filtro pode ser feita pela soma das correntes que estão chegando e das correntes que estão saindo (Lei de Kirchhoff) em cada um dos nós especificados na Figura 5.16 (nós A e B). Para ambos os casos, tais correntes podem ser especificadas de acordo com as equações 5.7 e 5.8 do sistema abaixo:

$$
\left\{\begin{array}{l}
\text { Para o nó } A \rightarrow i_{R 1}=i_{R 2}+i_{C 1} \\
\text { Para o nó } B \rightarrow i_{R 2}=i_{C 2}
\end{array}\right.
$$

No desenvolvimento de tais equações deve-se levar em consideração que a entrada inversora está conectada à saída do amplificador operacional. Com isso, devido ao "terra virtual", a entrada não inversora, e consequentemente o nó $\mathrm{B}$, também se encontram na mesma tensão de saída do amplificador. Sendo assim, foram encontradas as equações 5.9 e 5.10, mostradas abaixo: 


$$
\left\{\begin{array}{l}
\text { Para onó } A \rightarrow \frac{V_{i}-V_{A}}{R_{1}}=\frac{V_{A}-V_{O}}{\frac{1}{j \omega C_{1}}}+\frac{V_{A}-V_{O}}{R_{2}} \\
\text { Para o nó } B \rightarrow \frac{V_{A}-V_{O}}{R_{2}}=\frac{\frac{V_{O}}{\frac{1}{j \omega C_{2}}}}{}
\end{array}\right.
$$

Isolando-se a variável $V_{A}$ presente na equação do nó $\mathrm{B}$, chegamos às seguintes resoluções demonstradas abaixo:

$$
\begin{aligned}
& \frac{V_{A}-V_{O}}{R_{2}}=\frac{V_{O}}{\frac{1}{j \omega C_{2}}} \rightarrow \frac{V_{A}-V_{O}}{R_{2}}=(j \omega) \cdot V_{O} C_{2} \\
& V_{A}=V_{O}\left(1+s \cdot V_{O} \cdot C_{2} \cdot R_{2}\right)
\end{aligned}
$$

Substituindo o resultado da equação 5.12 na equação 5.9 referente ao nó A, encontramos uma função de transferência que estabelece a relação existente entre a entrada e a saída do filtro de Sallen-Key. Sendo assim:

$$
\begin{gathered}
\frac{V_{i}-V_{A}}{R_{1}}=\frac{V_{A}-V_{O}}{\frac{1}{s \cdot C_{1}}}+\frac{V_{A}-V_{O}}{R_{2}} \\
\frac{V_{i}-V_{O}\left(1+s \cdot V_{O} C_{2} R_{2}\right)}{R_{1}}=\frac{V_{O}\left(1+s \cdot V_{O} C_{2} R_{2}\right)-V_{O}}{\frac{1}{s \cdot C_{1}}}+\frac{V_{O}\left(1+s \cdot V_{O} C_{2} R_{2}\right)-V_{O}}{R_{2}} \\
A(s)=\frac{V_{O}(s)}{V_{I}(s)}=\frac{1}{s^{2} \cdot\left(R_{1} \cdot R_{2} \cdot C_{1} \cdot C_{2}\right)+s \cdot C_{2}\left(R_{2}+R_{1}\right)+1}
\end{gathered}
$$

Para o cálculo dos valores de cada componente do circuito, é necessário saber quais as posições das raízes no plano complexo da função de transferência ilustrada na equação 5.15. Visando dar maior estabilidade ao circuito, foi implementado um filtro passa-baixa de Butterworth de segunda ordem. Tal filtro é bastante comum em aplicações onde se deseja obter uma queda eficiente fora dos limites da banda do sinal, sem ocasionar um sobre-sinal nas proximidades da freqüência de corte.

Para obter tal resposta, os pólos da função de transferência devem ser organizados 
em ângulos com espaçamento igual ao redor de uma região semicircular. Um exemplo pode ser visto na Figura 5.17, o qual ilustra o caso de um filtro de Butterworth de quarta ordem e a resposta de sua respectiva função complexa. O módulo de tais pólos é dado de acordo com a freqüência de corte do filtro (Módulo $\rightarrow \omega_{C}=2 \pi \cdot f_{C}$ ).
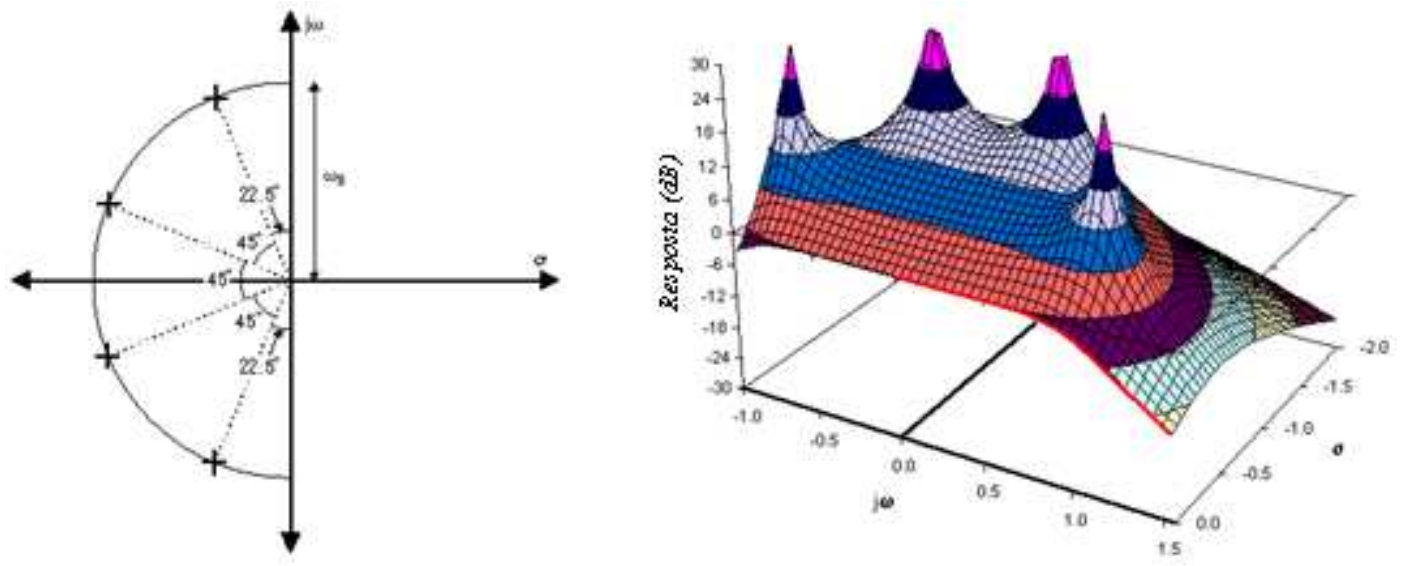

Figura 5.17 - Diagrama de pólos e zeros de um filtro de Butterworth de quarta ordem e a resposta da sua respectiva função complexa.

Como o filtro em estudo é de segunda ordem, o módulo e a posição dos pólos da função de transferência podem ser vistos na Figura 5.18, ilustrada abaixo:

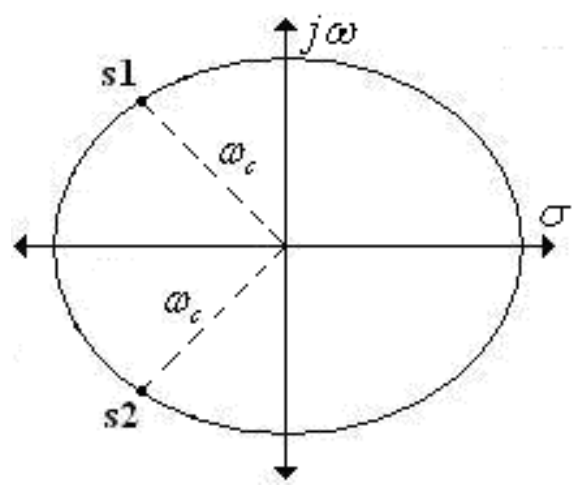

$$
\omega_{C}=2 \pi \cdot(24 \mathrm{~Hz}) \rightarrow \omega_{C}=150,796
$$

$$
\left\{\begin{array}{l}
s_{1}=150,796135^{\circ} \\
s_{2}=150,796 \lcm{225^{\circ}}
\end{array}\right.
$$

Figura 5.18 - Localização dos pólos do filtro de Butterworth de quarta ordem, frequiência de corte de $24 \mathrm{~Hz}$.

Com tal informação, é possível calcular uma função de transferência desejada, utilizando os dois pólos encontrados. Sendo assim:

$$
\begin{gathered}
A^{\prime}(s)=\frac{G}{\left(s-s_{1}\right) \cdot\left(s-s_{2}\right)} \\
A^{\prime}(s)=\frac{1}{[s-(-106,62+106,62 j)] \cdot[s-(-106,62-106,62 j)]}
\end{gathered}
$$




$$
A^{\prime}(s)=\frac{1}{s^{2}+213,25 \cdot s+22739,43} \rightarrow A^{\prime}(s)=\frac{1 / 22739,43}{1+\frac{213,25}{22739,43} \cdot s+\frac{1}{22739,43} \cdot s^{2}}
$$

Fazendo uma comparação entre os denominadores das equações 5.18 e 5.15, encontramos o seguinte sistema:

$$
\left\{\begin{array}{l}
C_{2} \cdot\left(R_{1}+R_{2}\right)=\frac{213.25}{22739,43} \\
R_{1} \cdot R_{2} \cdot C_{1} \cdot C_{2}=\frac{1}{22739,43}
\end{array}\right.
$$

Isolando a variável $R_{1}$ na segunda equação do sistema e a substituindo na primeira equação, temos:

$$
\begin{gathered}
R_{1}=\frac{1}{22739,43 \cdot R_{2} \cdot C_{1} \cdot C_{2}} \\
C_{2} \cdot\left[\frac{1}{22739,43 \cdot R_{2} \cdot C_{1} \cdot C_{2}}+R_{2}\right]=\frac{213,25}{22739,43}
\end{gathered}
$$

Com isso, é possível construir uma equação de segundo grau com a variável $R_{2}$. Tal equação é ilustrada abaixo:

$$
\begin{gathered}
\frac{1}{22739,43 \cdot R_{2} \cdot C_{1}}+C_{2} \cdot R_{2}=\frac{213,25}{22739,43} \\
1+22739,43 \cdot C_{1} \cdot C_{2} \cdot\left(R_{2}\right)^{2}=213,25 \cdot R_{2} \cdot C_{1} \\
22739,43 \cdot C_{1} \cdot C_{2} \cdot\left[R_{2}\right]^{2}-213,25 \cdot C_{1} \cdot\left[R_{2}\right]+1=0
\end{gathered}
$$

Como o valor da resistência $R_{2}$ deve ser um valor real e positivo, deve-se fazer uma condição para que a equação acima não forneça valores complexos. Para isso, considerando a forma genérica de equação de segundo grau $a x^{2}+b x+c=0$, onde $x=\left[R_{2}\right], a=22739,43 \cdot C_{1} \cdot C_{2}, b=-213,25 \cdot C_{1}$ e $c=1$, tem-se a seguinte condição:

$$
\begin{gathered}
b^{2}-4 a c>0 \\
\left(-213,25 \cdot C_{1}\right)^{2}-4 \cdot 22739,43 \cdot C_{1} \cdot C_{2}>0 \\
\left(-213,25 \cdot C_{1}\right)^{2}>+4 \cdot 22739,43 \cdot C_{1} \cdot C_{2} \\
\left(C_{1}\right)>\frac{4 \cdot 22739,43 \cdot C_{2}}{45475,56} \\
C_{1}>2 \cdot C_{2}
\end{gathered}
$$


Através de uma tabela de capacitores vendidos comercialmente, foram escolhidos os seguintes valores para $C_{1}$ e $C_{2}$ :

$$
\left\{\begin{array}{l}
C_{1}=680 \eta F \\
C_{2}=100 \eta F
\end{array}\right.
$$

Substituindo os valores encontrados acima no sistema de equações 5.19, temos o seguinte resultado:

$$
\left\{\begin{array}{l}
R_{1}+R_{2}=93779,83 \\
R_{1} \cdot R_{2}=6,467 \cdot 10^{8}
\end{array}\right.
$$

Isolando a variável $R_{1}$ na segunda equação do sistema e substituindo na primeira, encontra-se a seguinte equação de segundo grau:

$$
\begin{gathered}
R_{1}=\frac{6,467 \cdot 10^{8}}{R_{2}} \\
\left(R_{2}\right)^{2}-93779,83 R_{2}+6,467 \cdot 10^{8}=0
\end{gathered}
$$

Através da resolução da equação 5.32, e substituindo o valor encontrado no sistema 5.30, encontrou-se os seguintes valores teóricos para os resistores $R_{1}$ e $R_{2}$ :

$$
\left\{\begin{array}{l}
R_{1}=7,49 \mathrm{k} \Omega \\
R_{2}=86,28 \mathrm{k} \Omega
\end{array}\right.
$$

Com uma tabela de resistores vendidos comercialmente, os valores escolhidos para os resistores $R_{1}$ e $R_{2}$ foram:

$$
\left\{\begin{array}{l}
R_{1}=6,8 \mathrm{k} \Omega \\
R_{2}=100 \mathrm{k} \Omega
\end{array}\right.
$$

Sendo assim, com a substituição dos valores encontrados para cada um dos dispositivos na equação 5.15, encontramos a função de transferência do filtro implementado, como ilustrado abaixo:

$$
A(s)=\frac{V_{O}(s)}{V_{I}(s)}=\frac{1}{4,624 \cdot 10^{5} \cdot s^{2}+0,1068 \cdot s+1}
$$

O diagrama de Bode correspondente à equação 5.33 encontrada pode ser visto na 
Figura 5.19 (Diagrama de Bode do filtro passa-baixa de Butterworth implementado, com freqüência de corte de $24 \mathrm{~Hz}$ ), ilustrada abaixo. Como $\omega_{c}=2 \pi \cdot f_{c}=150,79 \mathrm{rad} / \mathrm{seg}$, pode-se perceber que a freqüência de corte do filtro $(-3 d B)$ ficou ligeiramente abaixo do projetado, porém sem afetar a banda do sinal. Outro fator que pode ser observado é a queda de $40 \mathrm{~dB} /$ década, o que é esperado para um filtro de segunda ordem.

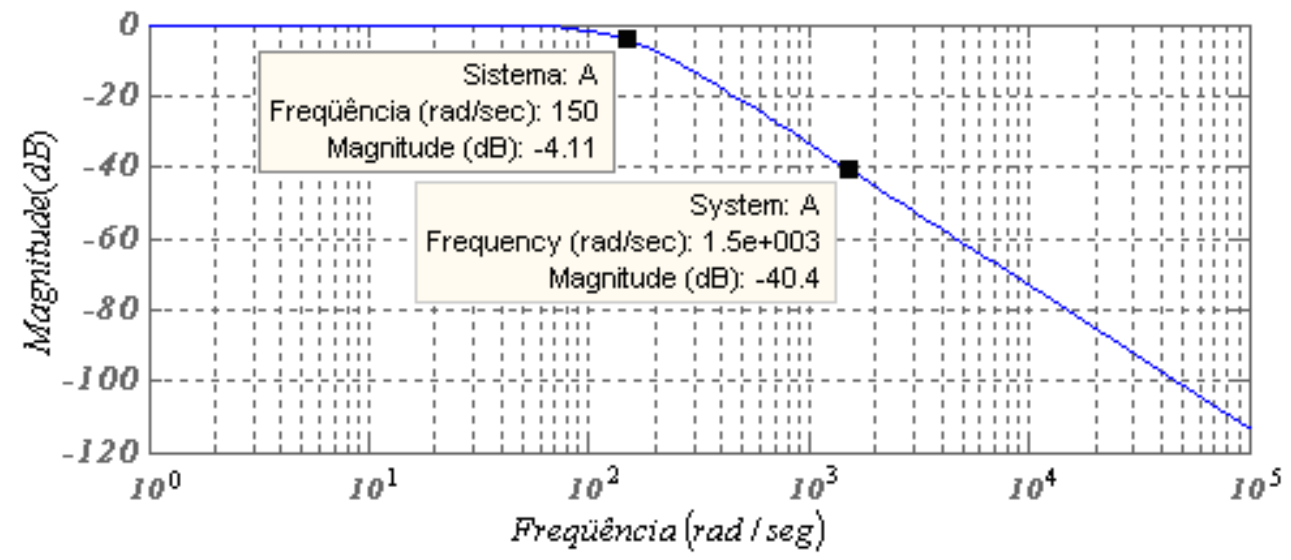

Figura 5.19 - Diagrama de Bode do filtro passa-baixa de Butterworth implementado, com freqüência de corte de $24 \mathrm{~Hz}$.

\subsection{3 - Módulo de adequação do sinal à faixa dinâmica de conversão}

O último módulo pertencente ao sistema de recepção é responsável pela adequação do sinal aos limites do conversor analógico-digital do microcontrolador (seção 4.4). Um esquemático de tal módulo pode ser visto na Figura 5.20, ilustrada abaixo.

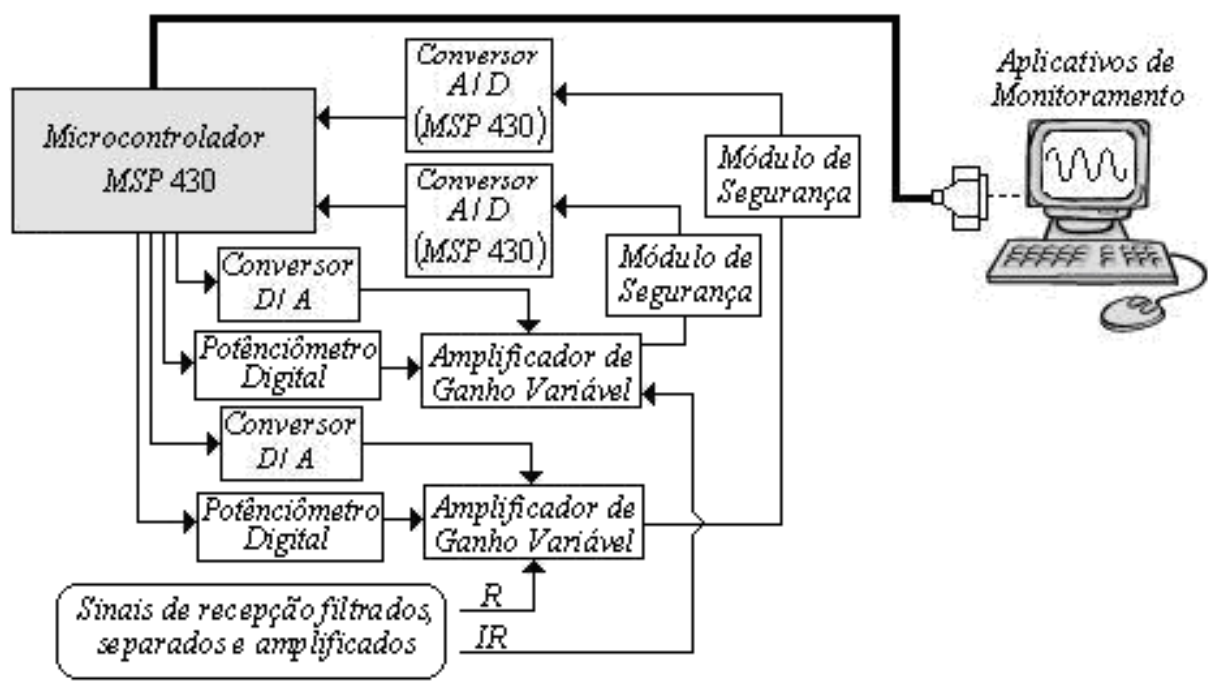

Figura 5.20 - Diagrama de blocos do módulo de adequação do sinal à faixa dinâmica de conversão

Como explicado nas seções anteriores do presente capítulo, o sinal gerado pelo fotodiodo é amplificado, separado de acordo com o LED em operação e em seguida 
filtrado para eliminar os ruídos associados ao processo de captação do sinal e do chaveamento.

Em tal estágio, os dados já possuem uma qualidade razoável. Porém, algumas providências devem ser tomadas antes de enviá-los ao conversor analógico-digital. Como explicado anteriormente, tal conversor possui um limite inferior e outro limite superior de tensão. Caso o valor de tensão extrapole tais limites, pode vir a queimar o canal de conversão. Em casos mais extremos, tal situação pode danificar outras partes do microcontrolador.

Por isso, o primeiro passo foi o desenvolvimento de um módulo que limite a tensão na entrada do ADC12, como ilustrado na Figura 5.21 (b), onde é possível perceber uma faixa linear de operação entre o valor de $0 \mathrm{~V}$ e uma tensão limite, que no caso no MSP430 é de $3.3 \mathrm{~V}$. Para valores abaixo de $0 \mathrm{~V}$, a saída do circuito deve ser ceifada em $0 \mathrm{~V}$. O mesmo ocorre para valores de tensão superiores à tensão limite, onde a tensão de saída será igual a tal tensão limite. Sendo assim, para cada uma das entradas do conversor analógico digital utilizadas, foi implementado um circuito seguidor de tensão, como ilustrado na Figura 5.21 (c).

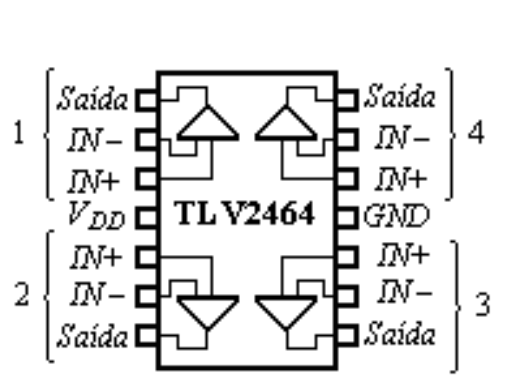

$(a)$

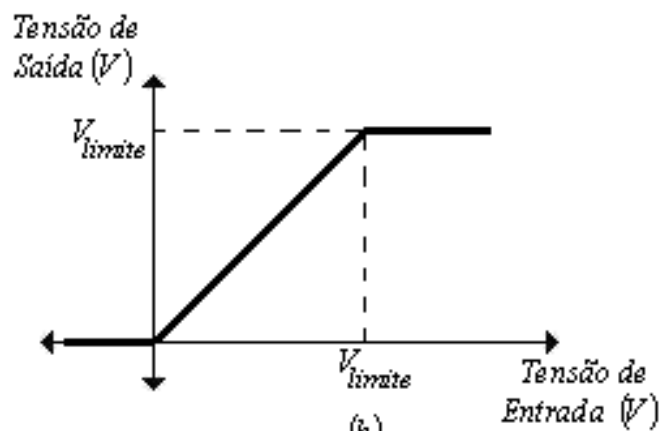

(b)

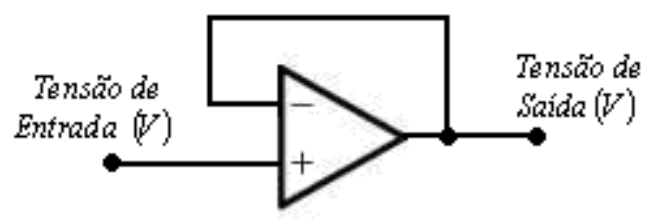

(c)

Figura 5.21 - a) Amplificador operacional TLV2464; b) Resposta do circuito seguidor de tensão; c) Circuito seguidor de tensão.

Para tal caso, não foi possível utilizar um amplificador operacional convencional (741), pois este necessita de uma alimentação simétrica para um funcionamento adequado. Tal situação foi solucionada usando um amplificador operacional da família TLV2464, os quais não possuem tal necessidade, Figura 5.21 (a). 
Com isso, alimentando o circuito seguidor de tensão com os valores limites estabelecidos para o conversor analógico digital $\left(G N D=0 \mathrm{~V}\right.$ e $\left.V_{D D}=3.3 \mathrm{~V}\right)$, garante-se que a tensão será ceifada caso extrapole tais limites, da mesma forma como o comportamento desejado, ilustrado na Figura 5.21 (b).

Uma segunda parte pertencente ao presente módulo de adequação do sinal se refere aos ganhos finais que serão dados ao sinal de oximetria. Isso é feito com o intuito de adequar à faixa de operação, dando uma resolução melhor e adequando aos limites de tensão estabelecidos para o conversor analógico digital. Tal operação pode ser melhor visualizada na Figura 5.22, ilustrada abaixo.

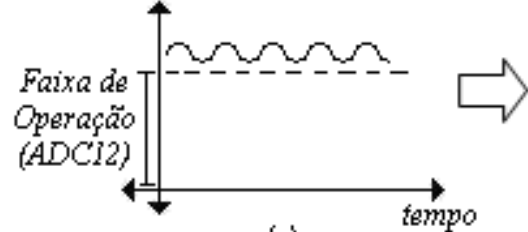

(a)

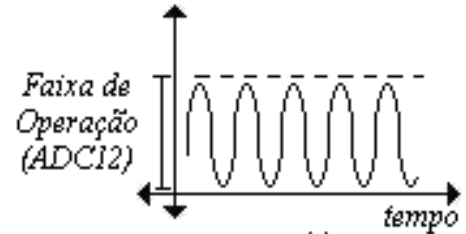

(b)

Figura 5.22 - Adequação do sinal de oximetria à faixa de conversão.

Mesmo depois de o sinal ter passado pelo módulo de pré-amplificação (seção 5.4.1), ao chegar ao presente módulo ele se encontra na ordem de milivolt $[m V]$. Dependendo da situação, o sinal pode inclusive se encontrar fora da faixa de operação do ADC12, como ilustrado na Figura 5.21 (a).

Para resolver tal problema, foi implementado um circuito utilizando um amplificador de instrumentação (INA118), um conversor digital analógico (TLV5620C) e um potenciômetro digital (MCP41010), de acordo com as ligações mostradas na Figura 5.23 , ilustrada abaixo.

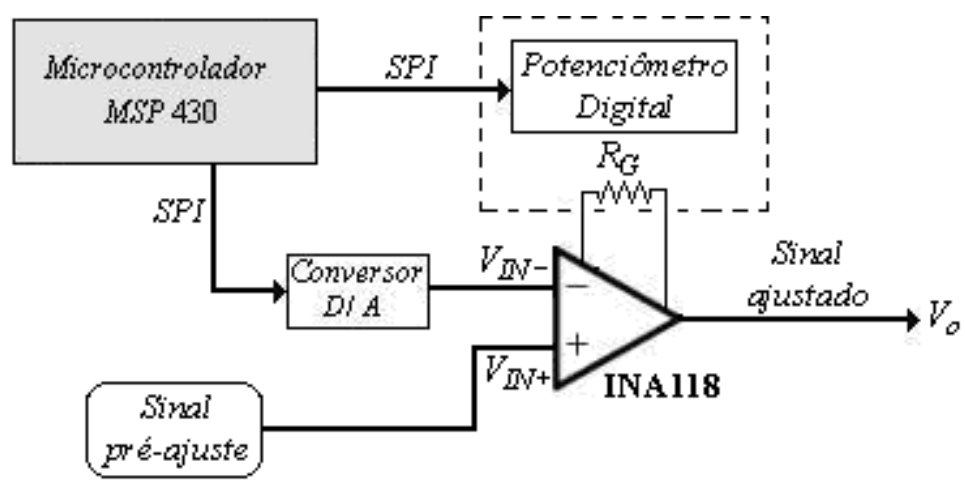

Figura 5.23 - Circuito de ajuste final do sinal de oximetria 
O microcontrolador MSP 430, como explicado na seção 4.7.4, faz uma análise do sinal recebido através do conversor analógico digital. A cada dois segundos ele avalia a necessidade de realizar ajustes no ganho do amplificador de instrumentação pela variação da resistência do potenciômetro digital. Já no caso que se refere ao conversor D/A, seu valor de saída é reajustado cada vez que o sinal de entrada extrapole os limites máximo e mínimo pré-estabelecidos.

Como explicado anteriormente, o amplificador de instrumentação opera fazendo uma subtração dos dois sinais presentes nos terminais de entrada $\left(V_{I N+}\right.$ e $\left.V_{I N-}\right)$. Na tensão de saída $\left(V_{o}\right)$ é dado um ganho ao resultado da subtração, o qual depende do valor de resistência $\left(R_{G}\right)$ acoplado ao amplificador de instrumentação. A resolução matemática de tal comportamento é explicada nas equações 5.34 e 5.35:

$$
\begin{gathered}
V_{o}=G \cdot\left(V_{I N+}-V_{I N-}\right) \\
G=1+\frac{50 k \Omega}{R_{G}}
\end{gathered}
$$

Tal propriedade do amplificador de instrumentação é utilizada pelo microcontrolador no módulo de ajuste. Caso o MSP 430 avalie que seja necessário diminuir ou aumentar o valor DC do sinal, ele atua no conversor analógico digital, enviando dados através de comunicação serial síncrona SPI. O conversor D/A, por conseguinte, aumenta ou diminui respectivamente o valor na entrada inversora do amplificador de instrumentação, de acordo com o valor DC que se queira tirar ou acrescentar ao sinal.

Outra operação que pode ser efetuada com o auxílio do INA118 é o fornecimento de ganho ao sinal. Tal fato é controlado pelo microcontrolador através de um potenciômetro digital. Como visto na equação 5.35, o ganho fornecido na saída varia de acordo com o valor de resistência acoplado no amplificador. Sendo assim, o microcontrolador envia os dados através de protocolo SPI para o potenciômetro, que ajusta a resistência, e conseqüentemente o ganho fornecido ao sinal de oximetria.

O potenciômetro digital possui 256 diferentes valores de resistência, os quais variam de $0 \mathrm{k} \Omega$ a um valor máximo de $10 \mathrm{k} \Omega$. Com o auxílio da equação 5.35, fica fácil perceber que o ganho mínimo fornecido pelo circuito da Figura 5.23 é de $G=6[V / V]$. 


\section{5 - APLICATIVOS DE MONITORAMENTO}

Uma importante parte da plataforma de aquisição e processamento de sinais de oximetria de pulso desenvolvida se refere aos aplicativos de monitoramento que formam implementados.

A parte que compreende todos os sistemas em conjunto com o microcontrolador MSP 430 é responsável pela geração, controle e recepção do sinal obtido através do sensor de oximetria. Todo o conteúdo captado é então enviado por porta serial para um microcomputador, onde é possível fazer uma análise gráfica do sinal, bem como o armazenamento de todos os dados recebidos.

\subsection{1 - Protocolo de comunicação serial para a comunicação entre MSP430 e microconputador}

Como adiantado na seção 4.6.1, o protocolo de comunicação serial assíncrono foi utilizado para o envio dos dados colhidos pelo sistema de recepção para os aplicativos de monitoramento localizados no computador.

Para que estes dados possam ser interpretados corretamente pelos aplicativos, algumas configurações devem ser realizadas. Primeiramente, o sinal fornecido pelo microcontrolador deve ser convertido para o padrão RS232. Para isto, foi implementado o circuito ilustrado na Figura 5.24, onde é possível perceber o sentido de envio de dados e a distribuição da alimentação e dos capacitores que são necessários ao bom funcionamento do circuito. 


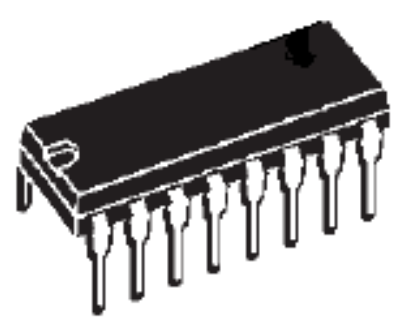

Encapsulamento DIP

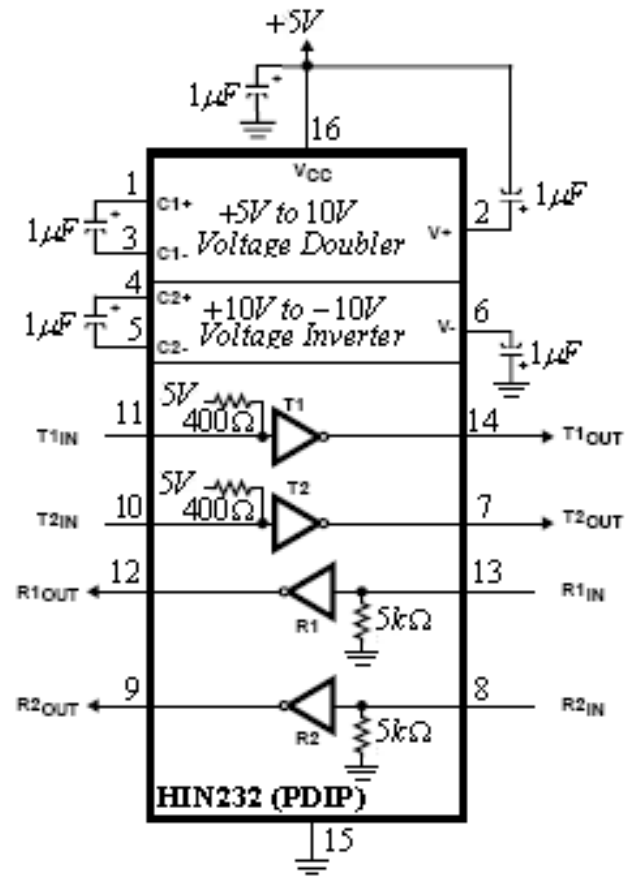

Figura 5.24 - Ilustração do circuito montado com o MAX232 para a comunicação serial assíncrona entre o MSP430 e o microcomputador.

Outras configurações pertinentes se referem a padronização da taxa de transmissão, a qual deve ser ajustada tanto na programação do MSP (a qual foi abordada na seção 4.7.2), quanto no aplicativo. Para tal, foi desenvolvida uma interface gráfica (seção 5.5.2) que possibilita a realização das modificações pertinentes.

\subsection{2 - Interface gráfica do aplicativo}

$\mathrm{O}$ aplicativo desenvolvido possui uma interface gráfica que possibilita um acesso de forma fácil aos principais comandos disponíveis para aquisição de dados e armazenamento. A figura 5.24 traz uma ilustração do protótipo que foi implementado. Na tela principal é possível acompanhar a recepção dos dados de forma gráfica ou através de valores numéricos discretos, os quais são os resultados finais do processo de conversão analógico-digital. 


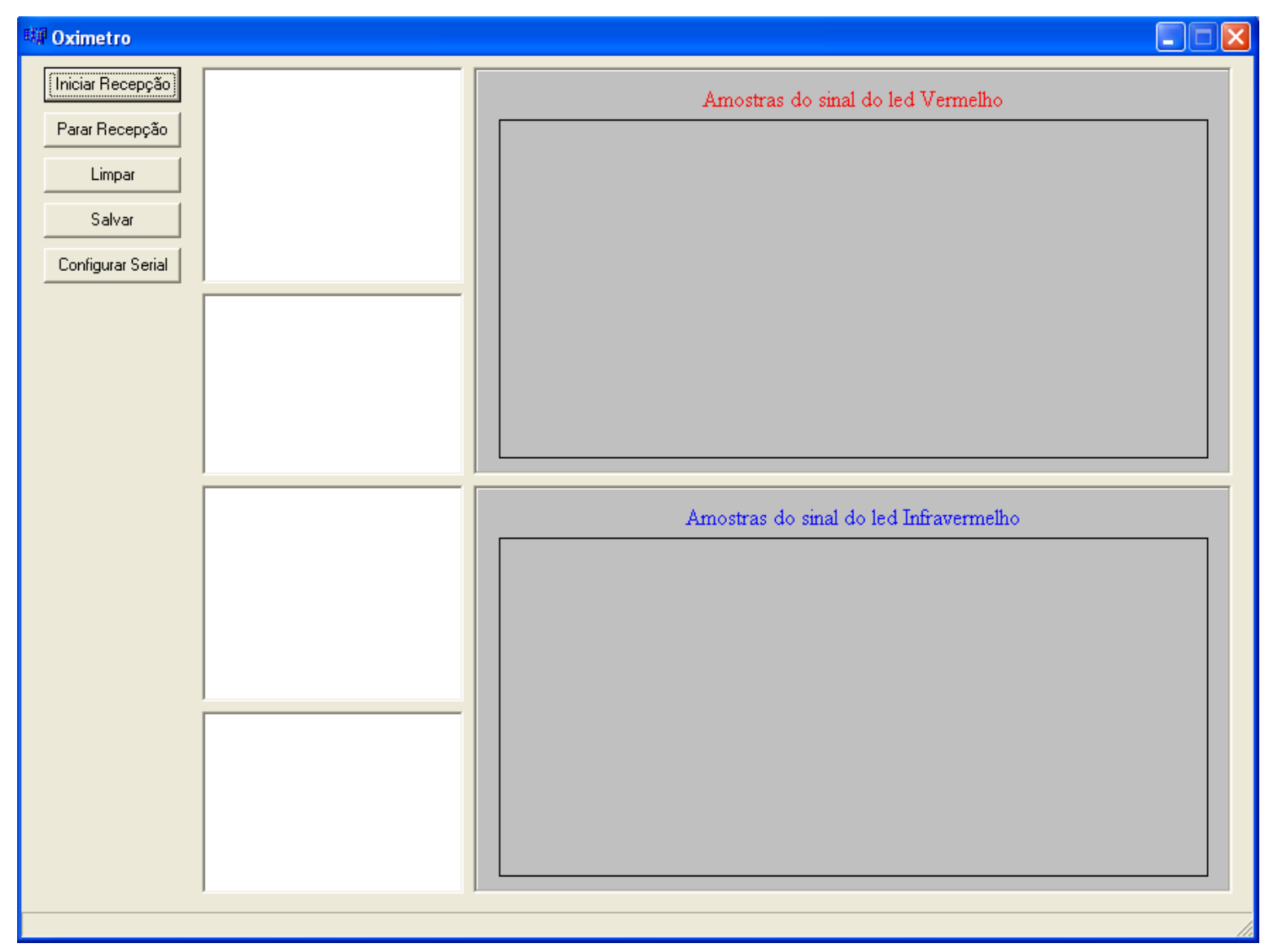

Figura 5.25 - Ilustração do aplicativo de monitoramento desenvolvido.

No lado esquerdo da tela do aplicativo de monitoramento, são encontrados cinco botões que controlam a operação realizada pelo programa. O primeiro deles, "Iniciar Recepção", como o próprio nome adianta, é responsável pelo início da comunicação com o microcontrolador MSP 430, que enviará dados através de protocolo de comunicação serial, a qual pode ser configurada no botão "Configurar Serial”. A figura 5.26 ilustra a janela que é aberta para a realização das modificações que podem ser realizadas em tal comunicação, como a escolha da porta serial utilizada, a taxa de transmissão, número de bits da palavra, tipo de paridade, dentre outros. Os outros três botões são responsáveis por parar a recepção de dados ("Parar Recepção"), armazenar os dados colhidos ("Salvar") e por fim limpar a tela principal com a visualização gráfica que estava sendo realizada (“Limpar”). Vale ressaltar que todos os dados colhidos são perdidos caso se limpe a tela sem que tenha sido realizado um armazenamento prévio. 


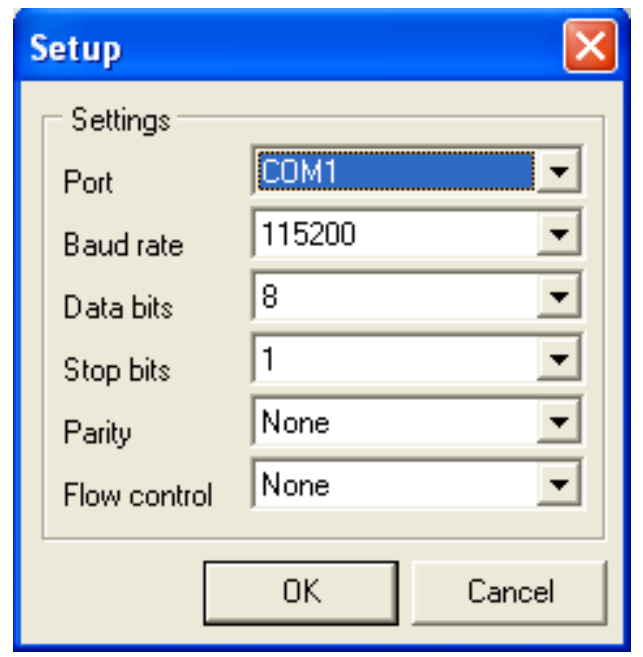

Figura 5.26 - Janela do aplicativo para a configuração da porta serial

\subsection{3 - Versão comercial de aplicativo de monitoramento}

Um segundo modelo de aplicativo de monitoramento foi desenvolvido com o intuito de ser utilizado em aplicações comerciais. Este modelo, assim como no protótipo exemplificado na seção 5.5.2, permite uma visualização gráfica do sinal infravermelho ao decorrer do tempo.

Algumas implementações extras foram adicionadas, como a possibilidade de se monitorar a taxa de saturação do sangue arterial através de valores numéricos, bem como o monitoramento dos batimentos cardíacos por minuto (BPM) de um determinado paciente. Vale ressaltar que o aplicativo para esta última aplicação não foi desenvolvida no presente projeto.

A Figura 5.27 traz uma ilustração do modelo comercial que foi desenvolvido no presente projeto. Percebe-se que as operações básicas, como iniciar recepção, salvar os dados e configurar a porta serial, forma mantidos no atual modelo. 


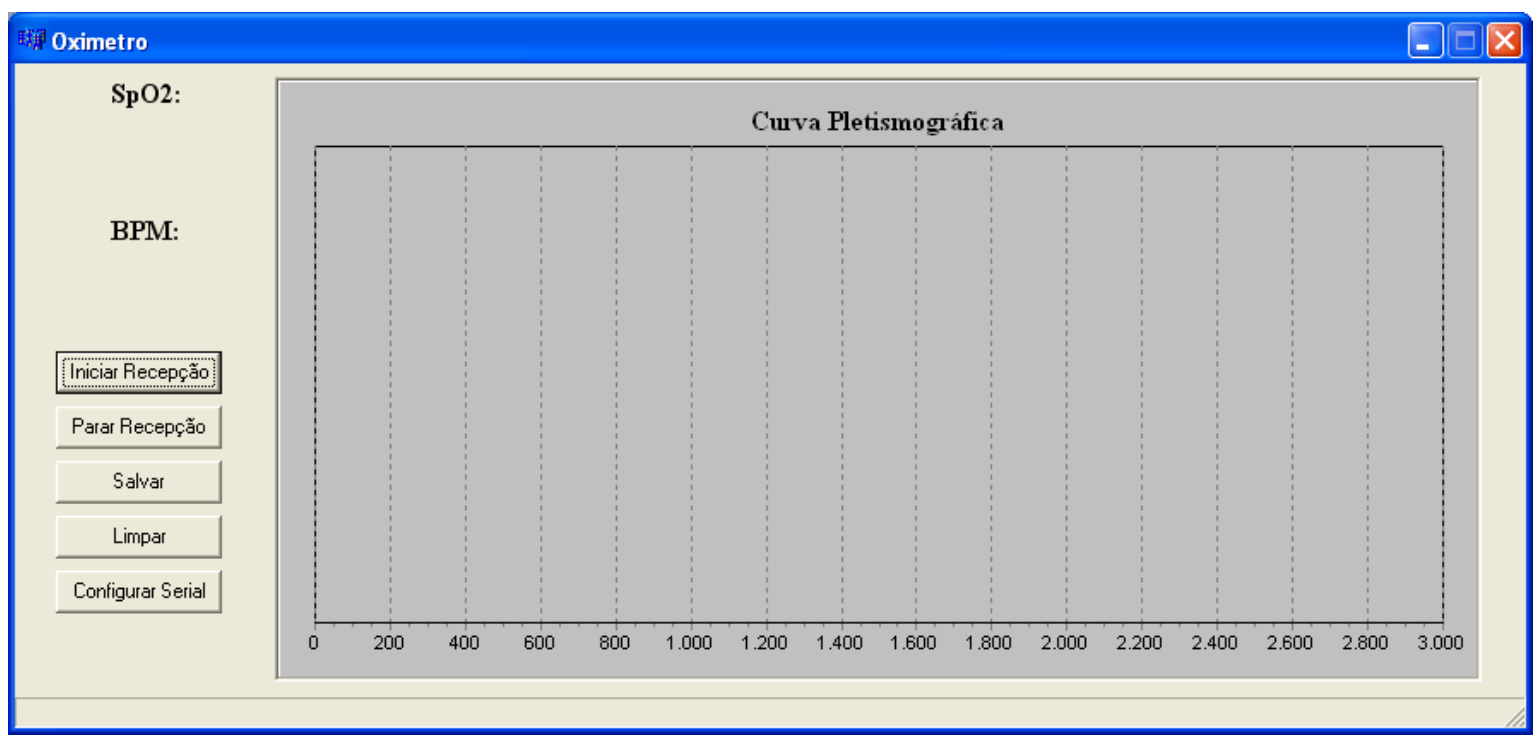

Figura 5.27 - Ilustração do modelo comercial do aplicativo de monitoramento desenvolvido

\section{6 - FONTE ANALÓGICA}

O último circuito desenvolvido para o funcionamento do oxímetro de pulso foi uma fonte analógica para alimentar todos os outros circuitos, bem como o microcontrolador. Com o auxílio de reguladores de tensão, foi possível suprir todos os sistemas desenvolvidos com $+5 \mathrm{~V},-5 \mathrm{~V},+12 \mathrm{~V},-12 \mathrm{~V},+3.3 \mathrm{~V}$ e $0 \mathrm{~V}$ de acordo com a necessidade dos dispositivos em questão. A Figura 5.28 (Fonte analógica simétrica) ilustra o esquemático padrão de fonte simétrica utilizado.

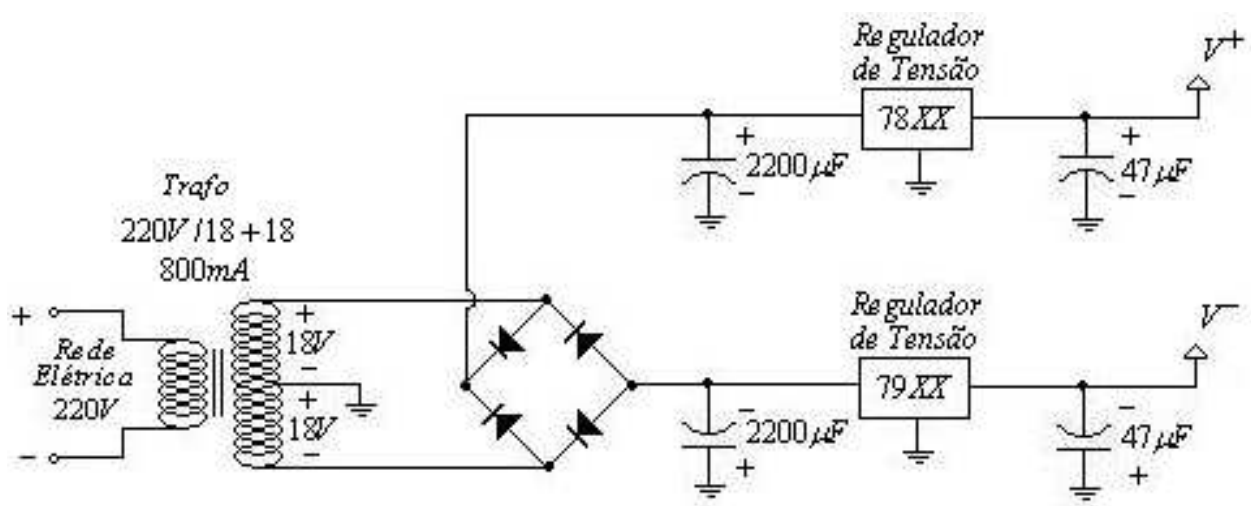

Figura 5.28 - Fonte analógica simétrica.

A principal variação entre os diferentes valores se refere ao regulador de tensão e à posição de conexão dos capacitores. Como ilustrado na Figura 5.28, para os valores de tensão positiva, foi utilizado um regulador de tensão da família $78 X X$, com a configuração de capacitores especificada. Da mesma forma, para valores de tensão negativa, o regulador de tensão utilizado foi da família 79XX. As Tabelas 5.2 e 5.3 ilustram os tipos de 
reguladores para tensões positivas e negativas implementadas:

Tabela 5.2 - Reguladores para as tensões positivas

\begin{tabular}{|c|c|}
\hline Tensão desejada & Regulador \\
\hline$+3.3 V$ & $\mathbf{7 8 3 3}$ \\
\hline$+5 V$ & $\mathbf{7 8 0 5}$ \\
\hline$+12 V$ & $\mathbf{7 8 1 2}$ \\
\hline
\end{tabular}

Tabela 5.3 - Reguladores para as tensões negativas

Tensão desejada Regulador

\begin{tabular}{l|r}
$-5 V$ & $\mathbf{7 9 0 5}$
\end{tabular}

\begin{tabular}{l|r}
$-12 V$ & $\mathbf{7 9 1 2}$ \\
\hline
\end{tabular}




\section{6 - RESULTADOS PRÁTICOS}

Devido ao grande número de circuitos e sistemas que foram implementados dentro do projeto do oxímetro de pulso, foi necessária uma avaliação separada do funcionamento de cada um dos módulos desenvolvidos.

\section{1 - AVALIAÇÃO DO SISTEMA DE GERAÇÃO DE ONDAS DE CONTROLE}

Como explicado na seção 5.1, o sistema de geração de ondas de controle é formado basicamente por portas lógicas, e tem como função a geração de sinais que serão responsáveis pela sinalização do tráfico de informações, bem como o acionamento ou não de diversos dispositivos de acordo com o LED em operação.

Tal sistema utiliza a onda de $4,8 \mathrm{kHz}$ produzida pelo microcontrolador MSP 430 para a formação das duas ondas de $1,2 \mathrm{kHz}$, Sinal1 e Sinal2, as quais indicarão, respectivamente, a habilitação dos LEDs vermelho e infravermelho. O comportamento de tais sinais foi observado na Figura 5.5, em conjunto com os mapas de Karnaugh que indicam a lógica booleana envolvida.

Tal módulo é relativamente simples, e os resultados foram bastante satisfatórios, como ilustrado na Figura 6.1 (Avaliação do sistema de geração de ondas de controle), onde é possível visualizar os dois sinais gerados como esperado e com o valor de freqüência desejado:

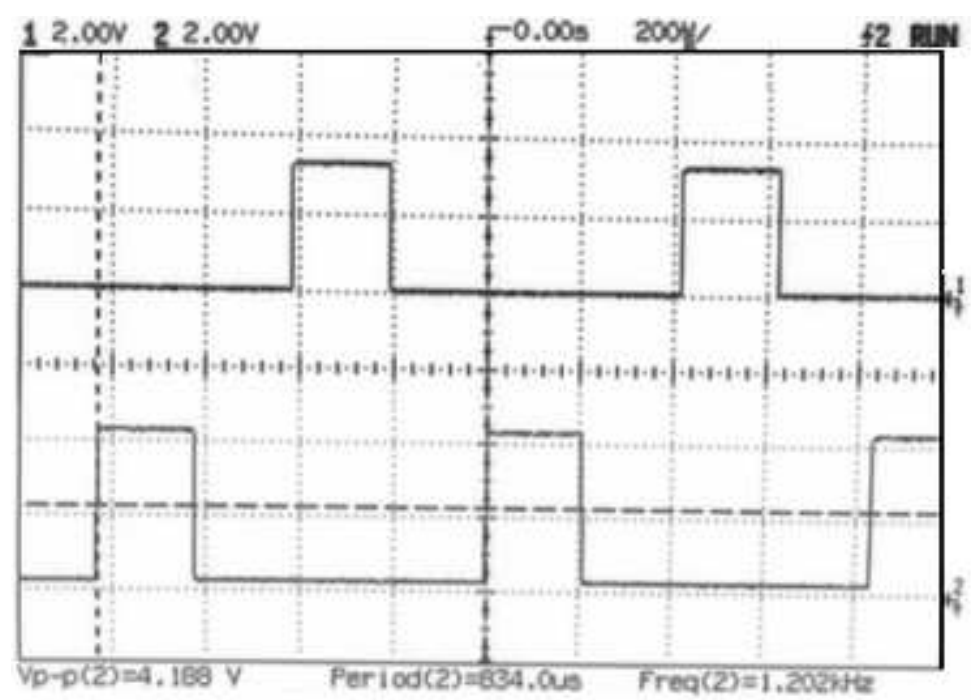

Figura 6.1 - Avaliação do sistema de geração de ondas de controle. 
Na Figura 6.2 é possível visualizar o módulo de geração de ondas de controle na placa de protótipo, formado pelo contador digital síncrono de 4 bits e as portas lógicas NÃO-E.

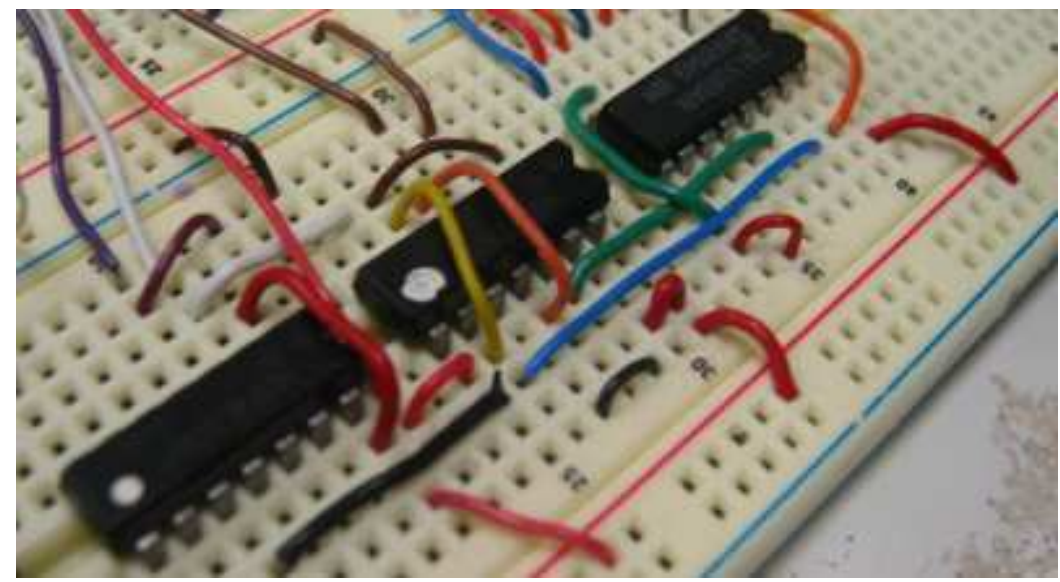

Figura 6.2 - Ilustração do sistema de geração de ondas de controle

\section{2 - AVALIAÇÃO DO SISTEMA DE CONTROLE DOS LEDs}

Como explicado na seção 5.2, o sistema de controle dos LEDs é formado por partes analógicas e digitais, as quais são responsáveis pelo acionamento de forma automática dos LEDs vermelho e infravermelho. Tal sistema utiliza os sinais de controle Sinal1 e Sinal2 para a escolha seletiva do LED em operação. A corrente enviada para cada LED também é controlada pelo microcontrolador MSP430 e por um conversor digital-analógico, como explicado anteriormente.

A avaliação do funcionamento de tal circuito pode ser feita de acordo com a capacidade de chaveamento seletivo do sistema e de acordo com a capacidade de mudança da corrente enviada ao sensor de oximetria.

Foi possível perceber que o presente módulo apresentou resultados bastante satisfatórios, conseguindo atuar de forma eficiente na habilitação e envio de corrente ao LED em operação.

Tal resultado pode ser confirmado na Figura 6.3 (Avaliação do sistema de controle dos LEDs), onde são visualizados dois sinais. A onda inferior corresponde ao Sinal2, o qual indicará quais os momentos em que o LED infravermelho estará em operação. A onda superior é o resultado do processo de chaveamento seletivo dos dois LEDs. Tanto nos 
momentos em que o LED vermelho ou LED infravermelho estão em operação, as correntes que circulam por tais dispositivos serão escoadas para o resistor R8 ilustrado na Figura 5.8. Sendo assim, é possível fazer o monitoramento da corrente no LED em operação de acordo com a tensão nos terminais de tal resistor.

Sendo assim, como Sinal2 indica o funcionamento do LED infravermelho, conclui-se de tal ilustração que os picos superiores correspondem à corrente do LED vermelho. Já os picos inferiores correspondem à operação do LED infravermelho.

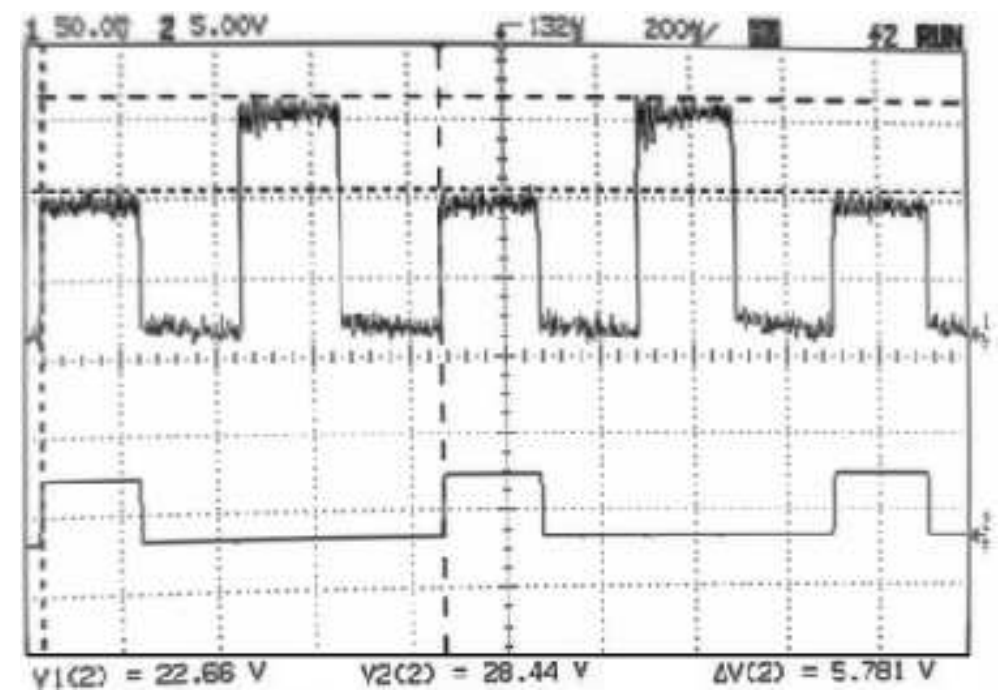

Figura 6.3 - Avaliação do sistema de controle dos LEDs

Através da Figura 6.4 (Ilustração do sistema de controle dos LEDs) é possível visualizar o presente sistema na placa de protótipos

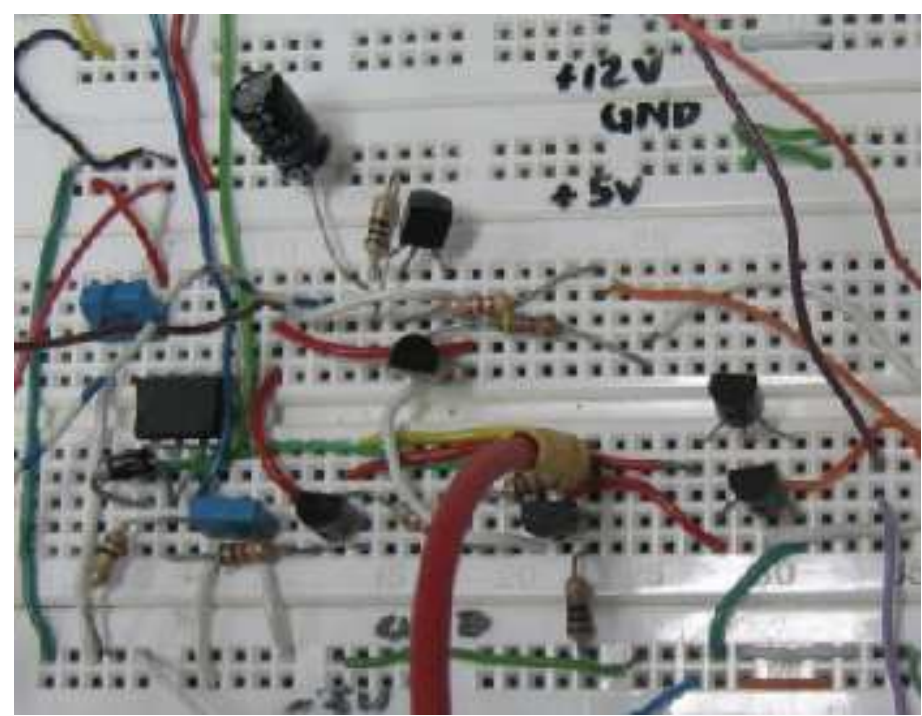

Figura 6.4 - Ilustração do sistema de controle dos LEDs. 


\section{3 - AVALIAÇÃO DO SISTEMA DE RECEPÇÃO}

Como explicado na seção 5.4, o sistema de recepção é formado por diversos módulos os quais são responsáveis pela captação, amplificação, demodulação e filtragem do sinal obtido através do sensor de oximetria de pulso. Tal sistema é controlado pelo microcontrolador MSP 430 (Capítulo 4) e pelo sistema de geração de ondas de controle (seção 5.1). Todos os módulos menores foram avaliados em separado e depois, uma avaliação geral foi feita sobre o sistema de recepção.

\subsection{1 - Análise do módulo de pré-amplificação e demodulação}

O primeiro módulo pertencente ao sistema de recepção é responsável pela préamplificação e pela separação dos sinais provenientes do LED vermelho e do LED infravermelho. Como visto na seção 5.4.1, o funcionamento adequado de tal módulo pode ser avaliado com a capacidade de geração de um sinal de tensão de acordo com a corrente enviada pelo fotodiodo, sem misturar as contribuições provenientes do LED vermelho com as contribuições provenientes do LED infravermelho. Outro ponto da avaliação recai sobre a capacidade de separação de tais contribuições, gerando dois sinais independentes (vermelho e infravermelho) com as informações que serão utilizadas no cálculo da saturação de oxigênio sanguínea.

O circuito de transimpedância (Figura 5.12) apresentou alguns problemas inicialmente, os quais foram resolvidos com os cálculos e escolha apropriada do capacitor de realimentação $C_{f}$.

A partir de então, o circuito passou a apresentar resultados de forma coerente com os comportamentos individuais de cada um dos LEDs. A Figura 6.5 (Avaliação do circuito de transimpedância) ilustra o resultado final de tal circuito, mostrando as contribuições dos LEDs vermelho e infravermelho no sinal $V_{o}$ na saída do amplificador de instrumentação INA118 (Figuras 5.12 e 5.13). Neste caso, são visualizados dois sinais. A onda inferior indica o comportamento da onda Sinal1 (seção 5.1), a qual indicará que o LED vermelho se encontra em operação quando seu nível estiver em valor lógico 1. Já o sinal superior indica a contribuição dos sinais provenientes dos dois LEDs. O circuito ilustra a 
capacidade do circuito de fornecer uma onda sem misturar os dois sinais.

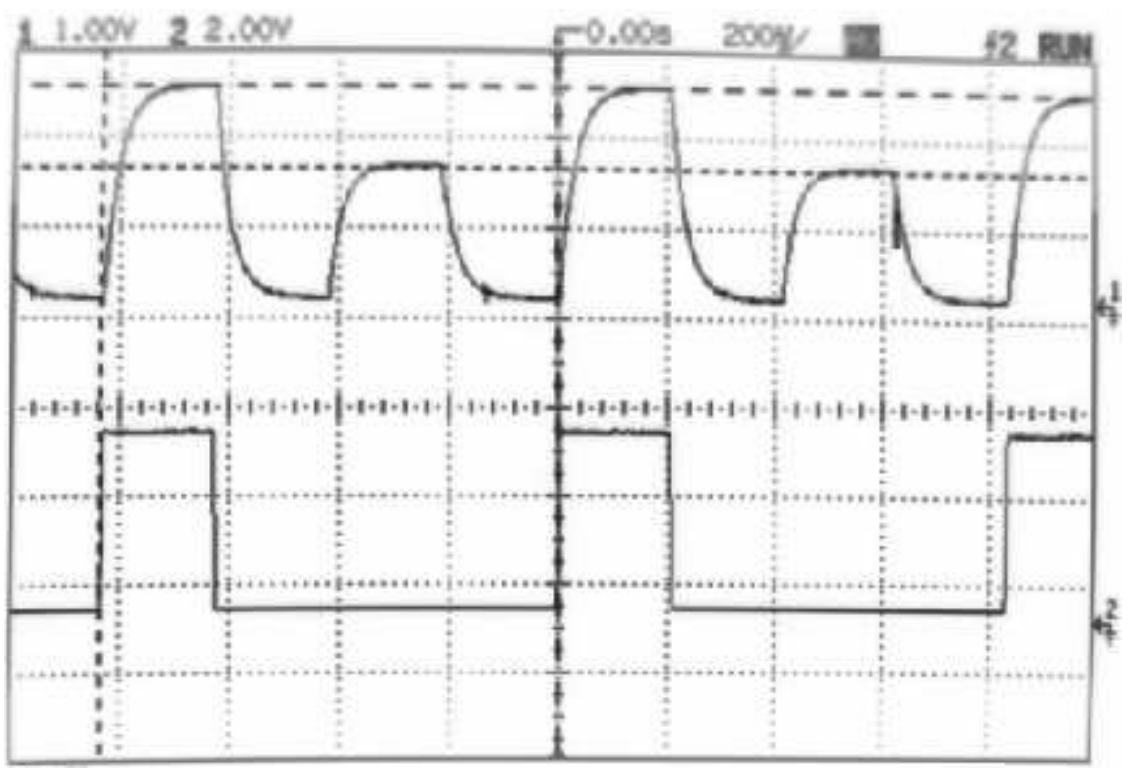

Figura 6.5 - Avaliação do circuito de transimpedância.

Através da Figura 6.6 (Ilustração do circuito de transimpedância) é possível visualizar os amplificadores operacionais, capacitores, resistores e amplificadores de instrumentação que compõem tal circuito na placa de protótipos.

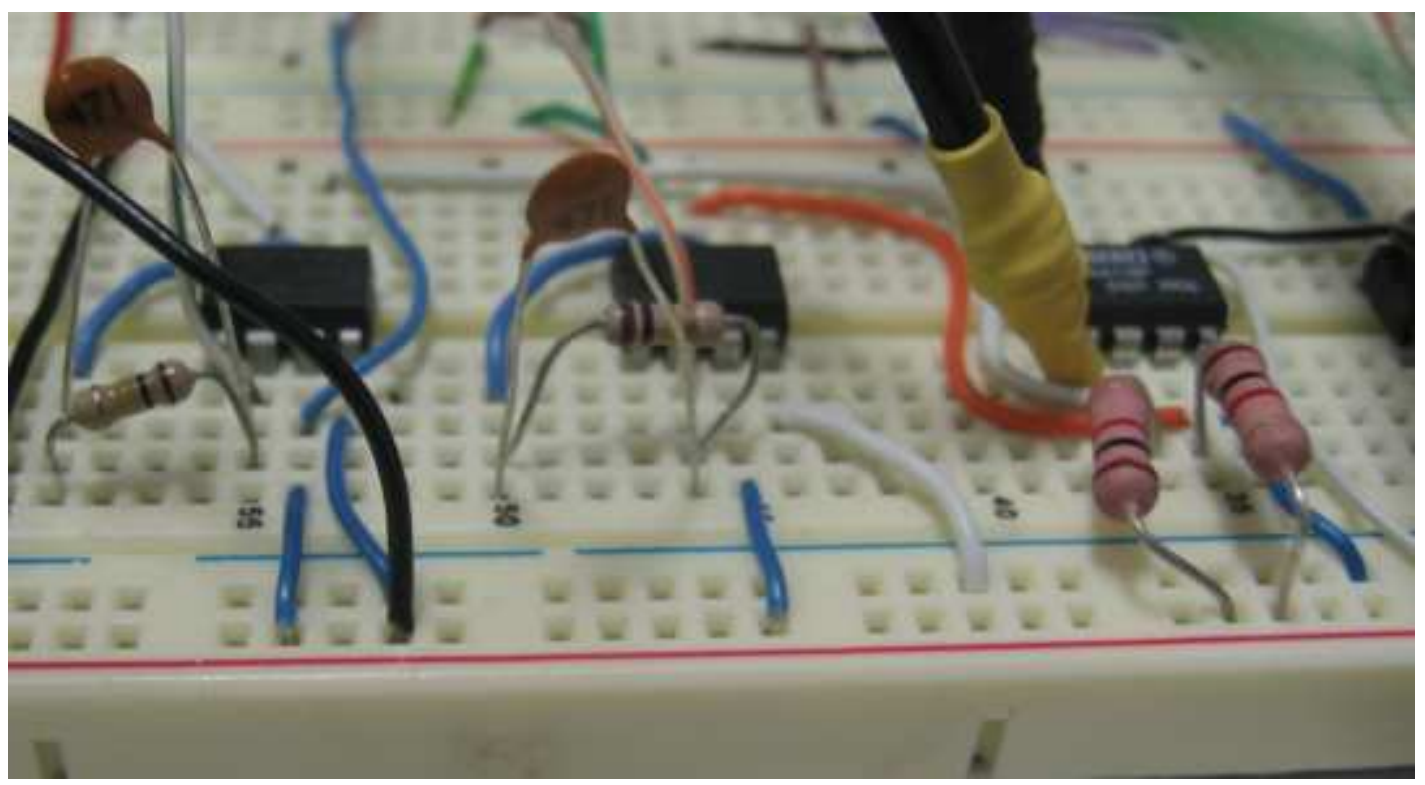

Figura 6.6 - Ilustração do circuito de transimpedância.

Tal sinal é então enviado ao circuito de demodulação, o qual é responsável pela separação de tais contribuições individuais, as quais irão ilustrar a resposta do fotodiodo de acordo com acionamento de cada um dos LEDs.

Como visto anteriormente, o circuito de demodulação é formado por um sistema de 
chaves, as quais são controladas pelos sinais provenientes do Sistema de geração de ondas de controle (seção 5.1). O resultado do circuito de demodulação pode se visto nas duas ondas observadas na Figura 6.7.

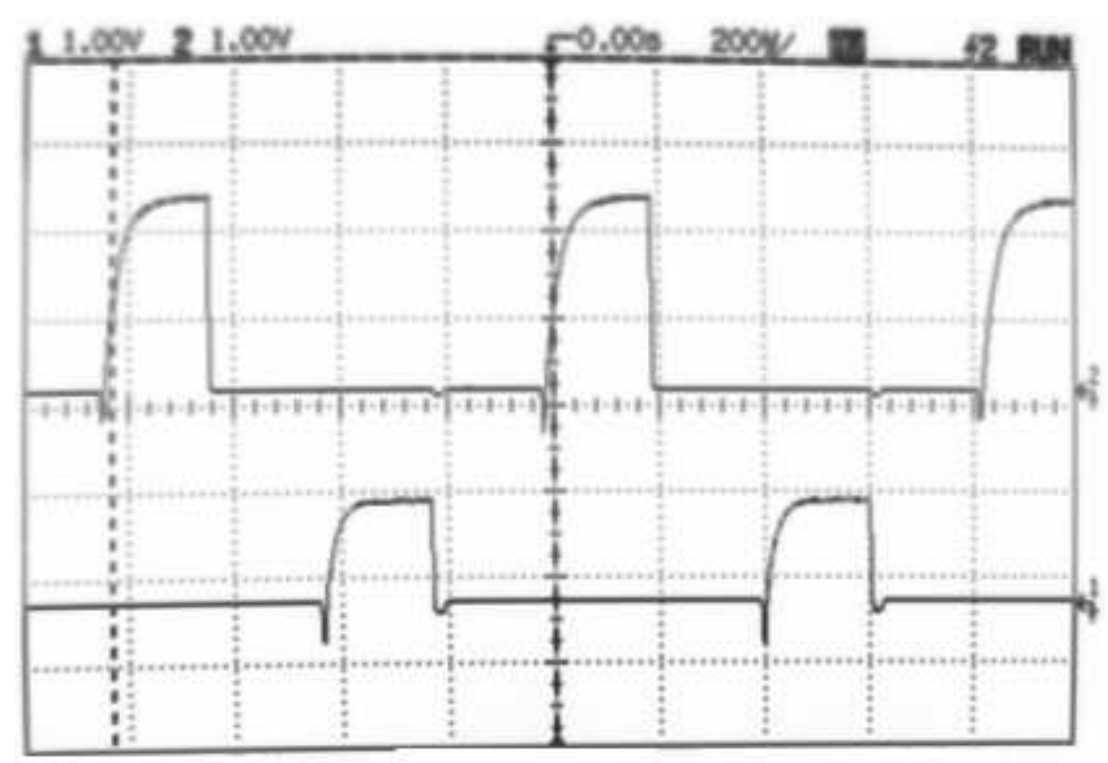

Figura 6.7 - Avaliação do circuito de demodulação.

\subsection{2 - Análise do filtro passa-baixa com freqüência de corte de $24 \mathrm{~Hz}$}

Com a separação em dois sinais realizada no circuito de demodulação (seção 5.4.1), se torna possível a partir de então, fazer operações individuais, sem a preocupação com a mistura de informações provenientes dos LEDs vermelho e infravermelho. Com isso, ambas as ondas passam por um processo de filtragem, a qual foi necessária para uma diminuição dos ruídos associados ao processo de captação do sinal, bem como a redução dos efeitos da componente de freqüência proveniente da rede elétrica e diminuição dos efeitos do processo de chaveamento realizado durante a demodulação do sinal.

Como ilustrado na seção 5.4.2, o filtro de segunda ordem escolhido foi do tipo Sallen-Key, com freqüência de corte de $24 \mathrm{~Hz}$, com queda de $40 \mathrm{~dB}$ por década para valores acima de tal freqüência.

A Tabela 6.1 (Resposta em freqüência do filtro passa-baixa; freqüência de corte de $24 \mathrm{~Hz}$ ), demonstra a resposta do filtro para diversas freqüências, com valores abaixo e acima do limiar de $24 \mathrm{~Hz}$, os quais foram obtidos através de testes experimentais. 
Tabela 6.1 - Resposta em freqüência do filtro passa-baixa, freqüência de corte de $24 \mathrm{~Hz}$.

\begin{tabular}{|c|c|c|c|}
\hline $\begin{array}{c}\text { Freqüência } \\
(\mathbf{H z})\end{array}$ & $\begin{array}{c}\text { Tensão de } \\
\text { Entrada }(\mathbf{V})\end{array}$ & $\begin{array}{c}\text { Tensão de } \\
\text { Saída }(\mathbf{V})\end{array}$ & $\begin{array}{c}\text { Queda } \\
(\mathrm{dB})\end{array}$ \\
\hline 1,250 & 5,062 & 5,062 & $\mathbf{0 ~ d B}$ \\
\hline 5,000 & 5,062 & 5,000 & $\mathbf{- 0 , 1 0 ~ d B}$ \\
\hline 10,10 & 5,062 & 4,750 & $\mathbf{- 0 , 5 5 ~ d B}$ \\
\hline 15,04 & 5,062 & 4,312 & $\mathbf{- 1 , 3 9 ~ d B}$ \\
\hline 20,00 & 5,062 & 3,688 & $\mathbf{- 2 , 7 5 ~ d B}$ \\
\hline 20,83 & 5,062 & 3,562 & $\mathbf{- 3 , 0 5} \mathbf{~ d B}$ \\
\hline 24,10 & 5,062 & 3,062 & $\mathbf{- 4 , 3 6 ~ d B}$ \\
\hline 30,00 & 5,062 & 2,312 & $\mathbf{- 6 , 8 0 ~ d B}$ \\
\hline 40,00 & 5,062 & 1,469 & $\mathbf{- 1 0 , 7} \mathbf{~ d B}$ \\
\hline 75,76 & 5,062 & 0,500 & $\mathbf{- 2 0 , 1 ~ d B}$ \\
\hline 130,7 & 5,062 & 0,164 & $\mathbf{- 2 9 , 7 ~ d B}$ \\
\hline 190,1 & 5,062 & 0,085 & $\mathbf{- 3 5 , 4 ~ d B}$ \\
\hline 240,0 & 5,062 & 0,060 & $\mathbf{- 3 8 , 5 ~ d B}$ \\
\hline $\mathbf{5 0 0 , 0}$ & $\mathbf{5 , 0 6 2}$ & $\mathbf{0 , 0 1 5}$ & $\mathbf{- 5 2 , 5 ~ d B}$ \\
\hline
\end{tabular}

A Figura 6.8 ilustra graficamente o comportamento dos dados colhidos na Tabela 6.1 em função da variação de frequiência entre $1,250 \mathrm{~Hz}$ e $500 \mathrm{~Hz}$.

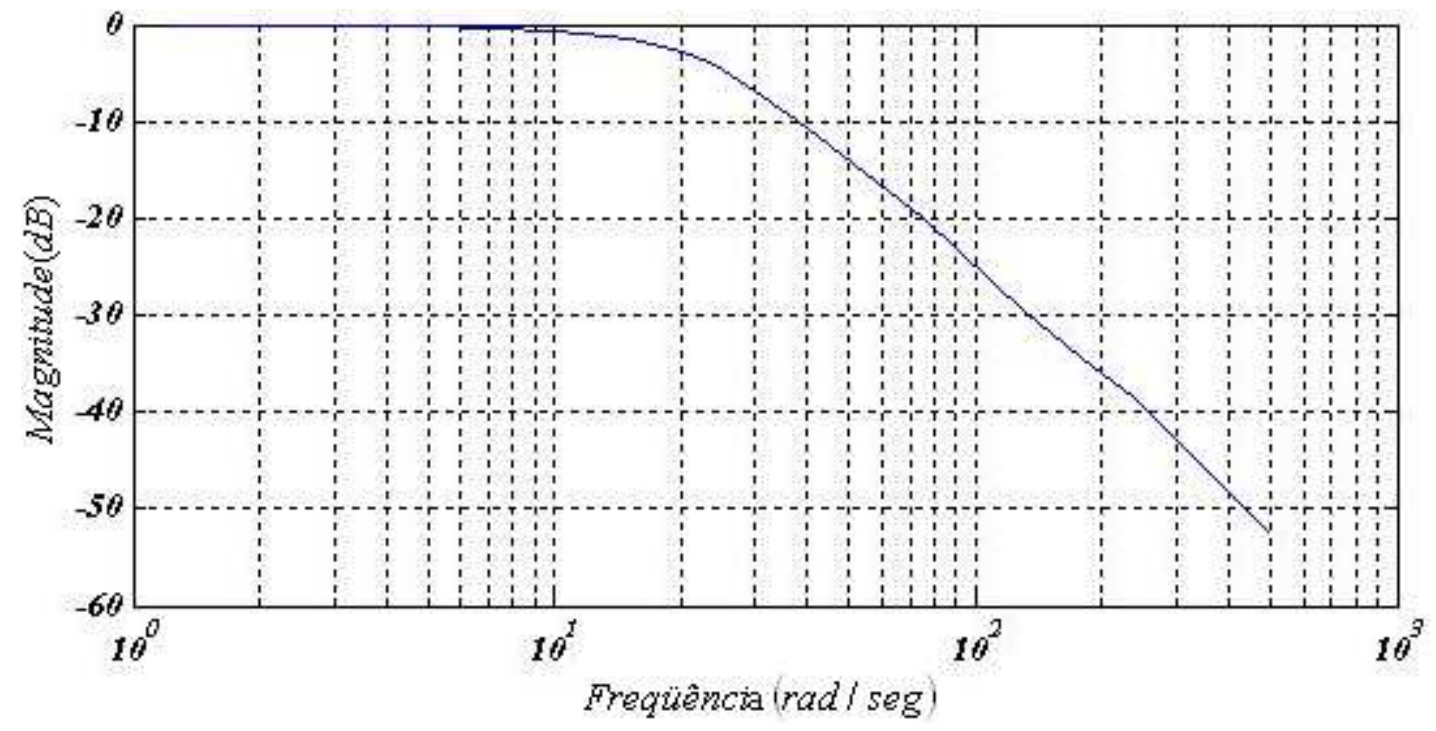

Figura 6.8 - Resposta em freqüência do filtro passa-baixa implementado.

A Figura 6.9 (Comportamento do filtro passa-baixa na freqüência de $24 \mathrm{~Hz}$ ), como o próprio nome indica, ilustra o comportamento do filtro passa-baixa na freqüência de $24 \mathrm{~Hz}$. 


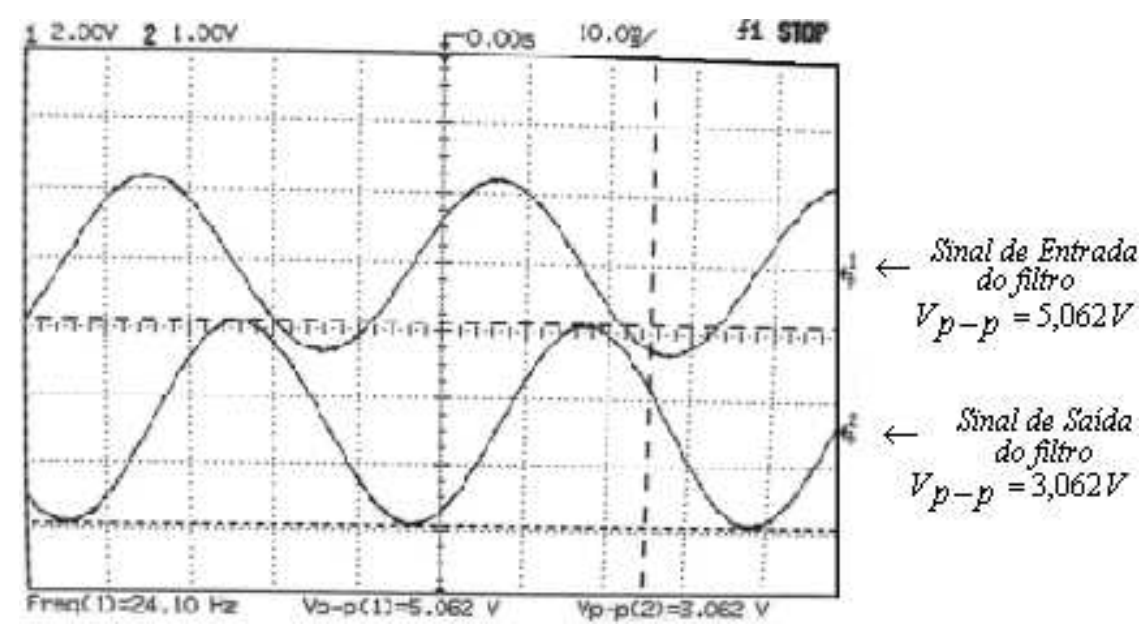

Figura 6.9 - Comportamento do filtro passa-baixa na freqüência de $24 \mathrm{~Hz}$.

O ganho do circuito em tal frequiência $(f=24 \mathrm{~Hz}$ ) pode ser calculado através da relação entre os valores da tensão de saída pela tensão de entrada, de acordo com a equação 6.1, mostrada abaixo:

$$
G=20 \cdot \log \left(\frac{V_{\text {saída }}}{V_{\text {entrada }}}\right) \rightarrow G=20 \cdot \log \left(\frac{3,062 \mathrm{~V}}{5,062 \mathrm{~V}}\right)=-4,36 \mathrm{~dB}
$$

Percebeu-se que a queda foi um maior que os $3 d B$ esperados. Tal fato pode ser explicado pela utilização de valores aproximados $\left(C_{1}=680 \eta F, C_{2}=100 \eta F, R_{1}=6,8 \mathrm{k} \Omega\right.$ e $\left.R_{2}=100 \mathrm{k} \Omega\right)$ do que os calculados teoricamente $\left(C_{1}=680 \eta F, C_{2}=100 \eta F\right.$, $R_{1}=7,49 \mathrm{k} \Omega$ e $R_{2}=86,28 \mathrm{k} \Omega$ ). Mesmo assim, através da Tabela 6.1, foi possível perceber que a banda do sinal, que vai até $16 \mathrm{~Hz}$, não foi afetada com tal pequena variação no valor da freqüência de corte.

Na Figura 6.10 é possível visualizar os componentes que formam os dois filtros na placa de protótipos. Um filtro é responsável pelo sinal proveniente do LED vermelho e outro do sinal proveniente do LED infravermelho.

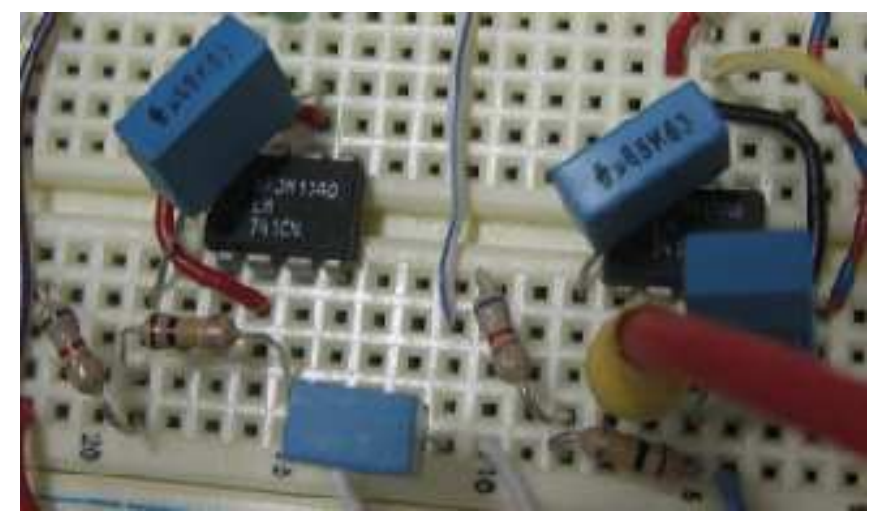


Figura 6.10 - Ilustração do filtro passa-baixa de $24 \mathrm{~Hz}$.

\subsection{3 - Análise do módulo de adequação do sinal à faixa dinâmica de conversão}

Como explicado na seção 5.4.3, foi implementado um circuito o qual é responsável pelo ajuste do sinal de oximetria aos limites de tensão do conversor ADC12. Tal módulo foi desenvolvido com o intuito de otimizar a faixa de operação, dando uma maior resolução e evitando que possíveis valores de tensão possam ocasionar a queima do conversor.

Diversos testes tiveram que ser realizados para a garantia do bom funcionamento de tal módulo. Inicialmente, testaram-se as comunicações com alguns dos dispositivos do circuito (conversor digital-analógico e potenciômetro digital), os quais são controlados pelo microcontrolador. Para ambos os casos, os resultados foram bastante satisfatórios, o que abriu caminho para testes mais complexos com o módulo completo.

Pata tal caso, a avaliação recai sobre a capacidade do sistema de atuar no ganho e no valor DC do sinal, a fim de se obter uma maior resolução, o que é necessário no cálculo mais eficiente da taxa de saturação da oxigenação sanguínea. A Figura 6.11 ilustra de forma clara a atuação de tal sistema.

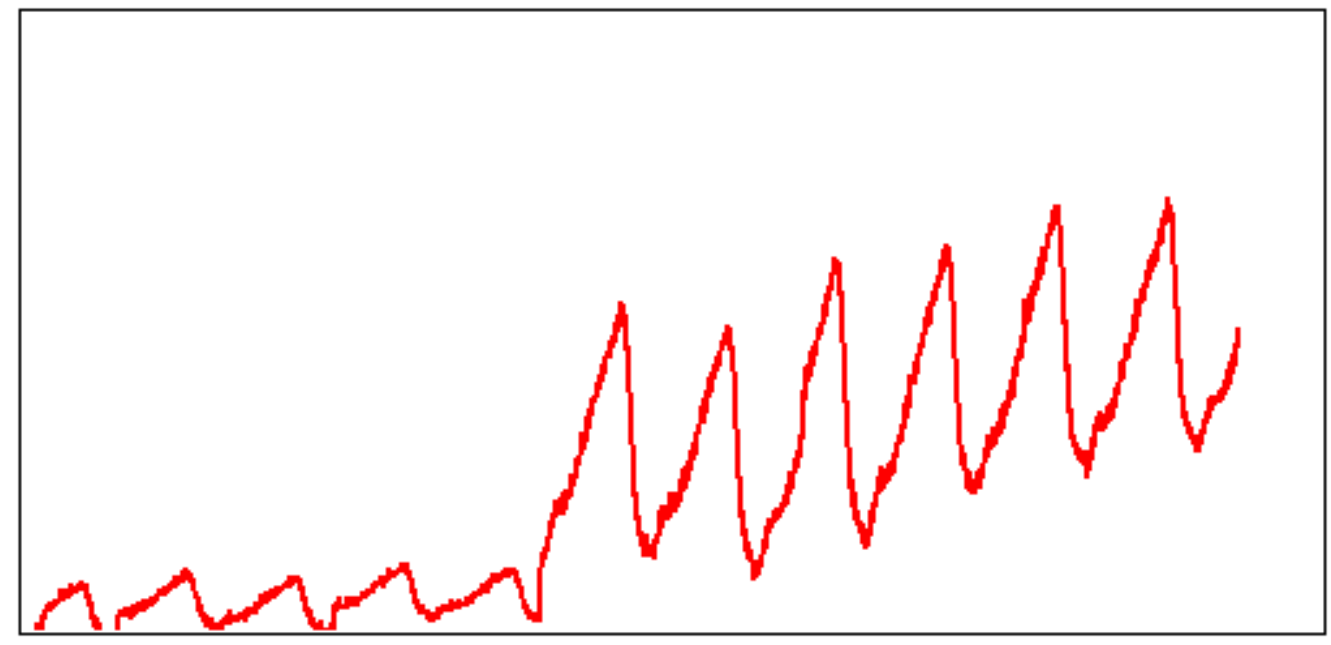

Figura 6.11 - Atuação do módulo de adequação do sinal à faixa dinâmica de conversão.

Tal figura, a qual foi obtida através dos aplicativos de monitoramento, demonstra duas situações distintas no mesmo sinal. Inicialmente, a onda possuía um valor de tensão pico a pico relativamente pequeno e seu valor DC se encontrava muito próximo de $0 \mathrm{~V}, \mathrm{o}$ que, em determinados momentos, faz com que a onda seja ceifada devido aos limites do conversor analógico digital. Com isso, acaba-se perdendo informações que seriam 
utilizadas no cálculo da saturação de oxigênio.

O microcontrolador então atua no conversor digital-analógico e no potenciômetro digital, modificando o ganho e o valor DC, como demonstrado na Figura 6.11. Com isso, foi possível concluir que tal módulo atingiu as expectativas, permitindo uma otimização clara do sinal.

A Figura 6.12 traz uma ilustração da placa protótipo de testes que foi implementada para o desenvolvimento de tal módulo.

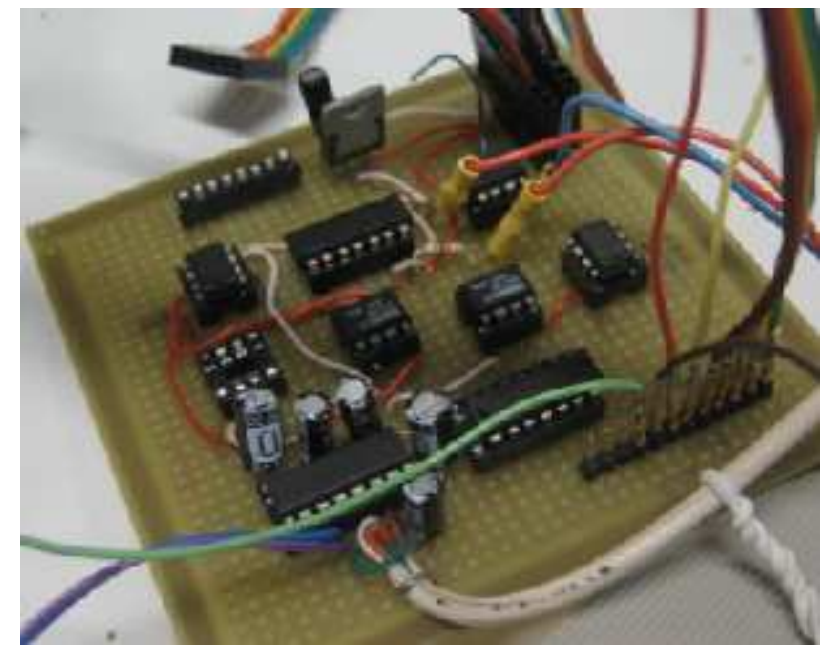

Figura 6.12 - Placa desenvolvida para o módulo de adequação do sinal à faixa dinâmica de conversão.

\subsection{4 - Análise geral do sistema de recepção}

Através da análise em separado de todos os módulos realizada nas seções anteriores, foi possível observar que o sistema de recepção conseguiu operar de forma eficiente na captação do sinal de oximetria.

Inicialmente, a corrente enviada pelo fotodiodo (seção 5.3) é transformada em um sinal de tensão pelo módulo de transimpedância. Em seguida, as contribuições dos LEDs vermelho e infravermelho são separadas pelo módulo de demodulação. Tais sinais são então filtrados por um filtro passa-baixa com frequiência de corte de $24 \mathrm{~Hz}$, o qual operou de forma bastante satisfatória. O sinal é então enviado ao módulo que o ajusta à faixa de operação do conversor ADC12 e em seguida enviado aos aplicativos de monitoramento.

O microcontrolador MSP 430, por sua vez, avalia os dados colhidos e atua no sistema, tentando controlar as diversas variáveis para uma captação eficiente das 
características necessárias ao cálculo da saturação de oxigênio.

\section{4 - AVALIAÇÃO DOS APLICATIVOS DE MONITORAMENTO}

Como apresentado na seção 5.5, um aplicativo de monitoramento foi desenvolvido a fim de se criar a possibilidade de visualização gráfica do sinal de oximetria captado. $\mathrm{Na}$ Figura 6.13 tal aplicativo é mostrado em funcionamento, sendo possível observar o resultado final de todo o processo de recepção e controle das ondas provenientes da plataforma de aquisição.

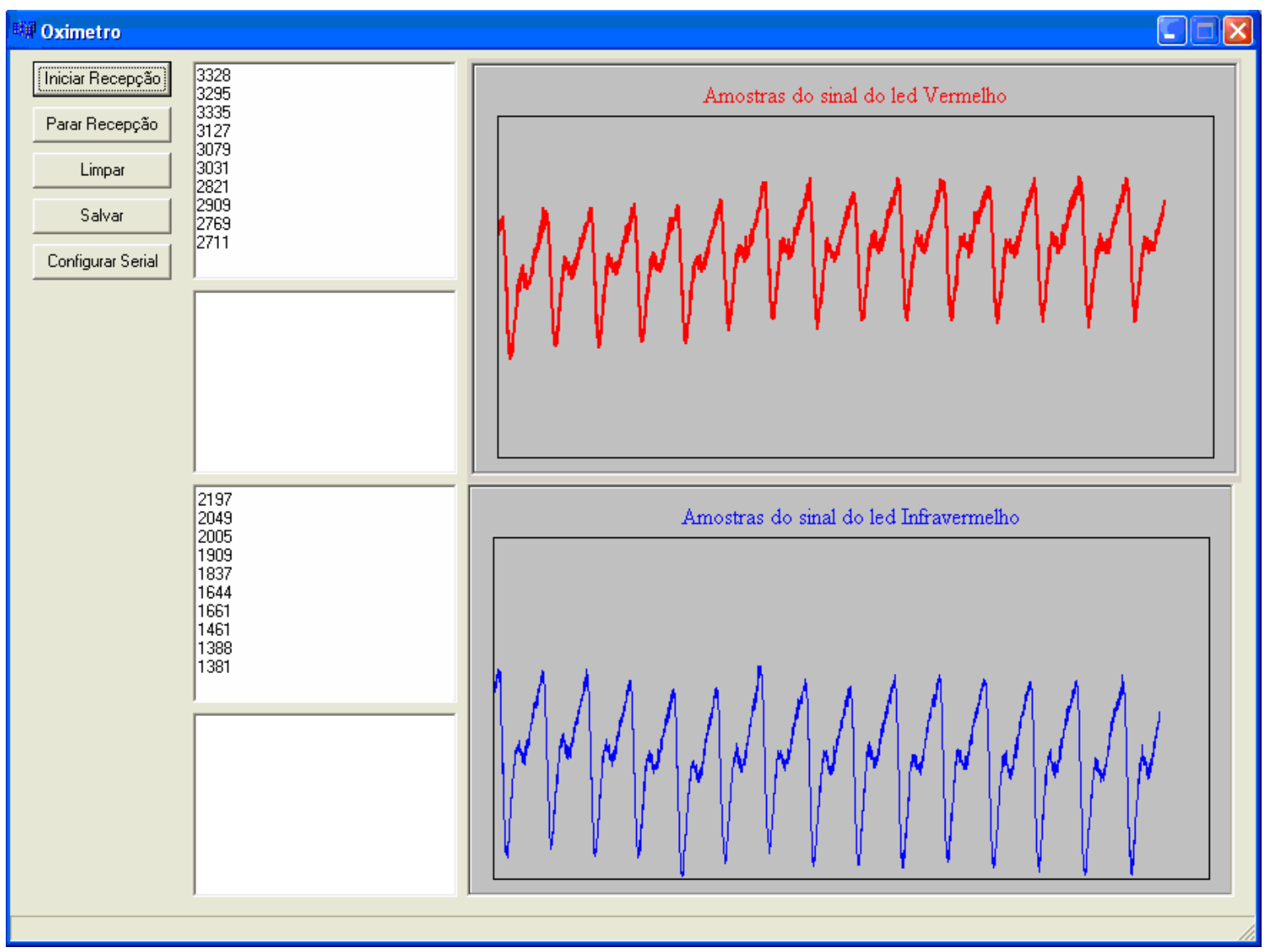

Figura 6.13 - Funcionamento do aplicativo de monitoramento.

Após diversos testes, concluiu-se que o programa opera de forma bastante satisfatória, permitindo realizar as modificações que são necessárias para a comunicação com o microcontrolador MSP 430.

O armazenamento dos dados realizado pelo aplicativo também abre a possibilidade de estudos mais avançados no sinal de oximetria de pulso. Um exemplo de tal fato pode ser visualizado através da Figura 6.14. 
Na figura ilustrada em 6.14 (a), tem-se uma determinada parte de um sinal (vermelho e infravermelho) que foi captado em um dos diversos testes realizados. A Figura 6.14 (b) ilustra o resultado final de um processamento que consiste em aplicar os sinais da Figura 6.14 (a) em um filtro de média-móvel com janela de 26 amostras.

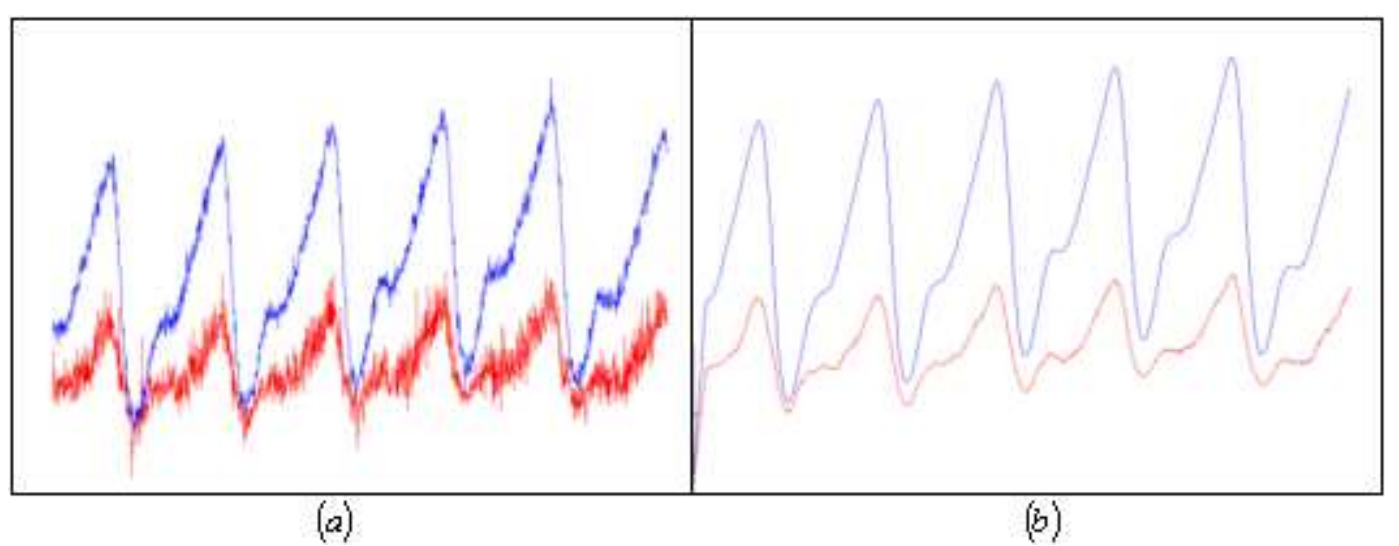

Figura 6.14 - a) Sinal Captado b) Ilustração da aplicação do filtro de média móvel com janela de 26 amostras em sinal de oximetria captado.

Tal exemplo é apenas um dentre os diversos progressos que podem ser utilizados no processamento dos sinais de oximetria de pulso. Percebeu-se claramente a melhoria da qualidade visual do sinal, bem como a diminuição dos ruídos. Por isso, a possibilidade de armazenamento dos dados colhidos pela plataforma desenvolvida é de extrema importância.

$\mathrm{Na}$ Figura 6.15, pode-se visualizar o funcionamento do aplicativo de monitoramento comercial, o qual ilustra o sinal captado em conjunto com o cálculo da saturação de oxigênio. Os resultados para tal modelo também foram bastante satisfatórios. 


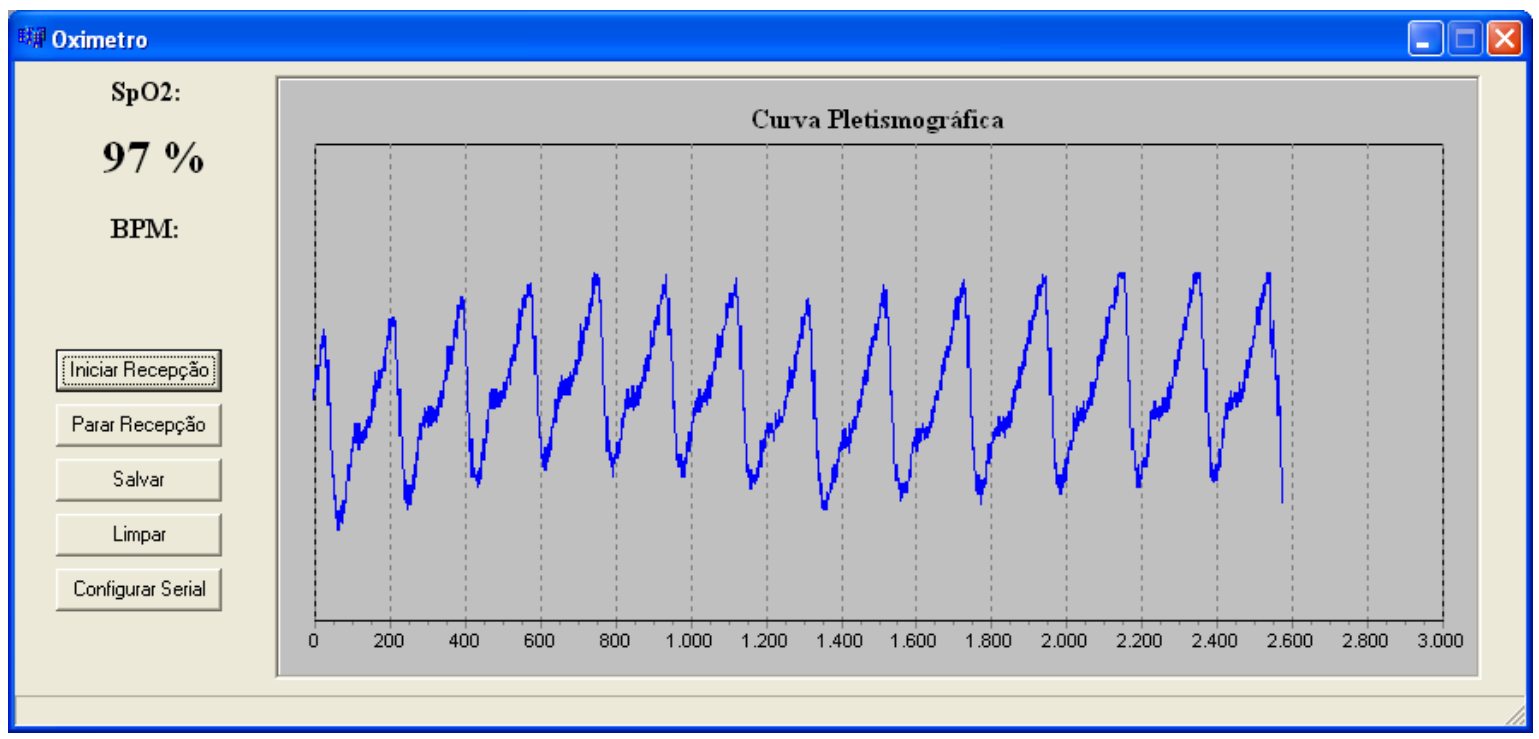

Figura 6.15 - Funcionamento do aplicativo de monitoramento comercial. 


\section{7 - CONCLUSÃO}

\section{1 - CONCLUSÃO DOS OBJETIVOS PROPOSTOS}

Neste trabalho foram estudados diversos conceitos e formas para apresentar soluções ao desenvolvimento de uma plataforma que seja capaz de capturar sinais de oximetria de pulso, bem como permitir uma análise gráfica em tempo real do comportamento da saturação de oxigênio e um armazenamento de todos os dados colhidos pelo sistema.

Tal projeto teve o intuito de servir como iniciativa pioneira na Universidade de Brasília no estudo das aplicações e possíveis melhorias que podem ser desenvolvidas no oxímetro de pulso. A implementação de todos os módulos foi feita através de forte embasamento teórico, obtendo-se resultados bastante satisfatórios nos testes realizados. Foram desenvolvidos cinco sistemas principais, os quais foram amplamente explicados no decorrer do trabalho, enfatizando suas características específicas e funções exercidas.

A conclusão de tal trabalho abrirá as portas para outros estudos no Departamento de Engenharia Elétrica da Universidade de Brasília que tragam uma melhoria constante na captação do sinal de oximetria, permitindo assim um processamento cada vez mais específico e eficiente.

\section{2 - DIFICULDADES ENCONTRADAS NO TRABALHO}

Por se tratar de um trabalho multidisciplinar, o qual envolve aspectos de protocolo de comunicação de dados, medicina, eletrônica digital e analógica é de se esperar que alguns empecilhos e desafios tivessem que ser enfrentados.

Primeiramente, vale ressaltar que tal projeto foi uma iniciativa pioneira de estudos em oximetria de pulso dentro no Departamento de Engenharia Elétrica da Universidade de Brasília. Todos os módulos e sistemas foram implementados de acordo com as necessidades do projeto e das peculiaridades do sinal de oximetria.

Por isso, um desafio inicial foi o aprofundamento do conhecimento relacionado aos 
aspectos fisiológicos referentes ao sinal a ser captado. Mesmo se tratando de um trabalho de Engenharia, foi necessário um estudo das características da oxigenação sanguínea e os meios que o corpo humano utiliza para o transporte de oxigênio aos mais diversos órgãos e tecidos. Tal desafio tornou-se uma ferramenta na construção de análises mais críticas em relação ao sinal captado e um facilitador na detecção de possíveis erros associados aos diversos módulos e sistemas.

Em relação aos circuitos analógicos e digitais projetados, vários dos problemas estavam associados às placas de protótipo (protoboard) utilizadas, as quais introduziam ruídos consideráveis ao sinal captado, diminuindo sua resolução e qualidade. Outro empecilho foi a dificuldade de se encontrar alguns dos dispositivos utilizados em lojas convencionais de eletrônica. Tal fato acaba encarecendo a compra de alguns componentes, como potenciômetros digitais, amplificadores de instrumentação e conversores digitalanalógico. Outro ponto foi o tempo de espera decorrido em alguns casos, onde só foi possível fazer o pedido de compra em lojas localizadas em outros estados.

Em relação ao código de programação do microcontrolador algumas dificuldades foram encontradas. O módulo de adequação do sinal à faixa dinâmica de conversão (seção 5.4.3) apresentou diversos problemas até começar a operar de forma satisfatória. Vários testes foram realizados, linhas do programa tiveram que ser revisadas diversas vezes e uma placa de protótipo foi implementada para um estudo mais detalhado do comportamento dos componentes que fazem parte de tal módulo.

Outra dificuldade encontrada referente ao microcontrolador se refere à comunicação com o microcomputador e os aplicativos de monitoramento (seção 5.5.1). Inicialmente, vários erros na implementação dos protocolos de comunicação impediam que o sinal de oximetria de pulso pudesse ser visualizado e processado. Novamente, foi necessária uma avaliação detalhada das linhas de código e da configuração estabelecida para a comunicação serial até que o problema fosse resolvido.

No que diz respeito a mensuração da saturação de oxigênio do sangue arterial, foram encontradas barreiras não superadas, pois os métodos utilizados em aparelhos comerciais são específicos de cada tipo e fabricante dos sensores e os mesmos não são divulgados devido a concorrência do mercado. Além disso, os métodos encontrados em artigos exigiam um esforço computacional muito grande, o qual demandaria um tempo 
suficientemente grande e inviabilizaria o controle e o processamento realizado pelo microcontrolador MSP430.

\section{3 - PROPOSTAS PARA TRABALHOS FUTUROS}

Apesar de a plataforma de aquisição de sinais de oximetria de pulso ter apresentado resultados bastante satisfatórios, várias modificações podem ser feitas para a melhoria do sistema.

Primeiramente, como explicado em seções anteriores, através dos aplicativos de monitoramento é possível fazer o armazenamento dos dados colhidos pelo sistema de oximetria. Tal ferramenta possibilita estudos mais aprofundados e um processamento mais eficiente dos sinais captados. Diversas universidades e centros de pesquisa ao redor do mundo vêm empenhando esforços na avaliação das características do monitoramento de oxigenação sanguínea que possam vir a ajudar na detecção de possíveis males e problemas associados aos sistemas circulatório e respiratório.

Uma segunda proposta para trabalhos futuros seria a implementação de todos os circuitos desenvolvidos em uma única placa de circuito integrado com dispositivos de encapsulamentos tipo SMD (Surface Mounted Device). Tal migração de tecnologia iria exigir uma avaliação detalhada de como os novos dispositivos afetariam o funcionamento do sistema como um todo. Apesar geralmente encarecer ligeiramente o projeto, tal mudança traz diversas vantagens, como a possibilidade de automatização do processo de fabricação em larga escala das placas de circuito integrado. Outro fator determinante é a redução significativa do tamanho final de tal placa, uma vez que os componentes e as trilhas condutoras são bem mais compactos.

Por fim, como última sugestão, surge a proposta de implementação de módulos de comunicação que permitam um monitoramento remoto da oxigenação sanguínea. Tal desenvolvimento pode ser feito através da utilização de protocolos de comunicação TCP/IP (Transmission Control Protocol) ou até mesmo a utilização de outros microcontroladores que permitam a comunicação via USB (Universal Serial Bus). Tais propostas trariam melhorias significativas nas taxas de transmissão e uma facilidade maior de monitoramento da oxigenação sanguínea por diversas pessoas em locais distintos. 


\section{REFERÊNCIAS BIBLIOGRÁFICAS}

[1] BROWN, John M., CARR, Joseph J; "Introduction to biomedical equipment

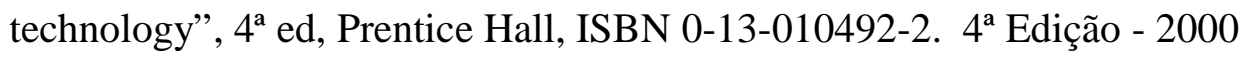

[2] DORF, Richard C.; “Sistemas de Controle Modernos”, Editora LTC, 8 Edição, 2001

[3] FEITOSA, Eumann M.; FREITAS, Patrícia de O.; FEITOSA, Virgínia F.. "Proposta de Componentes de Sistema de Telemetria para Monitoramento de ECG e de EMG durante Atividade Física.” Monografia de projeto final de graduação - Departamento de Engenharia Elétrica; Universidade de Brasília, Brasília, 2005.

[4] FRANCO, Otávio G.; BRAGA, Rodrigo F. C.. "Sistema de Telemetria para Monitoramento de Ciclistas." Monografia de projeto final de graduação - Departamento de Engenharia Elétrica; Universidade de Brasília, Brasília, 2005.

[5] MSP430x1xx Family - User's Guide, Texas Instrument Inc, Dallas - EUA, 2002.

[6] NOGUEIRA, Carlos Eduardo C. e FONSECA, Tiago A.. Internet Embarcada e Comunicação IrDA com o Microcontrolador 8051. Monografia de projeto final de graduação - Departamento de Engenharia Elétrica, Universidade de Brasília, Brasília, 2005.

[7] OPPENHEIM, Alan V., BUCK, John R., SCHAFER, Ronald W.; "Discrete Time Signal Processing"; Editora PRENTICE HALL-USA; 2 ${ }^{\text {a }}$ Edição - 1999

[8] PEREIRA, FÁBIO, "Microcontroladores MSP430 - Teoria e Prática", São Paulo, Editora Érica, $1^{\text {a }}$ Edição.

[9] SEDRA, Adel S.; SMITH, Kenneth, C. Microeletrônica, São Paulo: Pearson Education do Brasil, 2000

[10] TOCCI, Ronald J.; "Microprocessors and Microcomputers", Editora PRENTICE

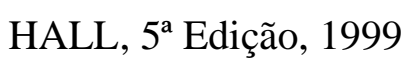


[11] WEBSTER, J.G., "Design of Pulse Oximeters", Deoartment of Eletrical and Computer Engineering, University of Wisconsin-Madison,

[12] Precision, Low Power Instrumentation Amplifier, INA118 Datasheet

[13] Quadruple 8-Bit Digital-to-Analog Converters, TLV5620 Datasheet

[14] Quad Bilateral Switch for Transmission or Multiplexing of Analog or Digital Signals, HCF4066B Datasheet

[15] SHELlEY, Kirk, SHELlEY, Stacey, "Pulse Oximeter: Photoeletric Plethysmography".

[16] KAMAT, Vijaylakshmi, "Pulse Oximetry", Índian Journal of Anaesthesia, 2002

[17] SCAHRF, John E., MD; ATHAN, Stephan A., MS EE; CAIM, David, MS EE, "Pulse Oximetry Through Spectral Analysis", University of South Florida Department of Anesthesiology \& University of South Florida Center for Microelectronics Research, 1993

[18] RUSCH, T.L., SANKAR, R., SCHARF, J.E., "Signal Processing Methods for Pulse Oximetry", Center for Medical Genetics, Marshfield, 1996

[19] John E. Scharf, MD; Terry L. Rusch, BS EE," Optimization of Portable Pulse Oximetry Through Fourier Analysis", USF Department of Anesthesiology \& USF Department of Electrical Engineering

[20] LINDER, Stephen P., WENDELKEN, Suzanne M., WEI, Edward, MCGRATH Susan P., "Using the Morphology of Photoplethysmogram Peaks to Detect Changes in Posture", Department of Computer Science, Thayer School of Engineering,, Dartmouth College, Hanover, NH, USA, 2005

[21] MENDELSON, Yitzhak, KENT, Joel C., "Variations in Optical Absorption Spectra of Adult and Fetal Hemoglobins and Its Effect on Pulse Oximetry", IEEE Transacions on Biomedical Engineering,. Vol. 36, 1989. 
[22] Single/Dual Digital Potentiometer with SPI Interface, MCP41XXX Datasheet

[23] www.ti.com, consulta em 23/03/2006

[24] http://www.msu.edu/user/hongbao/heart/images/heart1.jpg

[25] http://shoppingimages.50below.com/prodImages/products/497409529-5302003110617-AM-35930-display.jpg

[26] http://en.wikipedia.org/wiki/Hemoglobin

[27] http://en.wikipedia.org/wiki/Red_cell

[28] http://pt.wikipedia.org/wiki/Adenosina tri-fosfato

[29] http://icarito.latercera.cl/infografia/chumano/respiratorio/alveolos.htm

[30] http://www.corpohumano.hpg.ig.com.br/ab_news_health/noticias.html

[31] http://www.corpohumano.hpg.ig.com.br/circulacao/ciculacao.jpg

[32] http://www.nellcor.com/prod/List.aspx?S1=POX

[33] http://www.masimo.com/pulseOximeter/index.htm

[34] http://www.maxim-ic.com/appnotes.cfm/appnote_number/733

[35] GUYTON, Arthur C; HALL, John Edward: "Textbook of medical physiology", W.B. Saunders company, 9ª ed., Philadelphia, 1996.

[36] http://en.wikipedia.org/wiki/Hypoxia_\%28medical\%29

[37] http://pt.wikipedia.org/wiki/Glic\%C3\%B3lise anaer\%C3\%B3bica 
[38] ZELENOVSKY, Ricardo, "Microcontroladores, (MCS-51)" 


\section{APÊNDICES}

/l

// Programa desenvolvido para gerar uma onda quadrada no pino P1.1 de 4,8kHz, uma onda de sincronismo (CLEAR)

// no pino P2.0, filtro de mediana, deteccao de maximos e minimos numa janelade 2 segundos, ajuste de uma

// tensao DC fornecida pelo DAC TLV5620 a entrada inversora do amplificador de instrumetacao INA118 e ajuste

// do ganho desse amplificador atraves do potenciometro digital MCP41010 para adaptacao de um sinal de entrada

// a faixa de conversao do ADC12 do MSP430

$/ /$

\#include <msp430x14x.h>

\#include <stdio.h>

\#include <stdlib.h>

\#include <math.h>

// Constantes

\#define NOVA_AMOSTRA

\#define envia_LSB

\#define RED

\#define IR

\#define DAC_A

\#define DAC_B

0x00

\#define DAC_C

0x02

0x04

\#define DAC_D

0x06

\#define DAC_MIN_12

254

\#define DAC_MIN

12

\#define Vpp_desejado

2600

\#define Ganho_maximo

50

\#define Ganho_minimo

6

\#define Rn_maximo

255

\#define Rn_minimo

27

\#define POT_RED

0x01

\#define POT_IR

$0 \times 10$ 0x01

0x02

$0 \mathrm{x} 00$

0x01

\author{
// Bit 0 da STATUS_PROC \\ // Bit 1 da STATUS_PROC \\ // canal vermelho \\ // canal infravermelho
}

// Variaveis globais

int unsigned cont_ad $=0$;

int canal $=0$;

int unsigned STATUS_PROC $=0$;

int MSByte $=0$;

int LSByte = 0;
// Canal A do DAC

// Canal B do DAC

// Canal C do DAC

// Canal D do DAC

// DAC minimo em 12 bits

// DAC minimo em 8 bits

// max_desejado - min_desejado $=84 \%$ de 4095

// Ganho maximo do estagio 3

// Ganho minimo do estagio 3

// Resistor maximo para ganho minimo (6)

// Resistor minimo para ganho maximo (50)

// Potenciometro do estagio 3, Canal RED

// Potenciometro do estagio 3, Canal IR
// Contador indicador do canal para o conversor AD

// Canal a ser amostrado

// Variavel de status do processamento de amostras

// Byte mais significativo a ser transmitido pela serial para o PC

// Byte menos significativo a ser transmitido pela serial para o PC 


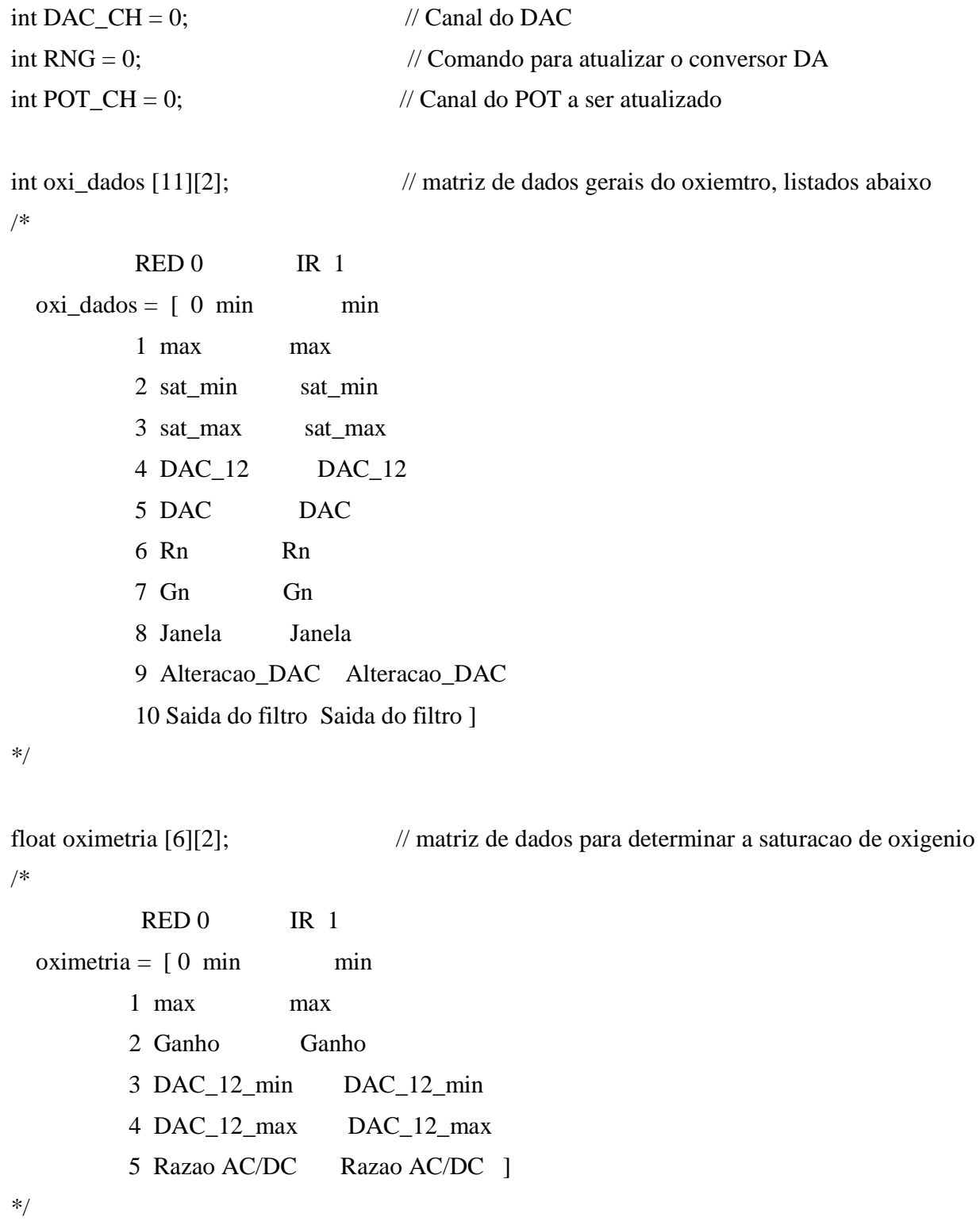


void Ajuste_DAC(int indica);

void Ajuste_POT(int indice);

void Atualiza_DAC(int indice_oxi);

void Atualiza_POT(int indice_oxi);

void Configurar_clock(void);

void Configurar_TimerB(void);

void Configurar_Porta(void);

void Configurar_ConversorAD(void);

void Configurar_UART(void);

void Deteccao(int indice);

void Inicializacao(void);

void Media_movel(int indicador);

void IR_sample(void);

void RED_sample(void);

void Razao (int in);

void Saturacao(void);

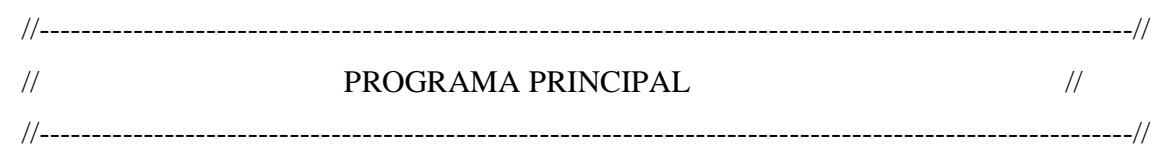

void main(void)

\{

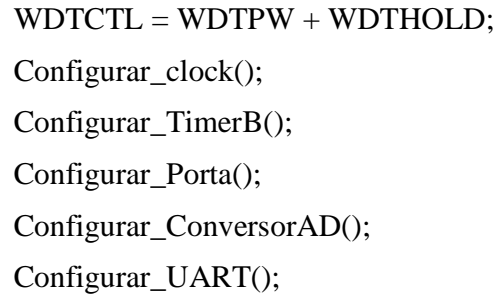

Inicializacao();

_BIS_SR(GIE);

while(1)

while (!(STATUS_PROC \& NOVA_AMOSTRA));// amostra = oxi_dados[10][canal]; $\quad$ // Transfere a
// Paraliza WDT

// Configura o clock do sistema

// Configura o TIMER_A

// Configura as portas usadas pelo sistema

// Configura o conversor Analogico/Digital

// Configura a UART0 para comunicacao com o PC e a UART1 para //comunicacao via SPI com outros dispositivos

// Inicializacao do BUFFER

// Habilita interrupções

// Loop infinito nova amostra para a variavel AMOSTRA
P1OUT \&= 0x0F7;
$/ / \mathrm{P} 1.3=0$
FINAL DO PROCESSAMENTO DA AMOSTRA IR
P1OUT \& $=0 \mathrm{x} 0 \mathrm{FB}$;
$/ / \mathrm{P} 1.2=0$
FINAL DO PROCESSAMENTO DA AMOSTRA RED

P1OUT $\mid=0 \times 20$;

MSByte $=(($ oxi_dados[10][canal] \& 0x0F00) $>>8)$;

MSByte $+=($ canal $\ll<4)$;

LSByte $=(($ oxi_dados[0] $[$ canal $] \& 0 x 0 F F))$;

STATUS_PROC $\&=\sim$ envia_LSB; $\quad$ // Zera o flag, indicando a interrupcao do TIMER_A

//que ainda nao podemos enviar o LSByte 


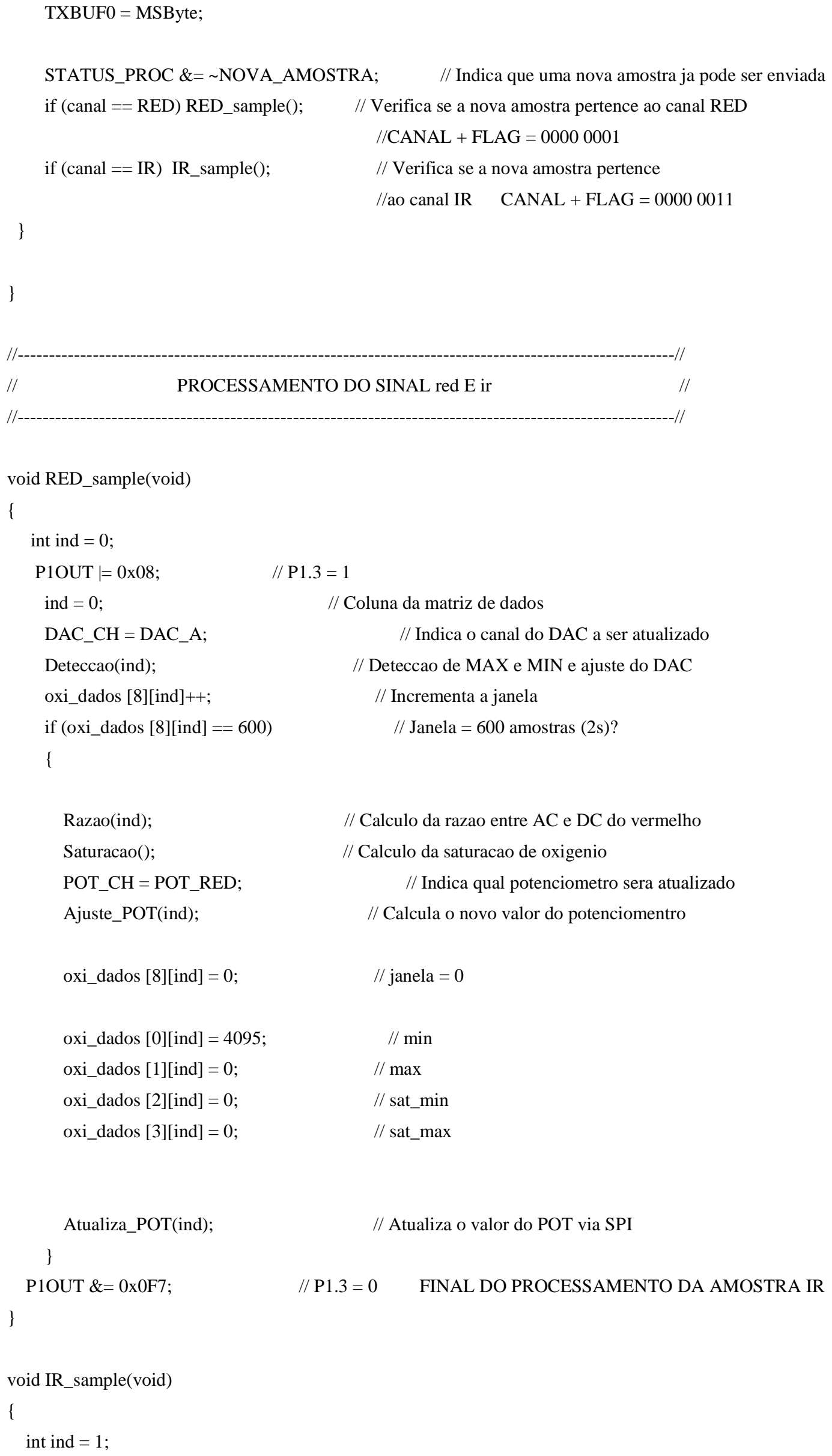




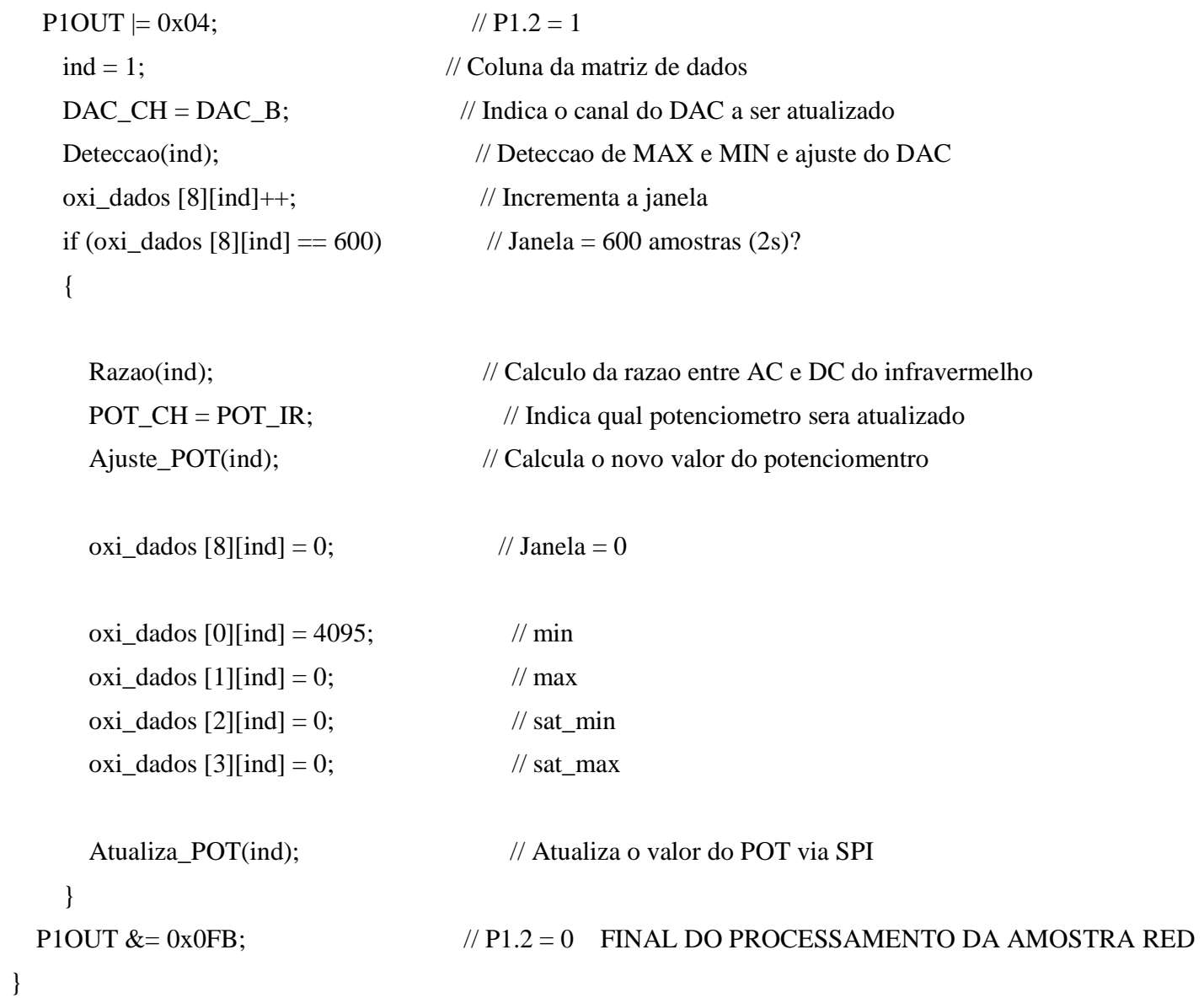

void Media_movel(int indicador)

\{

int media_parcial_1 $=0$;

int media_parcial_2 $=0$;

_EINT();

// MEDIA MOVEL

// SOMAR 13 AMOSTRAS E DIVIDIR POR 26. REPETIR A MEDIA DAS PROXIMAS 13 AMOSTRAS E SOMARAS DUAS MEDIAS PARCIAIS

media_parcial_1 = (buffer[0][indicador] + buffer[1][indicador] + buffer[2][indicador] + buffer[3][indicador] + buffer[4] [indicador] + buffer[5][indicador] + buffer[6][indicador] + buffer[7][indicador] + buffer[8][indicador] + buffer[9] [indicador] + buffer[10][indicador] + buffer[11][indicador] + buffer[12][indicador])/26;

media_parcial_2 $=$ (buffer[13][indicador] + buffer[14][indicador] + buffer[15][indicador] + buffer[16][indicador] + buffer[17][indicador] + buffer[18][indicador] + buffer[19][indicador] + buffer[20][indicador] + buffer[21][indicador] + buffer[22][indicador] + buffer[23][indicador] + buffer[24][indicador] + buffer[25][indicador])/26;

oxi_dados[10][indicador] = media_parcial_1 + media_parcial_2;

_DINT();

\} 

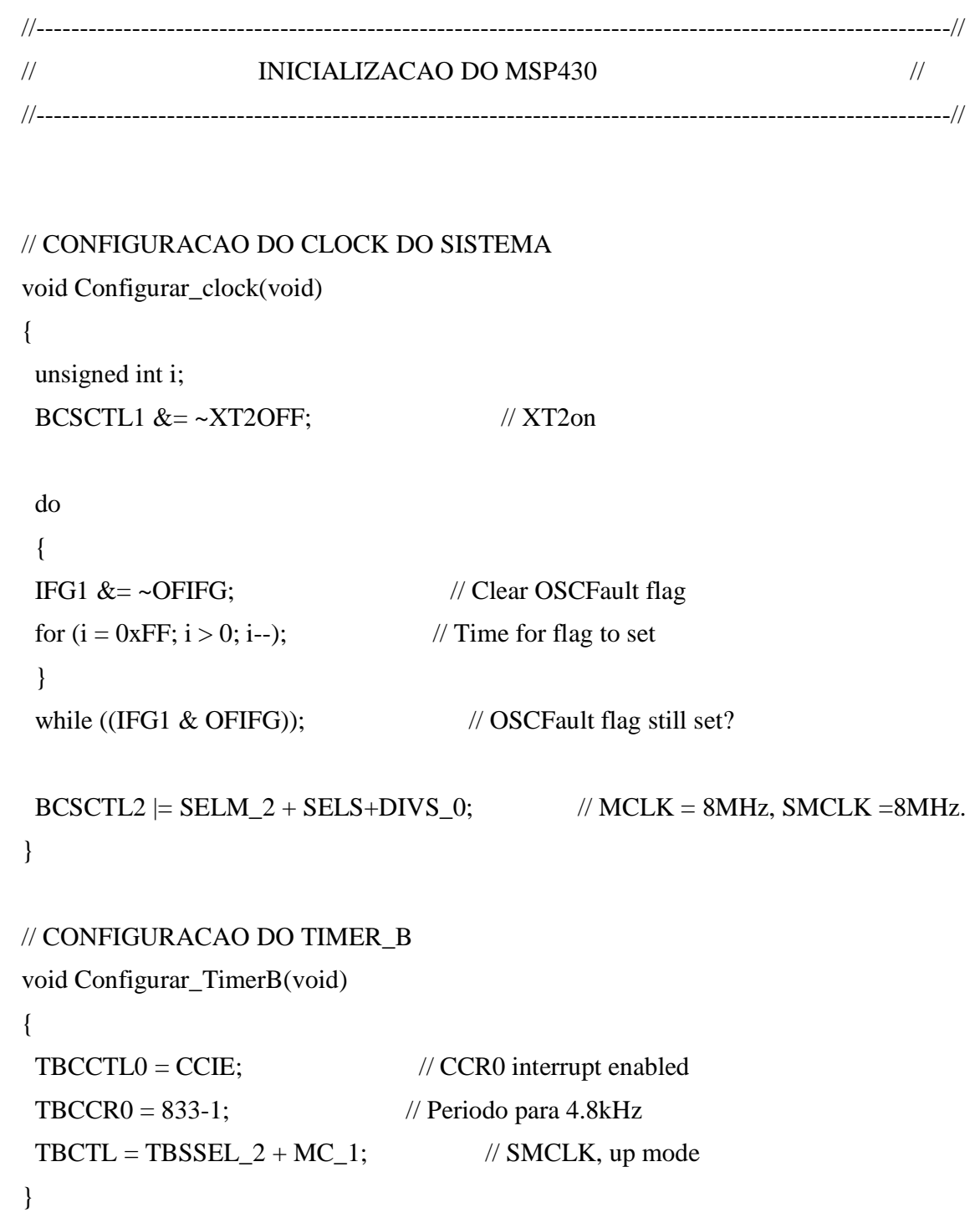
void Configurar_ConversorAD(void)

\{

P6SEL = 0x0FF; $\quad$ // Seleciona a funçào de AD da porta P6

P6DIR \&=0x00; $\quad$ // P6 como entrada

ADC12CTL0 |= SHT0_0 + REF2_5V + REFON + ADC12ON;

/*Usa 4 períodos de relógio para amostragem, referência de tensão

interna ligada e em 2,5V, amostra o canal 0 uma vez, liga o conversor.*/

ADC12CTL1 $=$ CSTARTADD_0 + SHS_0 + SHP + ADC12DIV_0 + ADC12SSEL_3

$/$ Salvar o resultado da conversão primeiro em ADC12MEM0, S/H controlado pelo bit

ADC12SC do registrador ADC12CTL0,SAMPCOM do timer de amostragem,clk dividido por 1

e vindo do oscilador, modo de conversão (conversao unica de um canal). */

ADC12IE = 0x01; $\quad$ // Habilita interrupção do ADC12MCTL0.

ADC12MCTL0 = INCH_1+SREF_1+EOS; $\quad$ // Converter o canal 1

\}

// CONFIGURACAO DA UART0 PARA O MODO SERIAL E UART1 PARA SPI MODE.

void Configurar_UART(void)

\{

/*Configuração da UART0.*/

P3SEL $\mid=0 \times 30$;

// P3.4,5 = USART0 TXD/RXD ;

UCTLO $=$ SWRST;

// Para garantir que SWRST=1 para poder fazer-se as configurações.

$\mathrm{UCTLO} \mid=\mathrm{CHAR}+\mathrm{SPB}$;

// 8-bit caracter com 2 bits de parada.

UTCTLO $=0 \times 30$;

// UCLK = SMCLK.

$\mathrm{UBR} 10=0$

$/ / 8 \mathrm{MHz} / 115200=069$ (aqui é posto o zero).

$\mathrm{UBR} 00=69$;

$\mathrm{UMCTLO}=44$;

// 8MHz/115200=069 (aqui, o 69 em hexadecimal).

ME1 |= UTXE0;

$/ /$ o resto de $8 \mathrm{MHz} / 115200$ (modulation).

UCTLO \& = SWRST;

// Enable USART0 TXD

IE1 |= UTXIE0;

IFG1 \&= UTXIFG0;

// Initialize USART state machine (SWRST=0)

// Enable USART0 RX/TX interrupt

// Clear inital flag on POR

/*Configuracao da UART1.*/

P5SEL $\mid=0 \mathrm{x} 0 \mathrm{~A}$

// P5.1,3 = SIMO1/UCLK

P5OUT $\mid=0 \times 05$;

// Coloca CS e LOAD em nivel alto

UCTL1 | = SWRST;

// Para garantir que SWRST=1 para poder fazer-se as configurações.

$\mathrm{U} 1 \mathrm{CTL}=\mathrm{CHAR}+\mathrm{SYNC}+\mathrm{MM}+\mathrm{SWRST} ; \quad$ // 8-bit, SPI, Master

$\mathrm{U} 1 \mathrm{TCTL}=\mathrm{SSEL} 1+\mathrm{STC}$;

$/ /$ CLK interno = CLK externo, SMCLK, 3-wire

$\mathrm{U} 1 \mathrm{BR} 0=0 \times 10$

$/ / \mathrm{SPICLK}=\mathrm{SMCLK} / 16=500 \mathrm{kHz}$

$\mathrm{U} 1 \mathrm{BR} 1=0 \mathrm{x} 00$ 


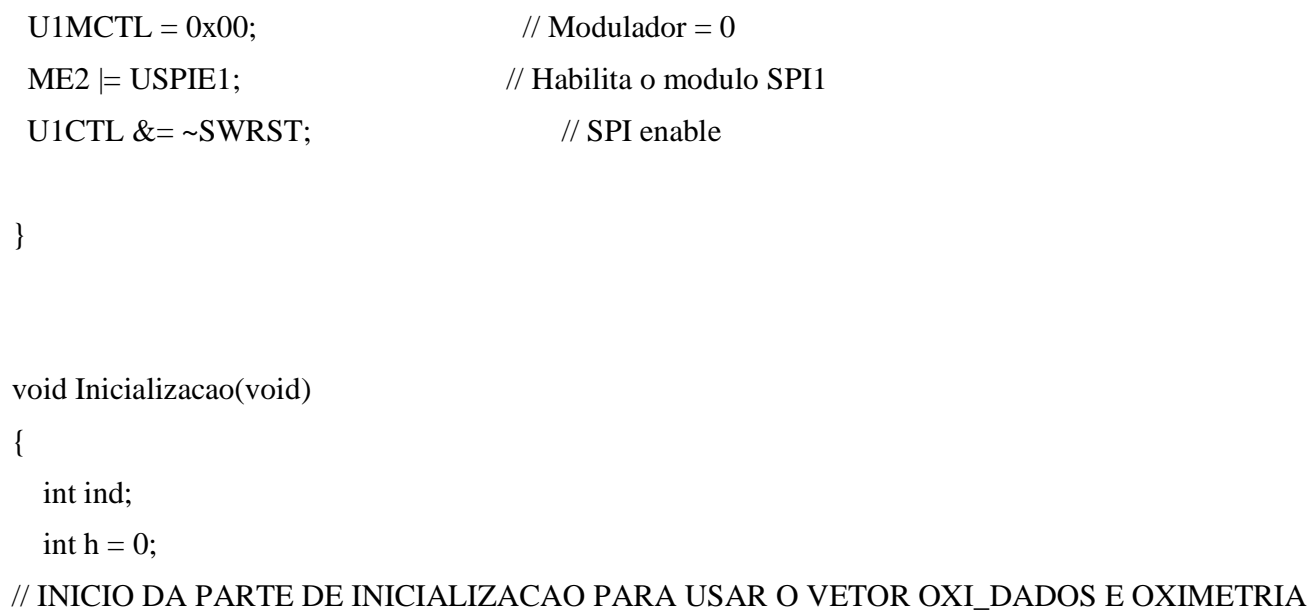

\section{// CANAL IR}

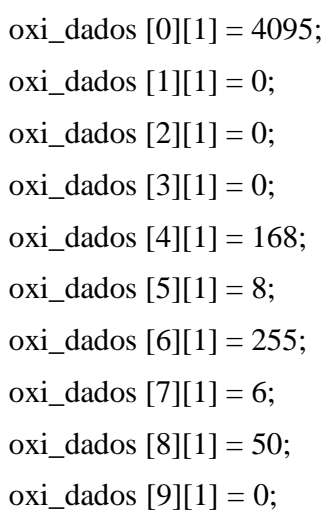

\section{// CANAL RED}

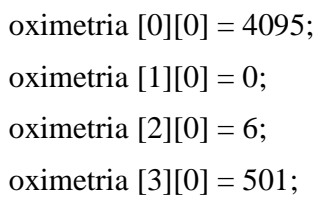




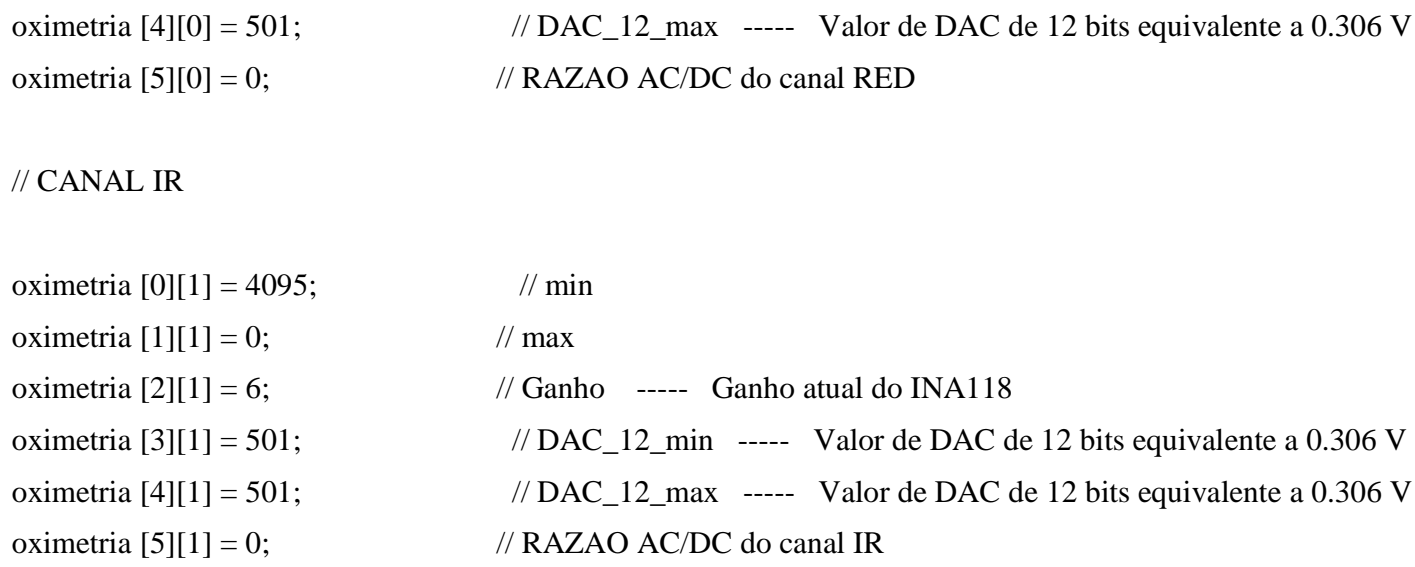

\title{
// CANAL RED
}

for $(\mathrm{h}=0 ; \mathrm{h}<26 ; \mathrm{h}++) \quad$ buffer[h][0] $=0 ; \quad$ // Amostra i do canal RED

// CANAL IR

for $(\mathrm{h}=0 ; \mathrm{h}<26 ; \mathrm{h}++) \quad$ buffer $[\mathrm{h}][1]=0 ; \quad$ // Amostra i do canal IR

\section{// CORRENTE, GANHO DOS INAs E TENSAO dc DE CADA CANAL; GANHO DO PRE-AMP}

\author{
// Atualiza o canal RED \\ ind $=0$; \\ DAC_CH $=$ DAC_A; \\ POT_CH = POT_RED; \\ Atualiza_POT(ind); \\ Atualiza_DAC(ind);
}

\section{// Atualiza o canal IR \\ ind $=1$; \\ DAC_CH $=$ DAC_B; \\ POT_CH = POT_IR; \\ Atualiza_POT(ind); \\ Atualiza_DAC(ind);}

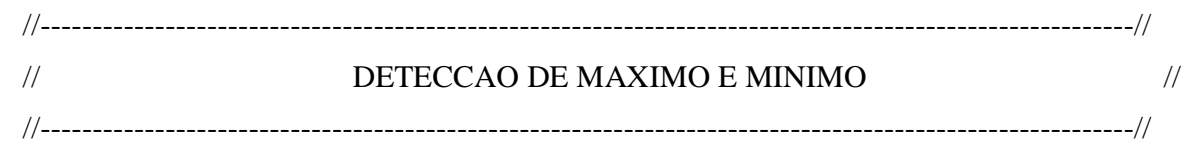

void Deteccao(int indice)

\{

if (oxi_dados[10][indice] < 100) 


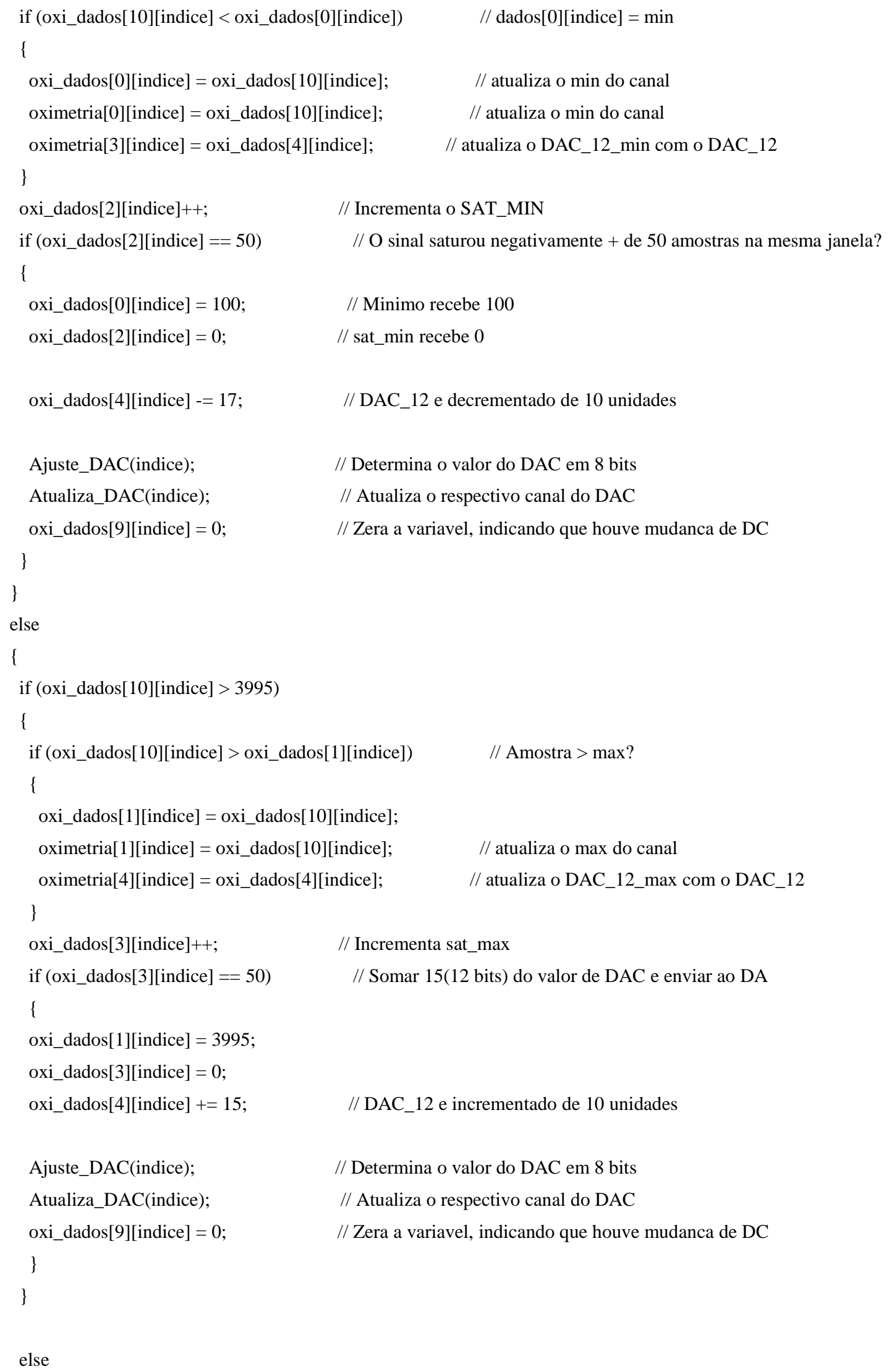




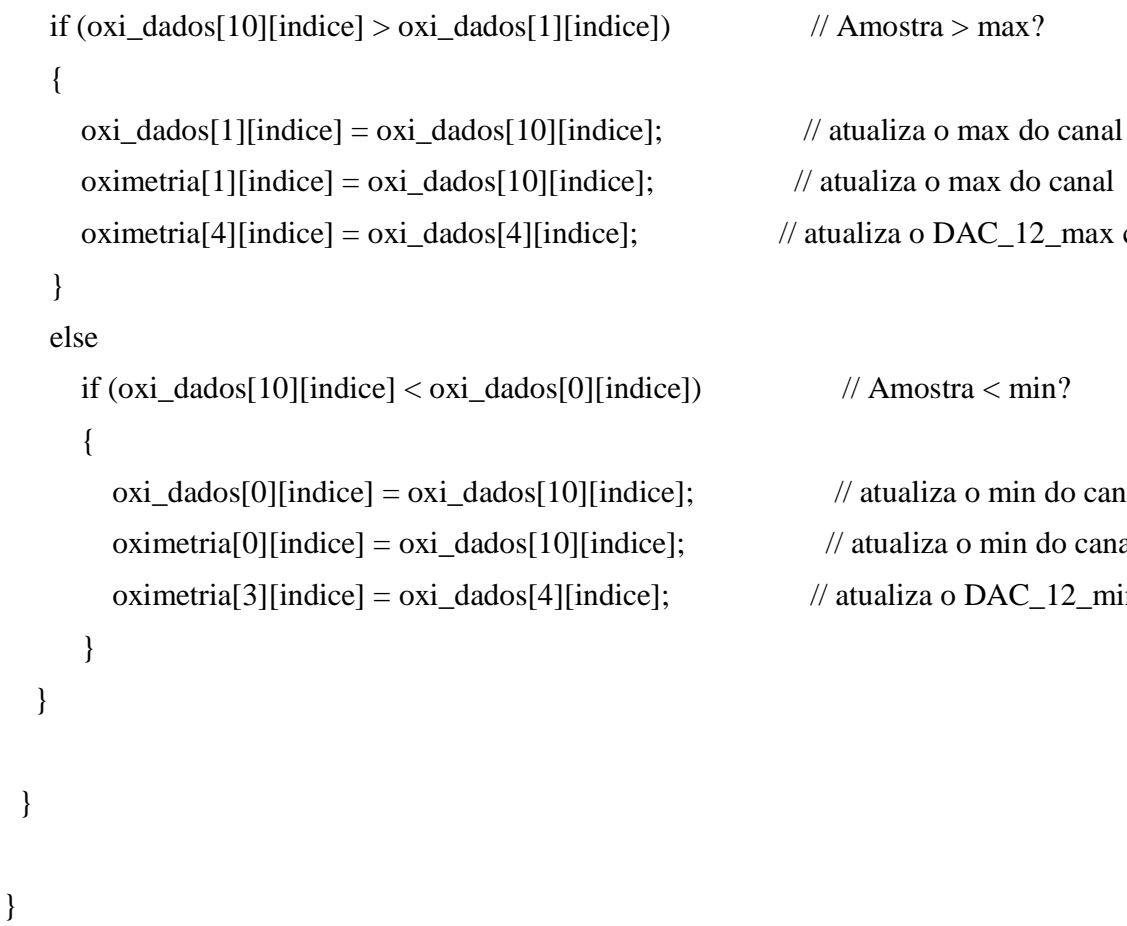

void Ajuste_DAC(int indica)

\{

if (oxi_dados[4][indica] > DAC_MIN_12) //DAC_12 > min definido para DAC?

\{

oxi_dados[5][indica] = oxi_dados[4][indica] / 21; // Equacao valida somente para tensao de referencia do ADC igual a $2,5 \mathrm{~V}$ e do DAC igual a $3,25 \mathrm{~V}$

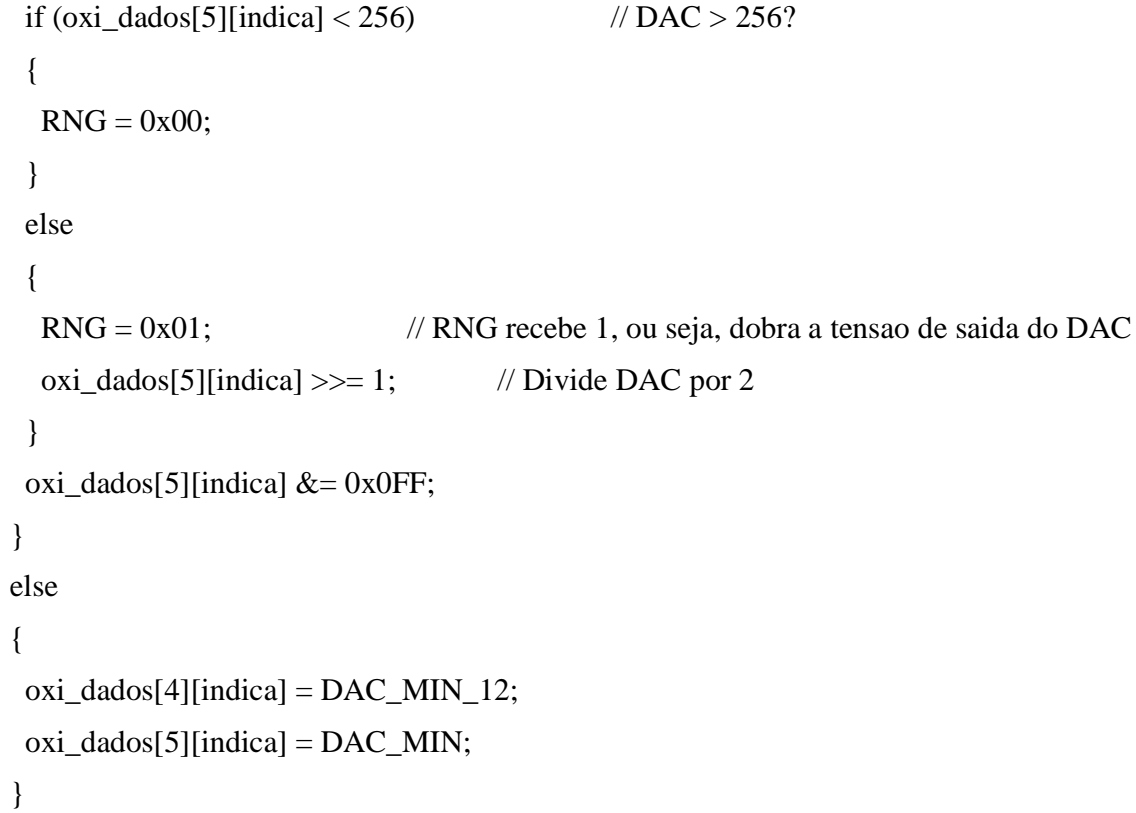




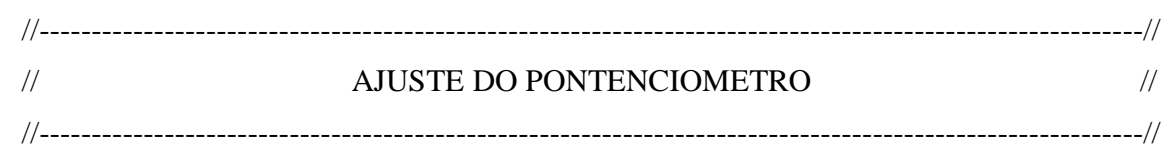

void Ajuste_POT( int indice )

\{

float $\quad$ Ganho $=0$;

float $\quad \mathrm{VPP}=0$;

float VPP_DESEJADO $=0$;

float R_novo $=0$;

int unsigned $\mathrm{Vpp}=0$;

Ganho = oximetria[2][indice];

// Atualização do FLOAT Ganho com o GANHO ATUAL(oximetria[2]

$[\ldots])$

if (oxi_dados[1][indice] > oxi_dados[0][indice]) $\quad / / \max >\min$ ?

Vpp = oxi_dados[1][indice] - oxi_dados[0][indice]; // Valor pico a pico do sinal de entrada

$\mathrm{VPP}=\mathrm{Vpp} ; \quad$ // Atualização do FLOAT VPP

VPP_DESEJADO = Vpp_desejado;

if $($ VPP $<100)$

\{

// CHAMAR ROTINA PARA TENTAR AUMENTAR CORRENTE E/OU GANHO DO PREAMPLIFICADOR

$\mathrm{VPP}=100$

// So para nao dar erro na funcao

oximetria[2][indice] = Ganho * (VPP_DESEJADO / VPP); / / Calculo do novo valor de ganho de acordo com o Vpp encontrado e o desejado

else

\{

if ( VPP > 3500 ) // Valor pico-a-pico está acima do esperado, 3600

\{ oximetria[2][indice] /= 3; $\quad$ // Tentativas de se baixar o ganho \}

else

\{ oximetria[2] [indice $]=$ Ganho $*($ VPP_DESEJADO / VPP $) ; \quad$ // Calculo do novo valor de ganho de acordo com o Vpp encontrado e o desejado

\}

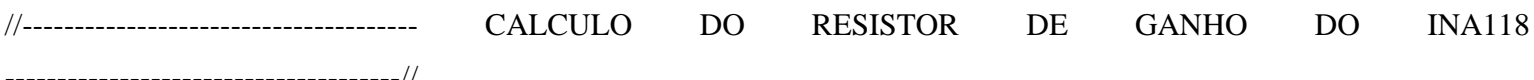



o estágio

oximetria[2][indice] = Ganho_maximo; oxi_dados[7][indice] = Ganho_maximo; oxi_dados[6][indice] = Rn_minimo;
// Ganho maximo do INA118 nese estágio (FLOAT)

// Ganho maximo do INA118 nese estágio (INT)

// Codigo para valor do resistor para ganho máximo $\mathrm{Rn}=20$

\}

else

\{

if (oximetria[2][indice] < Ganho_minimo)

// Verificar se o ganho calculado é menor que o mínimo oferecido pelo INA118 e o potenciometro digital

\{ oximetria[2][indice] = Ganho_minimo; $\quad / /$ Ganho minimo do INA118 nese estágio (FLOAT) oxi_dados[7][indice] = Ganho_minimo; // Ganho minimo do INA118 nese estágio (INT) oxi_dados[6][indice] = Rn_maximo; $\quad$ // Valor da resistencia maxima do POT \}

else

\{

R_novo $=1275$ / (oximetria[2][indice] -1$) ; \quad / /$ Novo valor de resistor de acordo com o ganho calculado R_novo++; // Incremento do ganho calculado para diminuir o ganho oxi_dados[6][indice] = R_novo; // Atualização da variável int Rn oxi_dados[6][indice] \&=0x0FF; // Máscara para pegar apenas o byte menos significativo oxi_dados[7][indice] = oximetria[2][indice]; // Atualizacao do ganho atual (INT) \}

\}

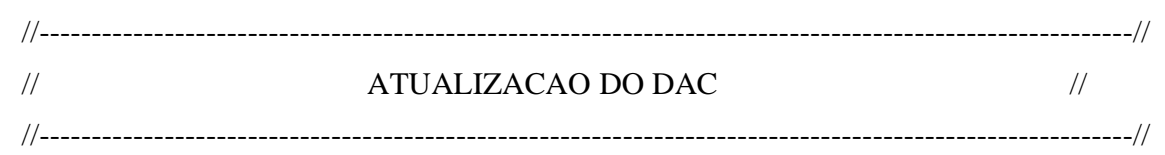

void Atualiza_DAC(int indice_oxi)

\{

TXBUF1 = DAC_CH + RNG; while $((\mathrm{UTCTL} 1 \& \mathrm{TXEPT})==0)$; TXBUF1 = oxi_dados[5][indice_oxi]; while $((\mathrm{UTCTL} 1 \& \mathrm{TXEPT})==0)$; P5OUT \& = 0x0FB; P5OUT $\mid=0 \mathrm{x} 04$; oxi_dados[9][indice_oxi] $=0$;
// Transmite o CANAL e o RNG de escrita para o DAC.

// Aguardar o buffer de transmissao ficar vazio

// Transmite o valor do DAC

// Aguardar o buffer de transmissao ficar vazio // Coloca LOAD em nivel baixo // Coloca LOAD em nivel alto

// Zera a variavel, indicando que houve alteracao do respectivo canal do DAC 


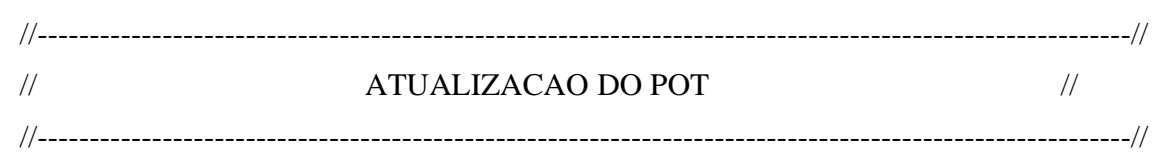

void Atualiza_POT(int indice_oxi)

\{

P5OUT \&= POT_CH;

// Coloca o CS do POT em nivel baixo

TXBUF1 = 0x11;

// Transmite o comando de escrita para o potenciometro digital.

while $((\mathrm{UTCTL} 1 \&$ TXEPT $)==0)$;

TXBUF1 = oxi_dados[6][indice_oxi]; $\quad$ // Transmit character

while $((\mathrm{UTCTL} 1 \& \mathrm{TXEPT})==0)$;

P5OUT |= POT_CH; $\quad$ // Coloca o CS em nivel alto novamente

\}

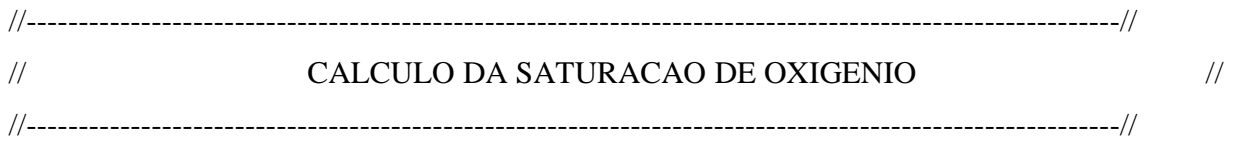

void Razao (int in)

\{

float DAC_MIN = 0;

float DAC_MAX $=0$;

float $\mathrm{DC}=0$;

float $\mathrm{AC}=0$;

float $\mathrm{G}=0$;

if (oximetria[1][in] > oximetria[0][in])

// Max > Min

if $($ oximetria[3][in] == oximetria[4][in]) // Verifica se o DAC_12 max e igual ao DAC_12 min

DAC_MIN = oximetria[3][in]/1622.72; $\quad$ // Calcula o DAC em Volts

$\mathrm{AC}=($ oximetria[1][in] - oximetria[0][in])/1638; // Calcula o AC do sinal em Volts

$\mathrm{G}=$ oximetria[2][in]*3276; // Variavel auxiliar para facilitar os calculos

$\mathrm{DC}=($ oximetria[1] $[\mathrm{in}]+$ oximetria[0][in] $) / \mathrm{G} ; \quad$ // Calcula o DC do sinal em Volts

DC $+=$ DAC_MIN; $\quad$ // Soma ao DC o DAC_MIN

\}

else

\{

DAC_MIN = oximetria[3][in]/1622.72;

// Calcula o DAC min em Volts

DAC_MAX = oximetria[4][in]/1622.72;

// Calcula o DAC max em Volts 


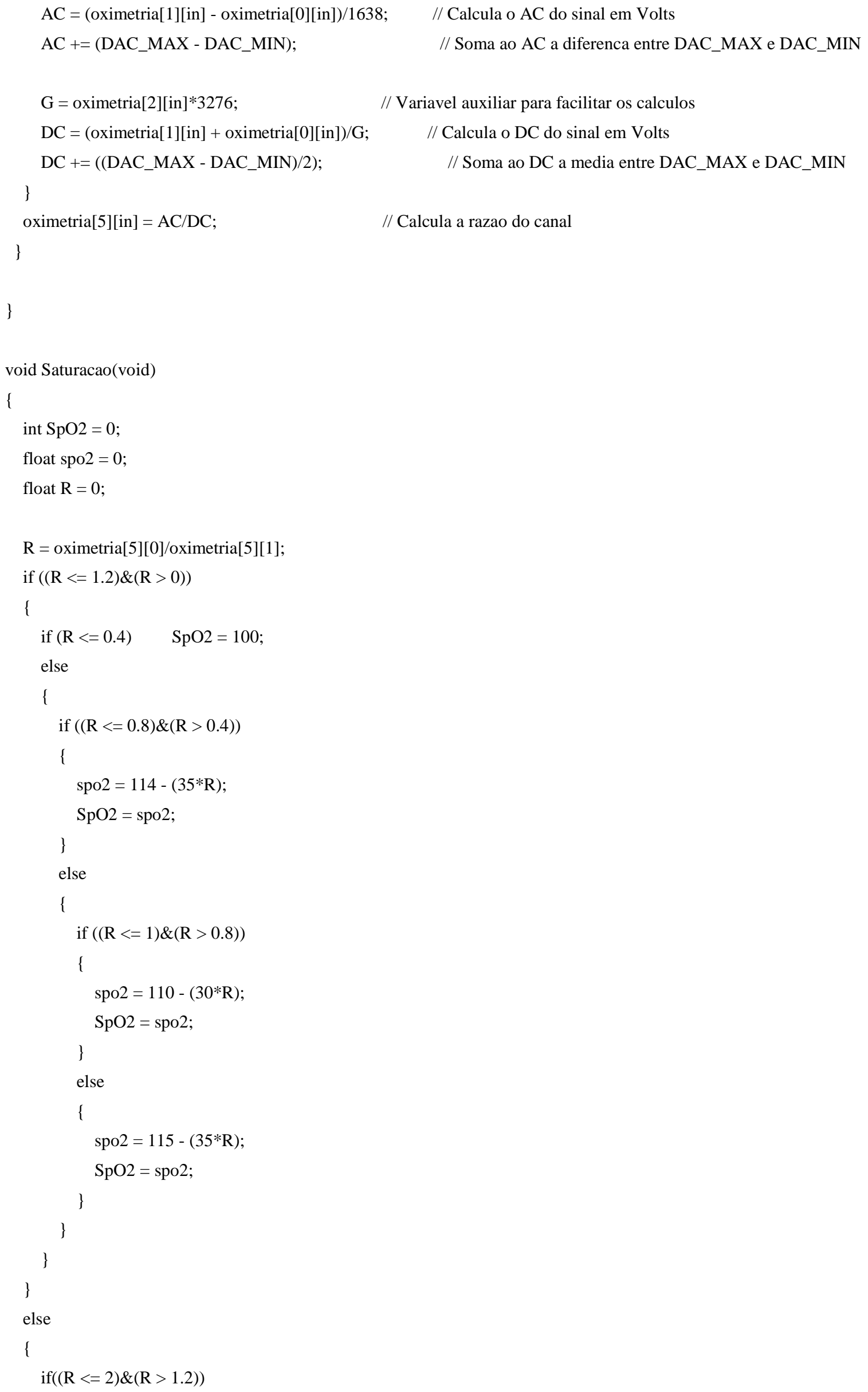




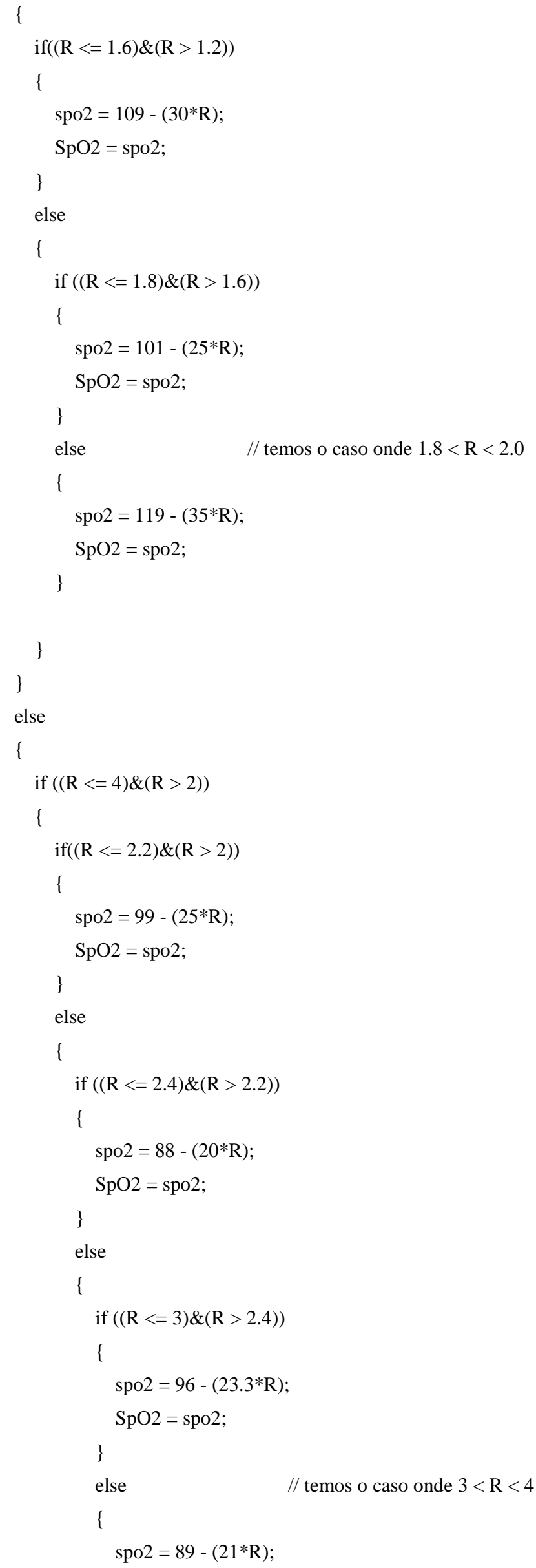




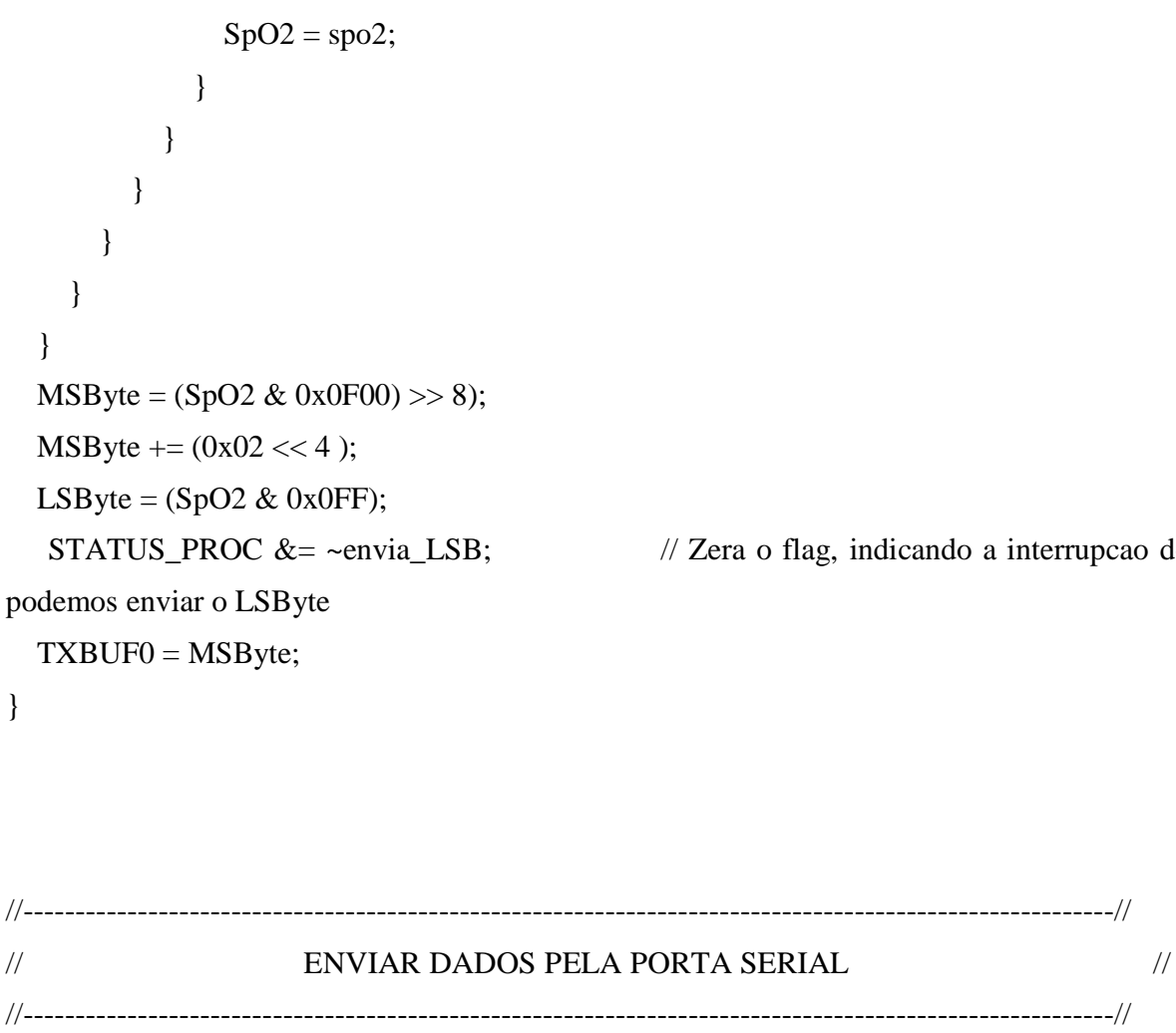

\section{// UART0 TX ISR}

\#pragma vector=UART0TX_VECTOR

__interrupt void usart0_tx (void)

\{

STATUS_PROC ${ }^{\wedge}=$ envia_LSB; $\quad$ // Inverte o flag ENVIA_LSB

P1OUT \&=0x0DF; $\quad$ // Coloca P1.5 = 0 para testar a duração da função ENVIAR

\}

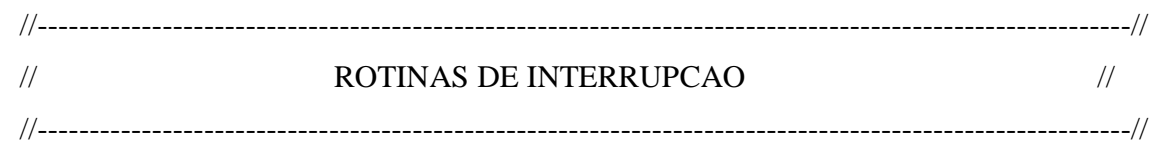

// ROTINA DE INTERRUPCAO DO TIMER_B

\#pragma vector=TIMERB0_VECTOR

__interrupt void Timer_B (void)

\{

cont_ad++;

if(cont_ad \& 0x01)

\{

$\mathrm{P} 1 \mathrm{OUT} \mid=0 \mathrm{x} 02$;

\}

else

\{
// Incrementa o contador do AD

// Verifica se CONT_AD e IMPAR, ou seja, se o bit 0 de cont_ad e 1

// Coloca P1.1 em 1 


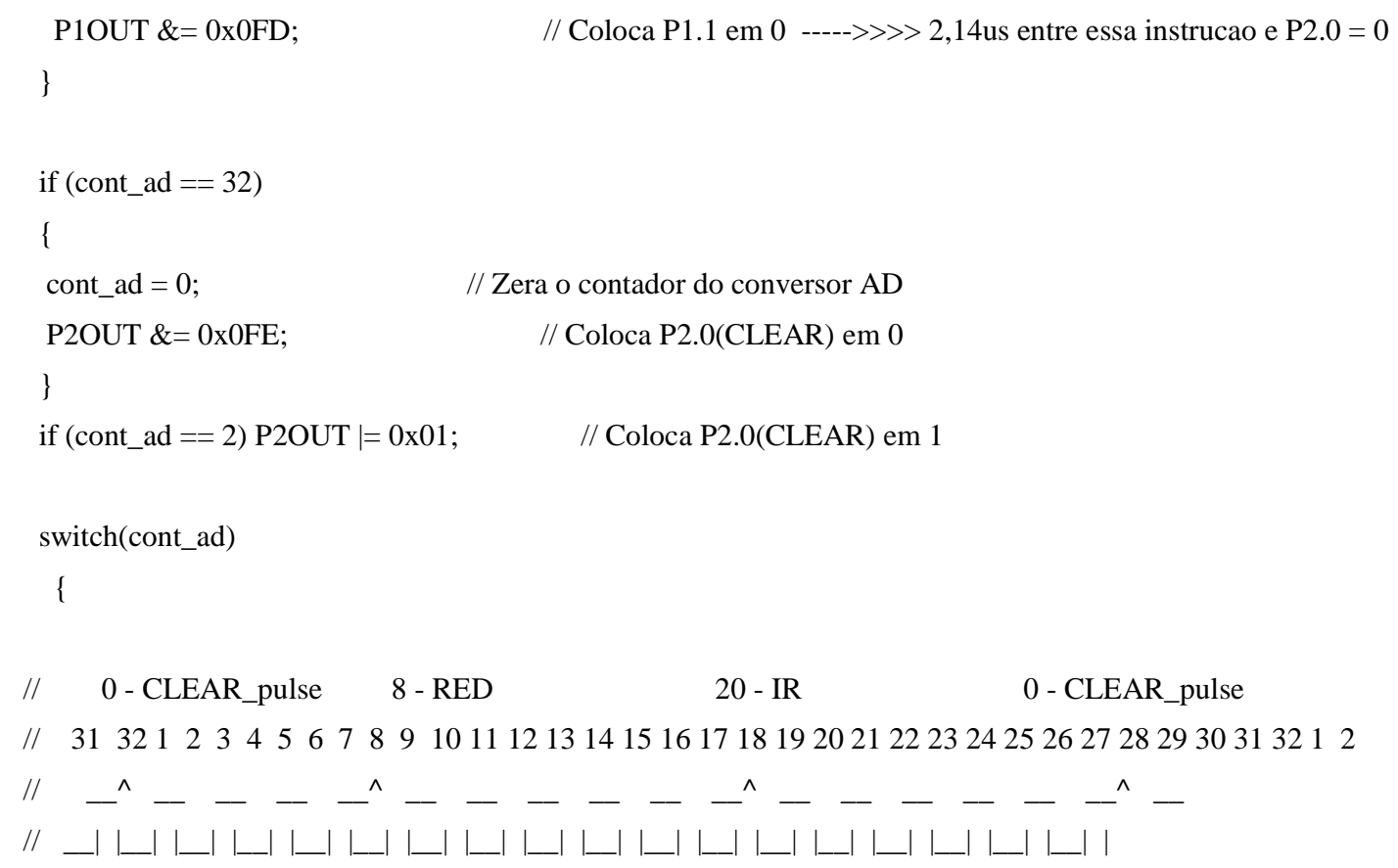


// ROTINA DE INTERRUPCAO DO CONVERSOR AD

\#pragma vector=ADC_VECTOR

__interrupt void ADC12ISR (void)

\{

int $\mathrm{i}=0$;

// ATUALIZACAO DO BUFFER

P1OUT $\mid=0 \times 10 ; \quad$ // P1.4 = $\quad$ // Teste para a duração do filtro de mediana

for (i=25; i>0; i--) buffer[i][canal] = buffer[i-1][canal]; / Atualizacao do BUFFER, descartando a amostra mais antiga, deslocando

buffer[0][canal $]=$ ADC12MEM0; $\quad$ // uma posicao no vetor as demais e colocando a nova

amostra na posicao 0

Media_movel(canal);

STATUS_PROC $\mid=$ NOVA_AMOSTRA;

P1OUT \&= 0X0EF;

// Final do pulso para medir a duração do filtro de mediana

\} 